Nominal Wage Adjustments and the Composition of Pay: New Evidence from Payroll Data

by

Daniel SCHÄFER

Carl SINGLETON

Working Paper No. 2011

June 2020

Johannes Kepler University of Linz Department of Economics Altenberger Strasse 69 A-4040 Linz - Auhof, Austria www.econ.jku.at 


\title{
Nominal Wage Adjustments and the Composition of Pay: New Evidence from Payroll Data
}

\author{
Daniel Schaefer* \\ Carl Singleton ${ }^{\dagger}$ \\ Johannes Kepler University Linz \\ University of Reading
}

First version: August 2019

This version: June 2020

Link to latest version

\begin{abstract}
We use representative payroll data from Great Britain to document novel facts about nominal wage adjustments, focusing on workers who stayed in the same firm and job from one year to the next. The richness of these data allows us to analyse basic pay and the other components of earnings, such as overtime and incentive pay, while accounting for hours worked. Weekly and hourly basic pay show signs of downward nominal rigidity, but non-basic pay components adjust more commonly. Unusually, these payroll-based data also report the wage rates of hourly-paid employees. A quarter of these workers typically see no change in their wage rates from one year to the next in the same job, and very few experience wage cuts. We exploit the employer-employee link in the data and find evidence of state-dependent pay setting, depending on the business cycle and whether firms are shrinking or expanding. Finally, we show that the basic and non-basic wages of new hires and existing employees are similarly flexible.
\end{abstract}

Keywords: downward nominal wage rigidity, components of pay, hourly pay rates, hiring wages, allocative wages

JEL codes: E24, E32, J31, J33

*daniel.schaefer@jku.at; Department of Economics, University of Linz, Altenberger Strasse 69, 4040 Linz, Austria

$\dagger$ c.a.singleton@reading.ac.uk; Department of Economics, University of Reading, Whiteknights, RG6 6UB, UK

We are grateful to Mike Elsby, Marco Fongoni, Robert Hart, Chris Martin, and Gary Solon for helpful comments. This work is based on the Annual Survey of Hours and Earnings Dataset (Crown copyright 2019), having been funded, collected and deposited by the Office for National Statistics (ONS) under secure access conditions with the UK Data Service (SN:6689). Neither the ONS nor the Data Service bear any responsibility for the analysis and discussion of the results in this paper. 


\section{Introduction}

Over eighty years have passed since Keynes (1936) introduced to economics the notion that workers simply refuse to accept cuts to their nominal wages. As far as this downward nominal wage rigidity (DNWR) prevents the real price of labour from falling during recessions, it provides a plausible theory of cyclical unemployment. An implication of Keynes' theory is that moderate inflation can "grease the wheels of the labor market" (Tobin, 1972), by bringing down real wages and boosting employment. With stubbornly low inflation becoming a feature in many developed economies, the question of whether labour markets display signs of DNWR has attracted renewed attention. The answer to this question has consequences for economic policy making; intervention can be justified if distortions in the labour market do not self-correct through wage adjustments (Schmitt-Grohé and Uribe, 2016). Despite being one of the central issues in macroeconomics, the actual extent of rigidity in nominal wage setting remains an open question. This is surprising, since Keynes' hypothesis is empirically testable. If nominal wages are downward rigid, then we should observe a lack of wage cuts and an excess of wage freezes. Therefore, studies have focused on measuring the extent of nominal wage cuts and freezes in microdata from individual workers. ${ }^{1}$

In our view, there are two key reasons why economists still do not agree on the empirical extent of DNWR. First, the datasets used to investigate it before were not well-suited to the task. A large literature has analysed household survey data, but the findings have frequently been discounted on the grounds that self-reported wages contain substantial response errors, which can bias the results. ${ }^{2}$ For this reason, recent studies have turned toward more accurate administrative or payroll data. However, such datasets normally do not contain information on hours worked; only employees' total earnings per quarter or year are available. With such data, a pay reduction which is caused by a change in working hours cannot be distinguished from a cut in the hourly wage. A few notable exceptions exist, which we discuss below.

The second key reason why economists disagree on the extent of DNWR is that administrative and payroll data normally give the value of total earnings, which includes extra payments, such as overtime or shift premiums. This makes it not obvious how to interpret any results, even when the hours worked are observed. For instance, frequent pay cuts may not be evidence against DNWR because reduced commissions or bonuses can indicate lower worker productivity, i.e., the implied pay per unit of labour input might be constant. A few studies have used administrative or payroll

\footnotetext{
${ }^{1}$ The importance of using individual-level data to control for sample composition when assessing wage changes has been known at least since Solon, Barsky and Parker (1994). They showed that US low-wage workers are more likely to leave employment during recessions, and so aggregate real wages appear less cyclical than they truly are for the average worker who remains employed. Devereux and Hart (2006) and Schaefer and Singleton (2019) demonstrated that this also matters for assessing the extent of real wage rigidity in Great Britain.

${ }^{2}$ The most prominent studies on nominal wage rigidity based on US household surveys include: McLaughlin (1994); Akerlof, Dickens and Perry (1996); Card and Hyslop (1996); Kahn (1997); Altonji and Devereux (2000); Lebow, Saks and Wilson (2003), and more recently Barattieri, Basu and Gottschalk (2014); Elsby, Shin and Solon (2016). Smith (2000) and Fehr and Goette (2005) similarly analysed household survey data from Great Britain and Switzerland, respectively.
} 
data to make progress toward results with a clearer economic interpretation, and have typically shown little evidence of DNWR. ${ }^{3}$

Our study makes two main contributions to the literature on DNWR. First, we document several novel facts about the adjustment of nominal labour costs. Specifically, we use representative longitudinal British payroll data, to analyse how the composition of pay affects the changes in the hourly wages of workers who stay in the same firm and job from one year to the next, henceforth referred to as job stayers. Our data allow us to separately analyse changes in basic pay, shift premiums, overtime, incentive pay, and other pay. We find that basic pay per hour shows more signs of DNWR compared with earnings per hour, where the latter includes basic and non-basic pay components. We show how frequent cuts in each non-basic pay component account for this finding.

The second main contribution of our analysis is based on another novel feature of the British payroll data: we can distinguish between hourly-paid and salaried (non-hourly-paid) employees. Some previous studies only analysed hourly pay rates because of a lack of working hours data for salaried employees (e.g., Card and Hyslop, 1996; Barattieri, Basu and Gottschalk, 2014), and it is important to understand how such findings generalise to all workers. For hourly-paid workers, we are able to directly compare their pay rates to the more commonly studied and derived measure of basic pay per hour. Two findings stand out. First, basic pay per hour appears to be substantially less downward rigid than reported pay rates among the same job stayers. We attribute this to two factors: (i) there are small measurement errors in the records of hours worked, which were previously unknown in the British payroll data; (ii) the amount of shift premium work is not defined in the hours records, whereas it is excluded from basic pay. Second, contrasting with existing payroll-based studies, we find substantial evidence of DNWR in reported hourly pay rates: year-to-year cuts are rare and every fifth job stayer experiences a wage freeze. It appears as though some firms use non-basic pay components, in particular overtime, to overcome the rigidity of hourly pay rates.

Additionally, we contribute to the understanding of employment and wage setting more broadly. The canonical search and matching model of the labour market attributes cyclical unemployment to the flexibility or lack thereof in hiring wages (Pissarides, 2009). Using regression analysis, we provide evidence that the flexibility of the basic and the non-basic pay of new hires and existing workers are not economically and statistically different in Great Britain, possibly due to internal pay structures. This suggests that DNWR in the nominal wages of job stayers can have allocative consequences. We also provide evidence of state-dependent wage setting. Specifically, the incidence of pay cuts and freezes rose substantially during the economic contraction that followed the 2007/08 global financial crisis. Firms which shed workers were more likely to have cut or frozen hourly pay than those which expanded their workforce. Small firms froze wages more frequently than

\footnotetext{
${ }^{3}$ This is the case except in countries where nominal wage cuts are legally impossible, e.g., Portugal and Sweden (see the recent survey by Elsby and Solon, 2019). Notable examples include: for Great Britain, Nickell and Quintini (2003) and Elsby, Shin and Solon (2016), who analysed hourly pay changes excluding overtime; Park and Shin (2017) studied Korean data that exclude overtime and incentive pay; Jardim, Solon and Vigdor (2019) used US data to analyse a selective subsample of US workers for whom overtime was unlikely to be a significant factor.
} 
medium-sized and large firms, but this was mostly accounted for by a lack of pay growth instead of less common pay cuts.

There have been three previous studies of DNWR in Great Britain that are highly relevant to this one. The first of these was by Smith (2000), who analysed the 1991-96 waves of the British Household Panel Survey. She discovered that respondents could check their pay slips when they were asked about their recent earnings. She found that cuts in weekly pay were quite common among the subsample of respondents that did check their pay slips. Nickell and Quintini (2003) studied the New Earnings Survey for 1975-99, which was based on a one percent sample of income-tax-paying employees, and was the precursor to the dataset we are using here. Nickell and Quintini confirmed the findings of Smith: job-stayer pay was frequently cut in Great Britain in the early 1990s. The former authors also studied the influence of overtime and incentive pay, of which the latter was measured with considerable inconsistency. They documented that the earlier years in their sample period, which had high inflation rates, did not show evidence of DNWR. Recent work by Elsby, Shin and Solon (2016) updated the study of Nickell and Quintini. They found that job-stayer earnings per hour, excluding overtime, are frequently cut in Great Britain and pay freezes do not occur excessively often.

Three research teams are investigating the extent of DNWR in US administrative or payroll data. Jardim, Solon and Vigdor (2019) and Kurmann and McEntarfer (2019) use administrative data on the near universe of employees in the State of Washington. Unusually, Washington requires firms to report hours worked, and so these authors can derive hourly wage measures. Both studies document a considerable proportion of hourly cuts among job-stayer earnings, and Jardim, Solon and Vigdor also confirm this among a subsample where overtime is unlikely to be a large factor. Their results provide important insights for total labour costs, but they cannot exclude other non-basic pay components, nor can they identify hourly-paid workers. It therefore remains unclear what drives the wage cuts documented in Washington. Using a proprietary dataset from one large US payroll processing firm, which contains separate records of employee basic pay and non-basic pay components, Grigsby, Hurst and Yildirmaz (2019) find significantly more evidence of DNWR in basic pay than was documented previously. We extend their insightful study with an analysis of the other non-basic pay components, such as overtime and shift premiums, and by deriving hourly measures of salaried workers' pay. Additionally, the British data studied here are a one percent random sample of income tax paying workers, while it is not entirely clear how representative the recent US findings are. Our results support Grigsby, Hurst and Yildirmaz's conclusion that basic pay exhibits considerable signs of DNWR, as well as adding new evidence for hourly pay rates.

The rest of the paper is structured as follows: after commenting on why a study of spot wages matters, we replicate some well-known results on earnings per hour adjustments in Great Britain (i.e., Nickell and Quintini, 2003; Elsby, Shin and Solon, 2016). Second, we break down earnings per hour, documenting the marginal contributions to nominal adjustments of its five component parts. We repeat the analysis separately for hourly and salaried workers. Thereafter, we look at the differences 
between the derived measures of hourly pay and the reported hourly pay rates for the subset of hourly-paid employees. Subsequently, we use regression analysis to show that the responsiveness of job-stayer and new-hire wages to the business cycle are not significantly different. Finally, we discuss heterogeneity, showing that nominal wage adjustments occurred more often during the last UK recession, and documenting how shrinking firms were more likely to cut wages than expanding firms.

\section{Why does a study of spot wages matter?}

The macroeconomics and labour economics literature on wage flexibility has typically studied the behaviour of spot wages, i.e., periodically observed wage rates. Similarly, the workhorse model of quantitative macroeconomics assumes that wages only depend on the current labour market state (Krusell and Smith Jr., 2006). But ever since Keynes (1936) put forward his theory that DNWR was the main reason for cyclical unemployment, the way economists think about the labour market has evolved. A firm makes its employment decisions based on the marginal costs of the marginal worker. If the marginal costs are sufficiently high, then the firm should lay off the marginal employee. But since many workers are in long-term employment relationships, their spot wages do not necessarily equal or even follow their marginal costs. In his seminal work, Becker (1962) demonstrated that the expected present discounted value of the entire stream of wages, current and future, over the expected duration of the worker-firm match, is allocative for employment. Any stream of remitted wages that adds up to the same present value does not affect the firm's employment decision. Barro (1977) interpreted this as an implicit contract that underlies a worker-firm match, whereby the total expected compensation of the contract is paid out to the worker in instalments. This is optimal, in the sense that a spot wage temporarily exceeding a worker's output will not lead to a separation so long as the total match output is higher than the total wage bill. In other words, inefficient separations do not occur. But due to the long-term nature of employment relationships, allocative wages can be flexible even while incumbent workers' spot wages may be empirically fully rigid from year-to-year. ${ }^{4}$

If we accept that employment relationships are frequently long-term, then signs of DNWR in spot wages should be interpreted only very carefully as evidence for inefficient separations. However, the extent of flexibility in job-stayer nominal wages can still have important macroeconomic consequences. For instance, by relaxing the assumption of perfect capital markets, Schoefer (2016) developed a model in which firms reduce their hiring if financial constraints bind. This liquidity shortage could be alleviated by reducing existing employees' wages. But this source of internal funds is unavailable because of DNWR. Such financial constraints do not only affect labour demand, as liquidity constrained households may have to decrease their consumption if wages are cut. Precautionary savings, which usually allow for consumption smoothing in these circumstances, might not be available to counteract the drop in current earnings, according to Kaplan and Violante

\footnotetext{
${ }^{4}$ See also the recent discussion in Basu and House (2016) on the importance of distinguishing remitted from allocative wages in modern monetary DSGE models.
} 
(2014). They argue that around a third of US households are "wealthy hand-to-mouth". These households possess positive wealth, but in the form of housing or pension savings, which cannot be liquidated easily. Therefore, they exhibit a high elasticity of consumption with respect to current income. $^{5}$

A more nuanced picture emerges from the anecdotal evidence collected by Bewley (1999). Throughout the early 1990s, Bewley gathered information on nominal pay setting by interviewing US employers. He found that they were reluctant to cut nominal pay because they feared it would damage worker morale, and in this way it would negatively impact on productivity, labour turnover, and the recruitment of new employees. Bewley also found that most managers believed that cutting incumbent workers' wages would not prevent layoffs; labour is only a small share of variable costs and the short-run price-elasticity of product demand is low, such that pay cuts would create little, if any, extra work, therefore not reducing the number of unneeded workers. Employers that responded to financial distress during a recession with pay cuts reported to Bewley only minor problems with worker morale and productivity.

Even if existing workers' wages were determined by implicit contracts and nominal wage rigidity did not cause inefficient separations, the extent of flexibility in job-stayer nominal wages can still have important macroeconomic consequences. Consider the case where the wages of existing workers and new hires are not set in isolation, but rather are linked by a firm's internal pay structure. If firms shield their existing employees from nominal wage cuts during recessions, then this could prevent hiring wages from sufficiently decreasing during downturns to soak up the excess labour supply and clear the labour market (Snell and Thomas, 2010). Kaufman (1984) presented survey evidence that firms' internal pay structures do limit hiring wage adjustments. From interviews with 26 British private sector employers in 1982, he gathered that hiring new employees at pay levels lower than those of existing workers was dismissed as unfeasible, since the new workers would eventually become disgruntled. Similarly, in interviews with the compensation executives of 184 Business Week 1000 companies, Campbell III and Kamlani (1997) documented a strong concern for fair wages and internal pay equity, such that new hires could not price themselves into jobs by undercutting existing employees' pay (see Bewley, 1999, for the same argument). ${ }^{6}$ We empirically investigate whether new hires can undercut incumbent workers' wages in Section 7, extending the regression approach proposed by Snell, Stüber and Thomas (2018). We exploit cross-regional variation in the unemployment rate and nominal gross value added over time, to measure the responses of hourly wages to the business cycle. The estimates show no evidence that the hiring wages are more flexible than existing employee wages, which suggests that internal

\footnotetext{
${ }^{5}$ Further evidence for the importance of downward rigidity in spot wages for employment in developing countries is provided by Kaur (2019). She exploited the randomness of rainfall across regions to analyse the consequences of relatively high nominal pay rates for agricultural day labourers in India, finding that employment in regions stuck with high pay rates is significantly lower during the next year.

${ }^{6} \mathrm{~A}$ related argument is presented in Dickson and Fongoni (2019) and Fongoni (2020), who showed that it is theoretically possible, in frictional labour markets, for incumbent workers' reluctance to accept pay cuts to increase the reservation productivity for new hires, thereby depressing job creation.
} 
pay structures, possibly due to concerns about equal treatment, can be a channel through which the rigidity in job-stayer wages causes aggregate unemployment fluctuations.

To summarise, modern macroeconomics has developed an intricate understanding of the relationship between wages and employment over the past 80 years. While some studies have suggested that spot wages are not relevant for employment, others have highlighted both theoretically and empirically the potential channels through which DNWR can have important consequences for unemployment and the real economy. Additionally, we will present evidence that one of those channels, the internal pay structures of firms, appears to be relevant for pay setting in Great Britain. Apart from an intrinsic interest, we believe that it is important to gain a better understanding of the rigidity in nominal wage adjustments.

\section{Data \& Method}

Our analysis of DNWR in Great Britain uses the Annual Survey of Hours and Earnings (ASHE) (Office for National Statistics, 2019). ${ }^{7}$ The ASHE provides a longitudinal panel of employees from 2004 to 2018, without attrition from the sampling frame, and is based on a $1 \%$ random sample of workers who pay income tax or make National Insurance contributions. Employers provide information relating to the pay period that includes a specific date in April, either by responding to a survey questionnaire or directly through the payroll by a special arrangement with the Office for National Statistics (ONS). This setup implies that we only have data for those employed on the survey reference date. ${ }^{8}$

The ASHE offers a unique combination of features which make it ideal for this study. First, employers are legally obliged to report employee earnings with reference to payrolls, making the data more accurate than those obtained from household surveys (Nickell and Quintini, 2003; Elsby, Shin and Solon, 2016). Second, employers are asked explicitly whether an employee has been working in the same job and role for more than a year, meaning that we can abstract from job changes within the same firm. This distinction matters, because we are interested in a firm's tendency to reduce its employees' pay for the same work; a promotion or change to the job may cause the adjustment of an employee's wage, but there is little reason to expect any DNWR for job changers. Finally, the ASHE has a large sample size, with up to 100,000 annual wage change observations of job stayers per year. One drawback of the ASHE is its coverage of very low-paid employees. The design of the sampling frame implies that it contains no observations of employees with earnings below the National Insurance threshold or who work for businesses that have a turnover below the Value Added

\footnotetext{
${ }^{7}$ Although the ASHE survey covers the whole United Kingdom, the datasets available to researchers only cover Great Britain, i.e., they exclude employees working in Northern Ireland, which contains approximately 2-3\% of the UK's population over the time period studied

${ }^{8}$ We use only data from 2006 because questionnaire changes in 2005 and 2006 introduced inconsistencies between these earlier years. Specifically, the wording of the question about incentive payments was changed and new instructions were included on how firms should report employee hours worked.
} 
Tax (VAT) threshold, e.g., £5,564 and $£ 73,000$ per year in 2012-13, respectively. The ONS estimates that this excludes around 3-4\% of employees in Great Britain. ${ }^{9}$

We study employees aged 16-64, who did not incur any loss of pay in the April reference period (e.g., unpaid sick leave or parental leave) and who were not paid at an apprenticeship or a trainee rate. We drop person-year observations if a worker held multiple jobs, worked on average less than one or more than 100 hours per week in April, was reported as being paid less than $80 \%$ of the age-relevant statutory National Minimum Wage, or had missing or imputed values for any of the pay variables which we are interested in. All together, our sample selection criteria result in a working dataset of 1,825,162 worker-year observations. Appendix A describes and justifies our sample construction in more detail.

We will use the following pay variables from the ASHE, summarised in Table 1. Basic pay is a worker's regular pay before adding anything extra. In addition to basic pay, a worker can receive overtime, shift premiums, incentive pay, and other pay (e.g., meal or travel allowances). The sum of basic pay and these extra components is gross pay. Importantly, and like all the other components, incentive pay is only for work carried out during the reference period in April. The dataset contains two measures of labour input: basic hours and overtime, whereby the former also includes hours worked at a shift premium. If an employer calculates an employee's basic pay by multiplying their basic hours worked by a pay rate, then the employer is also required to report this rate. Hereafter, we refer to employees for which hourly pay rates have been reported as 'hourly-paid' workers. All other employees are referred to as 'salaried' workers. The employer also reports an employee's pay period, which is most often either weekly, fortnightly, four-weekly or a calendar month. We do not observe the reported totals for these periods, but instead the ONS derives weekly averages of the variables. The ASHE also has records of an employee's annual gross pay and annual incentive pay, relating to the preceding tax year. These give the sum of all payments that an employee received in her current job. Unfortunately, we don't observe annual hours worked, and so it is not possible for us to compute average annual hourly earnings. Nevertheless, these measures are informative about payments that occur outside the April reference period, especially annual bonuses. We provide more details on the pay components and their exact definitions from the ASHE questionnaire in Appendix A. Within the 2007-18 period, we define a job stayer as an employee whom we observe working in the same job as they were in the previous April, i.e., employees for whom we can observe within-job year-to-year wage changes.

Table 2 shows descriptive statistics for job stayers in the 2006-18 working dataset and for all employees, i.e., also including job switchers, (re-)entrants to employment and 2006 job stayers. On average, the ASHE suggests that around $80 \%$ of British employees remain in the same job from year-to-year. Job stayers are less likely to be working for a private sector company, are slightly

\footnotetext{
${ }^{9}$ For the years 2004-05, the ONS conducted supplementary surveys of VAT-only businesses, i.e., businesses whose turnover was above the VAT threshold, but who paid their employees below the National Insurance threshold. The results indicated that the earnings characteristics of those employees were very similar to National Insurance paying employees, which is why the ONS discontinued the supplementary surveys, concluding that the ASHE data sufficiently represents such workers already.
} 
older, and are more likely to be employed on a full-time basis. More than half of all job stayers are covered by a collective agreement, which is defined as any type of agreement affecting the pay of more than one employee. For instance, the employee's pay could be agreed by a trade union or a workers' committee. While the median job stayer works the same basic weekly hours as the median employee, her median and average gross pay per hour, excluding overtime, are somewhat higher compared to the median employee.

TABLE 1: Overview of pay variables

\begin{tabular}{|c|c|c|}
\hline & & Description \\
\hline & ASHE variables & \\
\hline 1. & Basic pay & All basic pay, excluding any extra payment \\
\hline 2. & Overtime pay & Overtime pay \\
\hline 3. & Shift premium pay & Premium payments for shift work, night or weekend work \\
\hline 4. & Incentive pay & Incentive pay received for work carried out in the pay period \\
\hline 5. & Other pay & Pay received for other reasons, e.g., travel allowances \\
\hline 6. & Gross pay & Sum of basic, overtime, shift premium, incentive, and other pay \\
\hline 7. & Basic hours & Hours relating to basic pay (incl. hours paid at shift premium) \\
\hline 8. & Overtime hours & Paid overtime hours relating to overtime pay \\
\hline 9. & Hourly pay rate & Stated hourly rate of pay where applicable (see text) \\
\hline 10. & Annual gross pay & Annual gross earnings paid for the preceding tax year \\
\hline \multirow[t]{2}{*}{11.} & Annual incentive pay & Component of annual gross pay from incentive payments \\
\hline & $\underline{\text { Derived variables }}$ & \\
\hline 12. & Basic wage & Basic pay divided by basic hours \\
\hline 13. & Earnings per hour & Gross pay, excluding overtime pay, divided by basic hours \\
\hline 14. & Gross pay per hour & Gross pay divided by the sum of basic and paid overtime hours \\
\hline
\end{tabular}

Notes.- See Appendix A for further details on all variables.

\section{Earnings Per Hour Adjustments}

We begin by describing the year-to-year changes in job-stayer earnings per hour, for comparison with the previous studies of Great Britain. This updates the research of Elsby, Shin and Solon (2016), who used the New Earnings Survey Panel Dataset (NESPD), 1975-2012, the precursor of the ASHE dataset, and who also studied nominal adjustments in job-stayer earnings per hour. To better understand the effects of our sample selection procedure, we start by comparing the results of these authors to our findings for the 2006-12 period, where our two analyses overlap.

Whatever the exact reason why workers or firms might prefer unemployment over wage cuts, if DNWR is sufficiently common to cause job losses for some workers, then we should expect to find signs of nominal wage rigidity among job stayers as well. More specifically, the data should show 
TABLE 2: Descriptive statistics for UK employees, 2006-18

\begin{tabular}{lcc}
\hline & Job stayers & All employees \\
& $(\mathrm{I})$ & $(\mathrm{II})$ \\
\hline Private sector $(\%)$ & 62.6 & 63.4 \\
Female (\%) & 50.7 & 50.8 \\
Age (years) & 42.8 & 42.5 \\
Full-time ( $\geq 30$ hours, \%) & 76.3 & 75.7 \\
Collective agreement (\%) & 50.6 & 50.1 \\
Firm size (no. of employees, median) & 2,938 & 2,703 \\
Weekly basic hours (median) & 37.0 & 37.0 \\
Earnings per hour (mean, $£)$ & 14.39 & 14.31 \\
Earnings per hour (median, $£)$ & 11.93 & 11.81 \\
$N$ & $1,097,235$ & $1,825,162$ \\
\hline
\end{tabular}

Notes.- Earnings per hour are deflated to 2015 GB Pounds (GBP) using the UK Consumer Price Index. See Appendix A for further details on all variables.

a lack of cuts in job-stayer pay, while year-to-year freezes should be abundant. Table 3 displays the percentages of job stayers with year-to-year freezes or cuts in their earnings per hour. Our results confirm previous payroll-based findings for Great Britain (Smith, 2000; Nickell and Quintini, 2003; Elsby, Shin and Solon, 2016): nominal earnings per hour are cut quite frequently and the data show relatively few pay freezes, even during the most recent recession and low inflation period following the 2007-08 global financial crisis. Specifically, column (I) shows that the share of year-to-year freezes ranges from $3.1 \%$ in $2006-07$ to $9.9 \%$ in 2012-13. The proportion of cuts is substantial, with a low of $17.9 \%$ in $2007-08$ and a peak of $24.3 \%$ in $2009-10$. For comparison, our estimated frequencies of pay freezes are between 0.3 (2007-08) and 1.2 (2009-10) percentage points higher than the estimates of Elsby, Shin and Solon, while the frequency of cuts in earnings per hour is within a range of one percentage point of their findings. These small deviations are likely caused by our stricter sample selection criteria, which we describe in Appendix A.

A potential concern when assessing the empirical evidence relating to nominal wage rigidity is that pay changes might be measured with error; classical measurement error increases the variance of changes in pay, thus both decreasing the measured frequency of freezes and increasing the frequency of observed cuts. Although the data originate from employer payrolls, which should minimise any errors, the design of the ASHE questionnaire introduces a previously undocumented further source of relevant measurement error to the data. Employers have leeway over how they report working hours, and this means that the basic hours provided in the ASHE dataset are potentially incorrect, and only reliable within a range of one minute (see Appendix B for further details). To address this, we impute the same value of basic hours in subsequent years for job stayers, if two conditions are met: the year-to-year change in working hours is less than one minute, and gross pay, excluding overtime, remains constant. All the main findings in this paper are unaffected by the choice of which basic hours measure we use, either raw or adjusted in the above way. However, it seems reasonable, or even sensible, to treat year-to-year changes in monthly working time of less than one minute as 
TABLE 3: Nominal changes in job-stayer earnings per hour, 2006-18

\begin{tabular}{|c|c|c|c|c|c|c|}
\hline \multirow[b]{2}{*}{ Years } & \multicolumn{2}{|c|}{ Earnings per hour } & \multicolumn{2}{|c|}{ Earnings per hour, adjusted } & \multirow{2}{*}{$\begin{array}{c}\text { Unemployment } \\
\text { (April, \%) } \\
\text { (V) }\end{array}$} & \multirow{2}{*}{$\begin{array}{c}\text { Inflation } \\
(\mathrm{CPI}, \%) \\
(\mathrm{VI})\end{array}$} \\
\hline & $\begin{array}{c}\text { Freezes }(\%) \\
\text { (I) }\end{array}$ & $\begin{array}{l}\text { Cuts (\%) } \\
\text { (II) }\end{array}$ & $\begin{array}{c}\text { Freezes (\%) } \\
\text { (III) }\end{array}$ & $\begin{array}{l}\text { Cuts (\%) } \\
\text { (IV) }\end{array}$ & & \\
\hline 2006-07 & 3.1 & 20.3 & 4.4 & 19.6 & 5.4 & 2.7 \\
\hline $2007-08$ & 3.2 & 17.9 & 3.1 & 17.9 & 5.4 & 2.9 \\
\hline 2008-09 & 5.8 & 20.4 & 6.6 & 19.8 & 5.2 & 2.4 \\
\hline 2009-10 & 8.7 & 24.3 & 9.5 & 23.9 & 7.6 & 3.7 \\
\hline $2010-11$ & 7.8 & 22.8 & 8.4 & 22.5 & 7.9 & 4.4 \\
\hline 2011-12 & 9.7 & 23.4 & 11.2 & 22.5 & 7.8 & 3.0 \\
\hline $2012-13$ & 9.9 & 23.0 & 10.5 & 22.8 & 8.1 & 2.4 \\
\hline $2013-14$ & 6.5 & 20.4 & 6.8 & 20.2 & 7.8 & 1.8 \\
\hline $2014-15$ & 5.5 & 18.9 & 5.9 & 18.7 & 6.4 & -0.2 \\
\hline $2015-16$ & 6.6 & 20.7 & 7.1 & 20.4 & 5.6 & 0.3 \\
\hline 2016-17 & 6.0 & 19.8 & 6.3 & 19.5 & 4.9 & 2.7 \\
\hline $2017-18$ & 6.4 & 18.8 & 6.8 & 18.6 & 4.4 & 2.4 \\
\hline
\end{tabular}

Notes.- Freezes and Cuts show the percentage of job stayers with year-to-year no change and a negative change in the pay measure indicated. See Appendix Table E1 column (I) for annual sample sizes. Inflation is measured as the April-to-April log change in the UK Consumer Price Index (CPI). The unemployment rate refers to UK individuals aged 16 and over, seasonally adjusted and for the second April of each period, expressed as a percentage of the economically active population. Both series are from the Office for National Statistics.

practically constant from both a firm's and a worker's perspectives. Table 3 column (III) shows that the share of freezes in earnings per hour is thus between 0.1 percentage points lower (2007-08) and 1.6 percentage points higher (2012-13) than the raw ASHE data imply. Similarly, column (IV) shows that the share of nominal cuts is slightly lower, but always within one percentage point of the estimates using non-adjusted basic hours. Consistent with our presumption that year-to-year changes of less than one minute per month are best understood as classical measurement error, we find that the shares of marginally positive and negative earnings per hour changes decline by roughly equal amounts. However, these results suggest that the impact of any arbitrary rounding of hours records, caused by the design of the ASHE questionnaire, is not large enough to alter our previous conclusion that job-stayer earnings per hour display a high degree of downward flexibility.

Following the common practice in the literature, we construct histograms of year-to-year changes in job-stayer log earnings per hour, to analyse the entire distribution of nominal changes. Figure 1 displays the results for the years 2006-07 (dark bars) and 2012-13 (light bars). The bar at zero contains only observations for which earnings per hour remain exactly the same across two consecutive years. The bar directly to the right of zero shows the share of changes that are greater than zero but less than or equal to one log point, and so on. The patterns in Figure 1 are similar to the ones seen in the histograms of Elsby, Shin and Solon (2016), with the already mentioned exception that we find somewhat higher spikes at zero. Nominal cuts are not only quite common but also sizeable. Though not perfectly symmetric, the distributions do not show strong signs of a censoring of pay cuts. The spike at zero is substantial, especially because this bar indicates the frequency of exact zeros, while all other bars show the proportions for ranges with a width of one 
$\log$ point. Nevertheless, this spike is lower than what is typically found in the literature analysing household survey data, which are probably subject to rounding error. The growth in earnings per hour in 2012-13 declined relative to 2006-07, with less positive and more negative changes across the entire distribution since the UK's Great Recession. An important issue in macroeconomics relates to the existence of small adjustment costs, or 'menu costs', which mean that only large deviations of the desired earnings per hour from the current level warrant a firm incurring the costs of adjustment. If such costs are present, then we should observe a dip in the distributions at very small pay changes. Although Figure 1 demonstrates a small dip in 2012-13 at marginally positive hourly earnings changes, there is no clear evidence that menu costs noticeably affect the setting of earnings per hour in the UK.

FIGURE 1: Distribution of year-to-year adjustments in log earnings per hour for job stayers, 2006-07 and 2012-13

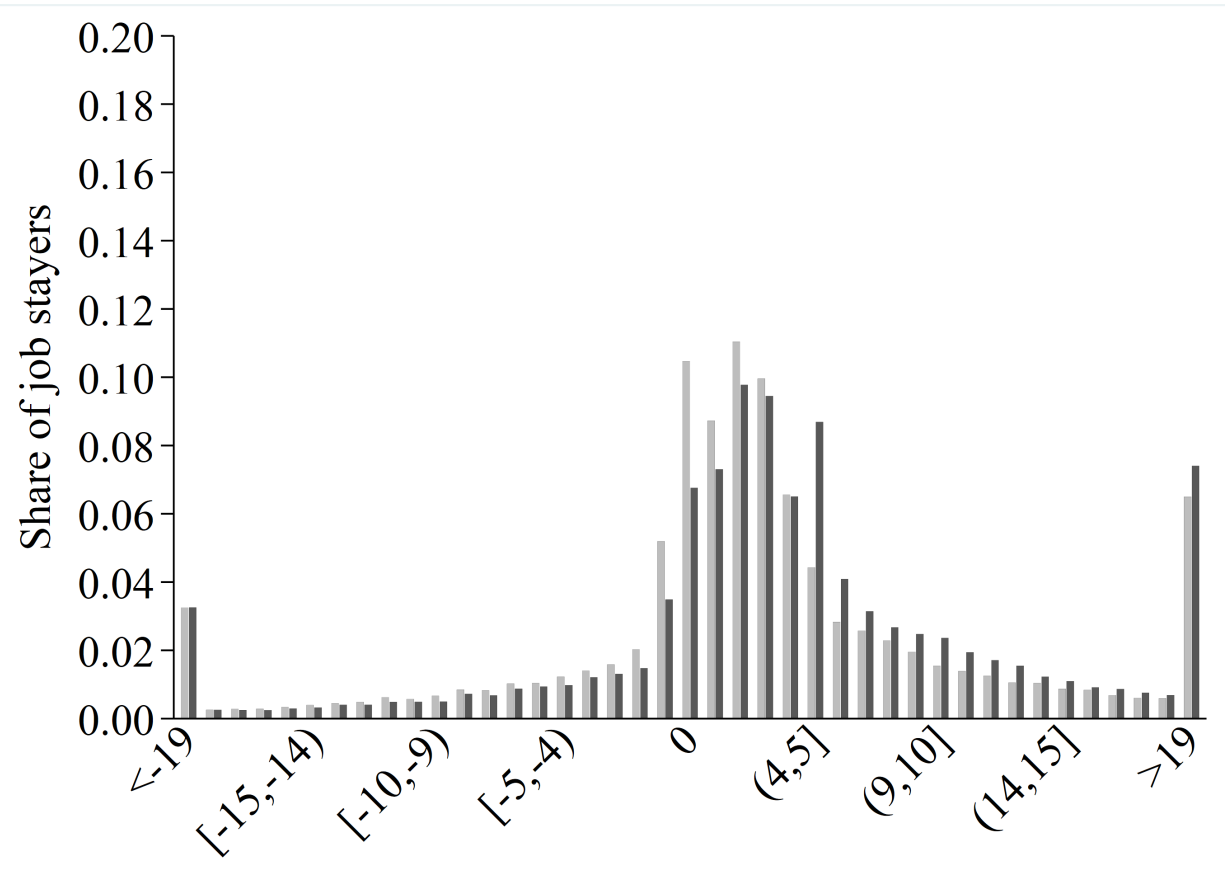

Notes.- ' 0 ' shows the share of job stayers with exactly no change. Positive changes exclude the lower limit and include the upper limit, and vice versa for negative changes. Dark bars: 2006-07. Light bars: 2012-13.

\section{Earnings Composition \& Adjustments}

So far we have presented evidence on the downward rigidity of job-stayer nominal earnings per hour, a measure that includes various kinds of extra pay, e.g., shift premium and incentive pay, and excludes overtime. It is not obvious which pay measure and components should be considered the most relevant when studying wage rigidity, since the answer depends on the particular research question. If one wanted to study how flexibly a firm can adjust its labour costs, then gross pay, including all extra components, is probably the correct measure for nominal adjustments. Alternatively, for assessing whether firms are constrained by DNWR, the adjustments of some 
individual pay components provide important evidence, especially the basic wage, as this is a payment per hour of labour input. The extent of changes in overtime and shift premium pay, however, provide neither clear evidence for nor against nominal rigidity, as workers may welcome reductions in long working times or shift work (e.g., Devereux, 2001; Jardim, Solon and Vigdor, 2019). Similarly, frequent downward adjustments in other pay do not necessarily suggest that workers accept pay cuts. It is plausible that both employees and employers do not perceive a reduction in meal and accommodation allowances, perhaps brought about by less travel in a downturn, as a pay cut per unit of labour input.

\subsection{The Composition of Gross Pay}

We first demonstrate the composition of job-stayer gross pay in Great Britain, to set the scene for a discussion of nominal adjustments in its different components. Within percentiles of the basic wage distribution for job stayers, we compute the average shares received of each component in gross pay. Figure 2 displays these results for the share of basic pay, showing that its contribution is increasing with the level of the basic wage, reaching up to $98 \%$ in the top percentile. The median share of basic pay is $100 \%$ across all job stayers (see also column (I) of Appendix Table C1). Basic pay is the primary earnings source for the vast majority of job stayers, which dovetails with the results for the US presented by Grigsby, Hurst and Yildirmaz (2019). In the bottom percentile, basic pay only accounts for $88 \%$ of gross pay, accounted for by a substantially larger share of incentive pay, which likely reflects more common commission and piece work among the low-paid. Figure 4A shows that incentive pay contributes less to gross pay when moving up the basic wage distribution. When Nickell and Quintini (2003) studied incentive pay in Great Britain, they found that almost $22 \%$ of job stayers in the New Earnings Survey received such payments, compared with only $7 \%$ in our sample. This difference might be explained by a change to the incentive pay definition between their dataset and the ASHE. ${ }^{10}$ The new definition in the ASHE questionnaire, by focusing on incentive payments earned and paid in the April pay period, is more precise and gives more consistent estimates between years (Office for National Statistics, 2005). Hence, Figure 4A is likely to understate the relative importance of annual bonuses, because these are typically paid between January and March in the UK (Schaefer and Singleton, 2020).

The importance of paid overtime for job stayers declines with the basic wage (Figure 3A). While overtime accounts for almost $5 \%$ of gross pay in the bottom percentile and around $3 \%$ at the median, its share in gross pay is less than $1 \%$ in the highest decile. ${ }^{11}$ Shift premiums typically contribute less

\footnotetext{
${ }^{10}$ The NES questionnaire used to ask for two types of incentive payments: first, payments that are made in each pay period, and second, payments that are made less often than every pay period, e.g., annually or quarterly. In the latter case, employers were supposed to report estimates of the proportionate amount of such payments for the April pay period. This question is such that the amount reported could depend on when the employer returned the questionnaire. According to the ONS, questionnaires returned in August were more likely to have information about bonuses than the ones returned in May.

${ }^{11}$ See Bell and Hart (2003) for more details on the relationship between overtime hours and overtime premiums in Great Britain.
} 
FIGURE 2: Average share of basic pay in gross pay for job stayers, 2006-18

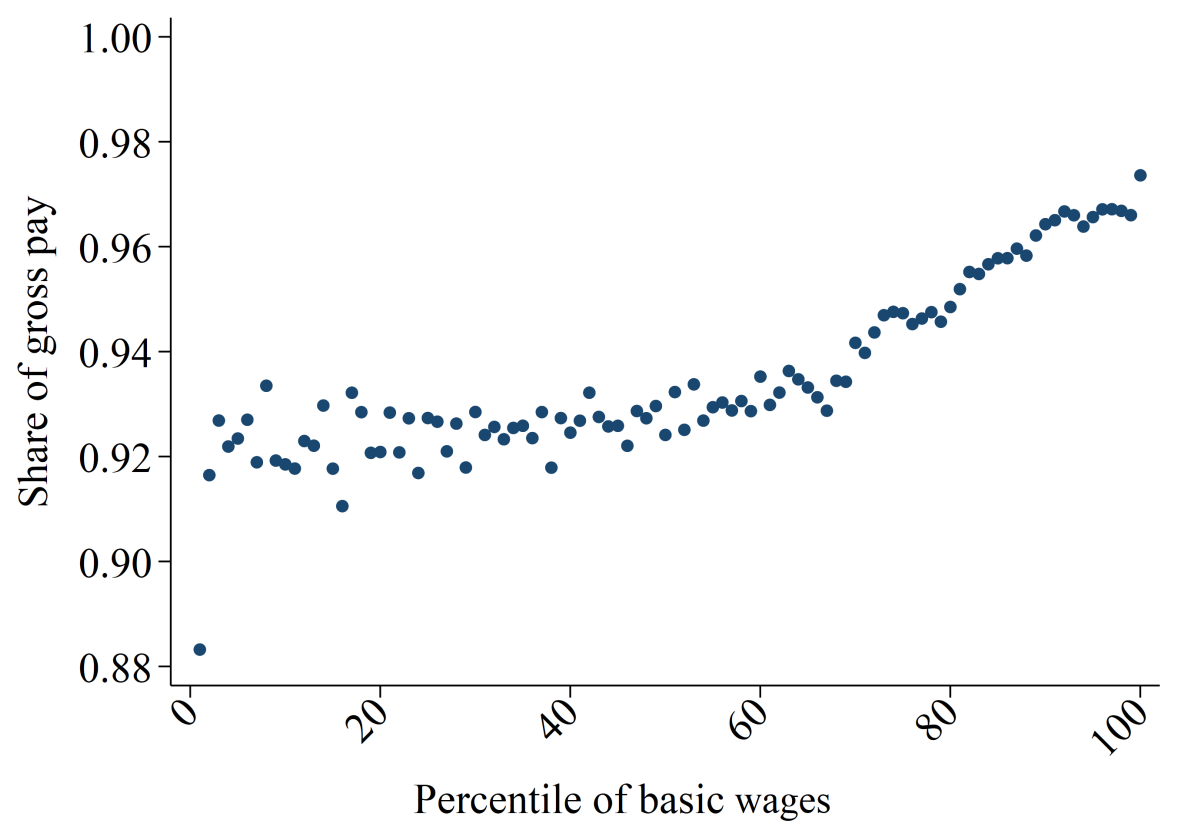

Notes.- Average shares of basic pay in gross pay within the corresponding percentile of the basic wage distribution. Data pooled across all years.

than $2 \%$ of gross pay, and are negligible in the top percentiles of basic wages (Figure 3B). A high basic wage is associated with a high share of gross pay from other pay, such as travel allowances (Figure 3C).

To assess the importance of bonus payments outside of the April reference period, we compute the share of annual incentive pay in annual earnings. Both values refer to the preceding tax year, and so complete information about those variables should have been available to employers when the questionnaire was completed. Figure 4B shows that the share of incentive pay in annual earnings increases along the basic wage distribution. This contrasts with the results for incentive pay earned and received in April. Within the highest decile, the importance of annual incentive payments is greater, especially among the top percentiles. The major differences between Figure 4A and Figure $4 \mathrm{~B}$ most likely originate in the composition of incentive pay. While the left panel probably reflects a larger share of commission-type payments earned throughout the year, annual incentive pay captures bonus payments, particularly for salaried high-earners.

Generally, overtime, shift premiums, and incentive pay, which are received and earned in the reference period, all contribute relatively little to the level of gross pay in the top percentiles. Workers in the lower percentiles receive a considerable part of their gross pay from the non-basic components. ${ }^{12}$

\footnotetext{
${ }^{12}$ See also Appendix $\mathrm{C}$ for additional results and discussion on the association of other pay components within the basic wage distribution.
} 
FIGURE 3: Non-incentive pay components along the basic wage distribution, 2006-18

A. Overtime

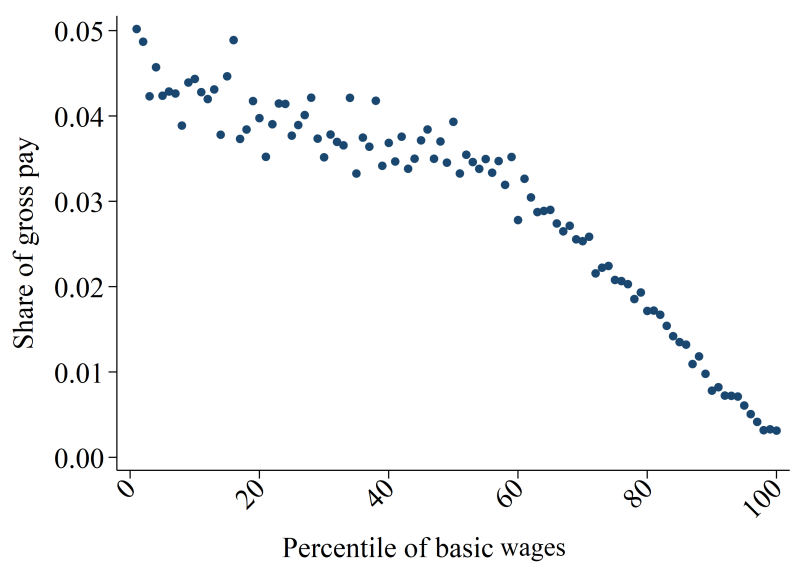

B. Shift premiums

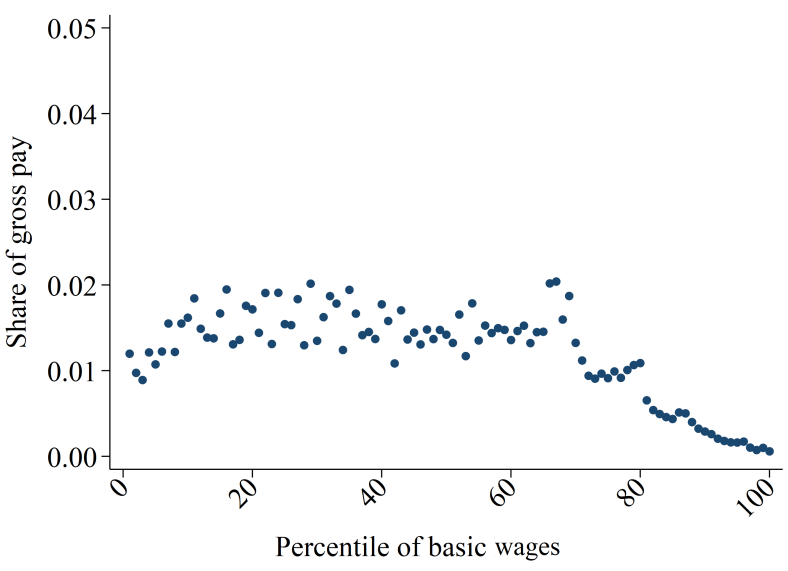

C. Other

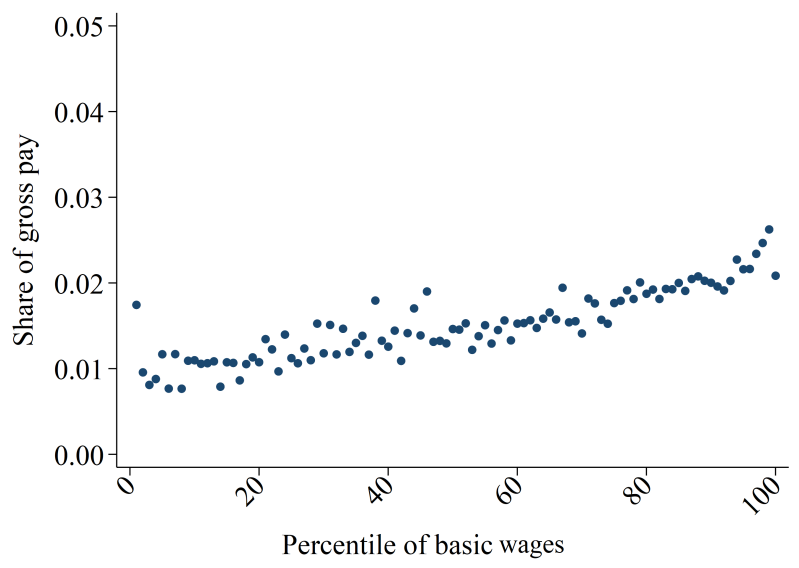

Notes.- Panel A: Average shares of overtime in gross pay within the corresponding percentile of the basic wage distribution. Panel B: Average shares of shift premiums in gross pay within the corresponding percentile of the basic wage distribution. Panel C: Average shares of other pay in gross pay within the corresponding percentile of the basic wage distribution. Data pooled across all years.

\subsection{Marginal Effects of Pay Components on Nominal Wage Adjustments}

In this section, we analyse how each pay component described above affects the nominal adjustments of earnings per hour. For convenience, Table 4 column (I) reproduces the percentages of job stayers with year-to-year freezes in earnings per hour from Table 3 columns (III) and (IV). The top panel of Table 4 displays the percentages of freezes and the bottom panel contains the percentages of cuts (see also Appendix Figure F1 for a time series representation of these results).

To describe the nominal adjustments of gross pay per hour, Table 4 column (II) adds overtime; we divide a worker's weekly gross pay by the sum of basic hours and overtime hours. The frequencies of nominal freezes are lower than without overtime, decreasing by between 0.6 (2007-08) and 2.0 (2009-10) percentage points. Reflecting this, the frequencies of nominal cuts increase by between 1.5 (2017-18) and 2.5 (2009-10) percentage points. These estimates are similar in magnitude to 
FIGURE 4: Incentive pay along the basic wage distribution, 2006-18

A. April

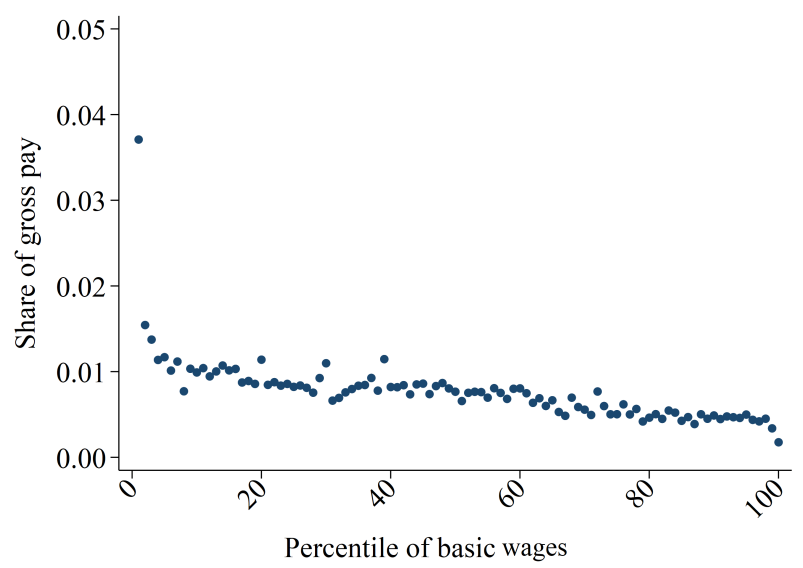

B. Annual

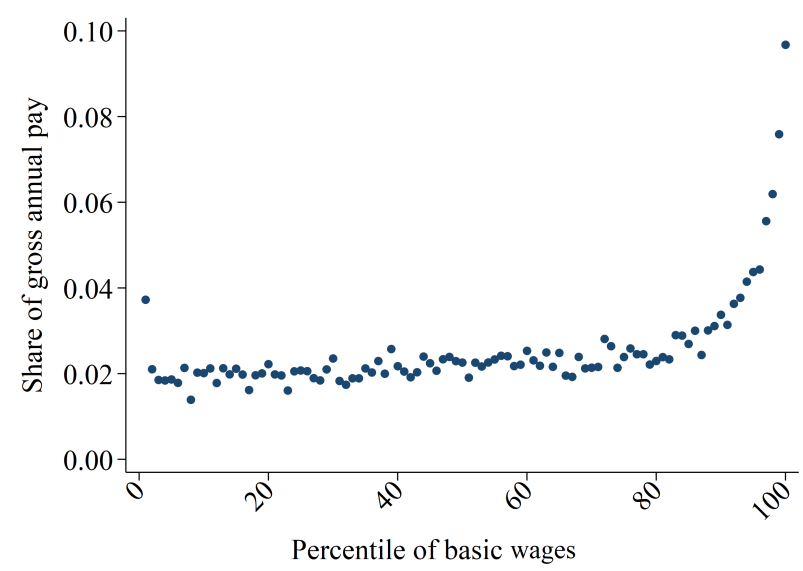

Notes.- Left panel - 'April': Average shares of incentive pay in gross pay within the corresponding percentile of the basic wage distribution in April. Right panel - 'Annual': Average shares of annual incentive pay in annual earnings within the corresponding percentile of the basic wage distribution. Data pooled across all years.

the results of Nickell and Quintini (2003) for Great Britain during 1975-95. ${ }^{13}$ We are aware of two contemporary US studies which also analyse the nominal adjustments of gross pay per hour, including overtime. Jardim, Solon and Vigdor (2019) and Kurmann and McEntarfer (2019) use administrative data from the State of Washington, covering nearly 95\% of private employment. Both studies present similar results, but while Kurmann and McEntarfer (2019) analyse gross pay per hour freezes within a range of $0.5 \mathrm{log}$ points around zero, Jardim, Solon and Vigdor (2019) focus on changes of exactly zero, which makes their results more directly comparable to ours. They find that the share of freezes ranges from $2.5 \%$ (2005-06) to $7.7 \%$ (2009-10), which is similar to the range we document of $2.5 \%$ (2007-08) to $9.2 \%$ (2011-12). These differences could to some extent be explained by the fact that the US data only allow to condition on employees who stay with the same employer rather than in the same job; Solon, Whatley and Stevens (1997) have documented that promotions and demotions within the same firm increased real wage cyclicality in a study of two US companies. The percentage of job stayers who see their gross hourly pay cut is similar in Washington and the UK, falling into ranges of around $20 \%$ to $25 \%$. Using overtime pay as an adjustment channel seems to be more important when earnings per hour freezes are more common, as was the case during 2009-13. These results suggest that overtime work increases the downward flexibility of employee earnings even further, allowing the gross pay per hour of every fourth job stayer to be cut during a recession. A similar finding was already discussed by Bils (1985) and, more recently, in Shin and Solon (2007): both studies found that job-stayer overtime pay is more procyclical than basic pay in the US.

\footnotetext{
${ }^{13}$ Nickell and Quintini (2003) split their sample into employees with and without overtime, and found that the fraction of cuts among those who worked overtime is up to 3.8 percentage points higher than among those employees without overtime. Similarly, they found that the spike with zero changes is up to 1.5 percentage points lower for workers who received overtime pay.
} 
TABLE 4: Marginal effects of pay components on nominal adjustments in earnings per hour, 2006-18

\begin{tabular}{|c|c|c|c|c|c|}
\hline \multirow[b]{2}{*}{ Years } & \multirow{2}{*}{$\begin{array}{l}\text { Earnings } \\
\text { per hour } \\
\text { (I) }\end{array}$} & \multirow{2}{*}{$\begin{array}{c}\text { Adding } \\
\text { Overtime } \\
\text { (II) }\end{array}$} & \multicolumn{3}{|c|}{ Excluding } \\
\hline & & & $\begin{array}{l}\text { Shift premium pay } \\
\text { (III) }\end{array}$ & $\begin{array}{c}\text { Incentive pay } \\
\text { (IV) }\end{array}$ & $\begin{array}{l}\text { Other pay } \\
\text { (V) }\end{array}$ \\
\hline \multicolumn{6}{|c|}{ Freezes (\%): } \\
\hline 2006-07 & 4.4 & 3.5 & 4.6 & 4.9 & 5.2 \\
\hline $2007-08$ & 3.1 & 2.5 & 3.3 & 3.4 & 3.4 \\
\hline 2008-09 & 6.6 & 5.2 & 6.8 & 7.3 & 7.3 \\
\hline $2009-10$ & 9.5 & 7.5 & 9.9 & 10.5 & 10.8 \\
\hline 2010-11 & 8.4 & 6.9 & 8.4 & 9.0 & 9.6 \\
\hline 2011-12 & 11.2 & 9.2 & 11.2 & 12.1 & 12.9 \\
\hline $2012-13$ & 10.5 & 8.6 & 10.9 & 11.4 & 11.9 \\
\hline $2013-14$ & 6.8 & 5.6 & 7.2 & 7.5 & 7.5 \\
\hline $2014-15$ & 5.9 & 4.9 & 6.1 & 6.4 & 6.4 \\
\hline $2015-16$ & 7.1 & 5.9 & 7.3 & 7.6 & 8.1 \\
\hline $2016-17$ & 6.3 & 5.4 & 6.6 & 6.8 & 7.1 \\
\hline $2017-18$ & 6.8 & 5.8 & 7.1 & 7.3 & 7.4 \\
\hline \multicolumn{6}{|c|}{ Cuts (\%): } \\
\hline 2006-07 & 19.6 & 21.3 & 18.8 & 17.6 & 17.7 \\
\hline 2007-08 & 17.9 & 19.8 & 17.2 & 16.8 & 15.8 \\
\hline 2008-09 & 19.8 & 22.3 & 18.7 & 18.5 & 17.6 \\
\hline $2009-10$ & 23.9 & 26.1 & 22.7 & 22.8 & 21.6 \\
\hline 2010-11 & 22.5 & 24.7 & 21.5 & 21.3 & 20.1 \\
\hline $2011-12$ & 22.5 & 24.6 & 21.5 & 21.2 & 20.4 \\
\hline $2012-13$ & 22.8 & 24.9 & 21.9 & 21.1 & 21.4 \\
\hline $2013-14$ & 20.2 & 22.3 & 18.6 & 19.1 & 17.7 \\
\hline 2014-15 & 18.7 & 20.4 & 17.2 & 17.6 & 17.0 \\
\hline $2015-16$ & 20.4 & 22.4 & 19.4 & 19.4 & 18.3 \\
\hline 2016-17 & 19.5 & 21.2 & 18.1 & 18.6 & 17.4 \\
\hline $2017-18$ & 18.6 & 20.1 & 17.4 & 17.6 & 17.1 \\
\hline
\end{tabular}

Notes.- Percentages of job stayers with exactly zero year-to-year changes in nominal hourly pay, or cuts. Each column uses earnings per hour as the baseline pay variable and then either adds or excludes the shown pay component.

While the number of shift workers has been shown to be procyclical in medium and large US firms (Mayshar and Solon, 1993), little is known about the adjustments of shift pay per worker. Nonetheless, around $10 \%$ of British job stayers receive some shift premium pay, and for half of these workers shift premiums contribute over $10 \%$ of total earnings (column (IV), Appendix Table C1). Table 4 column (III) shows results when we exclude shift premiums from earnings. Comparing these percentages to column (I) indicates that adjustments in shift premium pay, like overtime, decrease the frequency of year-to-year freezes and increase the frequency of cuts. Although overtime and shift pay are relevant for a firm's total labour costs, it is not obvious whether these components are informative about DNWR. Employees can alter shift patterns, possibly switching with one another, 
which does not necessarily change a firm's unit production costs. Further, some employees might welcome a reduction in unwanted shift work.

Once we exclude incentive payments from earnings per hour, the frequency of nominal pay freezes increases between 0.3 (2007-08) and 1.0 (2011-12) percentage points, and the share of cuts decreases between 0.9 (2016-17) and 2.0 (2006-07) percentage points (column (IV), Table 4). Nickell and Quintini (2003) also found that incentive pay is relatively frequently cut, and that the percentage of job stayers with freezes in earnings per hour is lower among those who receive incentive pay. But their results pointed toward a larger effect of incentive pay, doubling the share of pay cuts in the subsample of workers who receive such pay. However, results have to be compared with caution, because Nickell and Quintini based their analysis on the New Earnings Survey, which used a different definition of incentive pay; one that was more inclusive and less consistent between years, as explained above.

The largest marginal effect on the pattern of nominal earnings per hour adjustments, when excluding the different pay components, comes from other pay (column (V), Table 4). When we exclude this component, the incidence of pay freezes increases in all periods, but most notably between 2011-12, where the share of freezes increases by 1.7 percentage points. Omitting other pay has the largest impact on the incidence of nominal pay cuts as well, peaking in 2013-14 with a decrease of 2.5 percentage points. A firm's marginal labour costs might be unaffected by these adjustments, if other pay changes proportionally with the amount of business activity. For instance, accommodation and meal allowances will decline when employees undertake less business related travel. However, if the allowances per meal were cut, then this would imply a decrease in the firm's marginal labour costs. Unfortunately, our data do not allow us to distinguish these two cases, but they show the importance of analysing the pay components separately to gain a better understanding of nominal wage rigidity.

We also extend the analysis of Nickell and Quintini (2003) by considering annual incentive pay. Incentive pay relating to the April reference period is likely to miss a significant part of overall incentive pay, as most annual bonuses are paid from January to March. We restrict the sample to employees who stay in the same job with the same employer for two consecutive years, to minimise the effects of calendar working time differences on annual pay values. This more restrictive sample selection criteria means that we lose around $10 \%$ of job-stayer observations. The results in Table 5 suggest that nominal annual gross pay is more flexible than earnings per hour. This is unsurprising, because even if annual gross pay per hour was fully rigid, sick leave and unpaid holidays are likely to affect job-stayer annual working hours and pay from year-to-year. Almost every third job stayer saw their annual pay decline in nominal terms in 2009-10, the period when unemployment rose fastest in the UK following the global financial crisis. This relatively high frequency of cuts cannot be explained by changes in annual incentive pay alone (column (IV), Table 5). Incentive pay increases the shares of annual pay cuts in most years by at most 1.1 percentage points, except for 2008-09 and 2009-10 when the effects are more notable, increasing cuts by 2.4 and 1.7 percentage points, 
respectively. Both annual incentive pay and incentive pay in the April reference period increase the downward flexibility of nominal earnings.

TABLE 5: Nominal adjustments in job-stayer annual pay, 2006-18

\begin{tabular}{|c|c|c|c|c|c|}
\hline \multirow[b]{2}{*}{ Years } & \multicolumn{2}{|c|}{ Annual gross pay } & \multicolumn{2}{|c|}{ Excl. annual incentive pay } & \multirow{2}{*}{$\begin{array}{c}\text { Number of } \\
\text { Job stayers } \\
\text { (V) }\end{array}$} \\
\hline & $\begin{array}{c}\text { Freezes }(\%) \\
\text { (I) }\end{array}$ & $\begin{array}{l}\text { Cuts }(\%) \\
\text { (II) }\end{array}$ & $\begin{array}{c}\text { Freezes }(\%) \\
\text { (III) }\end{array}$ & $\begin{array}{l}\text { Cuts }(\%) \\
\quad \text { (IV) }\end{array}$ & \\
\hline 2006-07 & 1.7 & 23.8 & 1.9 & 23.0 & 67,486 \\
\hline $2007-08$ & 1.6 & 22.1 & 1.8 & 21.5 & 68,289 \\
\hline 2008-09 & 1.8 & 27.5 & 1.9 & 25.1 & 67,136 \\
\hline $2009-10$ & 2.8 & 31.9 & 3.5 & 30.2 & 80,695 \\
\hline $2010-11$ & 3.4 & 29.1 & 3.9 & 28.6 & 91,331 \\
\hline $2011-12$ & 3.5 & 30.1 & 3.9 & 29.1 & 87,706 \\
\hline $2012-13$ & 3.5 & 30.1 & 4.2 & 29.0 & 85,643 \\
\hline 2013-14 & 2.4 & 29.4 & 2.9 & 28.3 & 86,846 \\
\hline $2014-15$ & 2.2 & 26.9 & 2.7 & 25.9 & 85,681 \\
\hline $2015-16$ & 2.6 & 27.9 & 3.0 & 26.8 & 81,164 \\
\hline $2016-17$ & 2.6 & 25.9 & 3.0 & 24.8 & 77,240 \\
\hline 2017-18 & 2.6 & 26.0 & 3.0 & 25.1 & 74,311 \\
\hline
\end{tabular}

Notes.- Freezes and cuts show the share of job stayers who experienced exactly zero and negative year-to-year changes in their annual gross pay.

So far we have looked at the impact of pay components on nominal adjustments in isolation. But what is the combined implication for DNWR of all non-basic pay components? To answer this question, we describe the nominal adjustment patterns of basic wages. As the previous section demonstrated, this is the only source of wage income for most job stayers. Table 6 presents novel findings for the UK. Basic wages appear more rigid than earnings per hour: they are more likely to be frozen and less likely to be cut among employees. Nevertheless, the frequency of basic wage cuts remains strikingly high, substantially exceeding the extent documented by Grigsby, Hurst and Yildirmaz (2019) for the US. However, those authors lacked reliable data on hours worked, and so they analysed year-to-year changes in basic pay per pay period. To better understand whether hours worked can account for the differences between our studies, we also computed the share of year-to-year freezes and cuts in job-stayer basic weekly pay. The share of basic weekly pay cuts is slightly lower than for hourly pay. Additionally, the incidence of wage freezes is $50 \%$ higher for basic weekly pay; during 2011-12 and 2012-13 more than one-in-five job stayers had their basic weekly pay frozen (Appendix Table B1, columns (III)-(IV)).

Figure 5 shows the effects of removing all additional pay components from earnings per hour across the entire distribution of job-stayer nominal adjustments. The frequency of changes within one log point of zero is only slightly smaller for basic wages than for earnings per hour, while moderate pay increases in the range of 2-6 log points occur more frequently in the former. Large positive changes exceeding $6 \log$ points and negative changes in basic wages are less common than 
TABLE 6: Combined effects of pay components on nominal adjustments: earnings per hour and basic wages, 2006-18

\begin{tabular}{|c|c|c|c|c|}
\hline \multirow[b]{2}{*}{ Years } & \multicolumn{2}{|c|}{ Earnings per hour } & \multicolumn{2}{|c|}{ Basic wage } \\
\hline & Freezes $(\%)$ & Cuts $(\%)$ & Freezes $(\%)$ & Cuts $(\%)$ \\
\hline 2006-07 & 4.4 & 19.6 & 6.2 & 13.8 \\
\hline $2007-08$ & 3.1 & 17.9 & 4.2 & 12.9 \\
\hline 2008-09 & 6.6 & 19.8 & 8.8 & 13.8 \\
\hline 2009-10 & 9.5 & 23.9 & 13.1 & 18.0 \\
\hline $2010-11$ & 8.4 & 22.5 & 11.9 & 16.1 \\
\hline 2011-12 & 11.2 & 22.5 & 13.7 & 17.4 \\
\hline $2012-13$ & 10.5 & 22.8 & 13.9 & 17.4 \\
\hline $2013-14$ & 6.8 & 20.2 & 9.0 & 13.8 \\
\hline $2014-15$ & 5.9 & 18.7 & 7.3 & 13.2 \\
\hline $2015-16$ & 7.1 & 20.4 & 9.2 & 15.2 \\
\hline $2016-17$ & 6.3 & 19.5 & 8.3 & 14.2 \\
\hline $2017-18$ & 6.8 & 18.6 & 8.5 & 14.1 \\
\hline
\end{tabular}

Notes.- Freezes and Cuts show the percentage of job stayers with year-to-year no change and a negative change in the pay measure indicated.

for earnings per hour. These results indicate that non-basic pay components play a role in facilitating both cuts to job-stayer earnings per hour and large raises.

FIGURE 5: Distribution of year-to-year adjustments in log earnings per hour and basic wages for job stayers, 2006-18

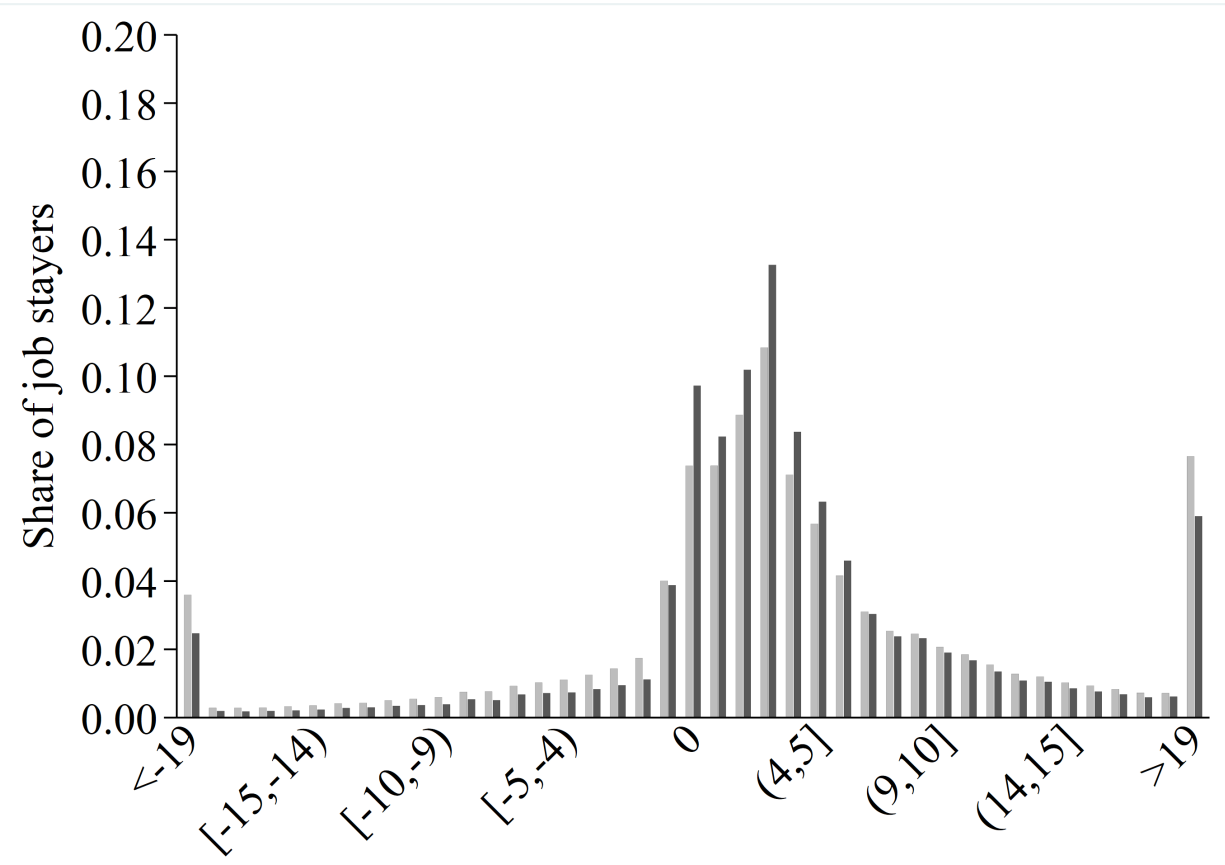

Notes.- See Figure 1. Pooled data for 2006-2018. Dark bars: earnings per hour. Light bars: basic wages.

In summary, we find that gross pay per hour is cut frequently. Zero seems to be a significant number in terms of year-to-year wage changes for some job stayers in the UK, but wage cuts are 
also common. None of the non-basic pay components accounts on its own for the observed high frequency of earnings per hour cuts, but rather all components increase the downward flexibility somewhat. That said, we also find that large shares of job stayers experience year-to-year cuts in their basic wages or basic weekly pay.

\section{Hourly Pay Rates}

Almost every third job stayer in our working dataset is paid by the hour, i.e., basic pay is computed by multiplying an hourly pay rate by the number of basic hours worked. ${ }^{14}$ Up until now, we have provided statistics for a combined sample of hourly-paid and salaried workers. But, previous research has found conflicting evidence on the extent to which DNWR appears to differ between these two types of workers. For example, Card and Hyslop (1996) analysed the Current Population Survey covering the 80s and the early 90s, concluding that DNWR is not lower for salaried than for hourly-paid workers in the US. Contrary to this, Kahn (1997) found that hourly wage rates exhibit substantially more signs of DNWR than salaries in the Panel Study of Income Dynamics for the period 1970-88. Similarly, when Elsby, Shin and Solon (2016) updated the analyses of Card and Hyslop to 2012, they found more evidence for downward rigidity in US wage rates than in salaries. The main reason why the literature has been inconclusive on this issue is that administrative datasets do not typically allow hourly-paid workers to be identified, while household surveys that do allow this have well-known reliability issues. The ASHE dataset allows us to address this by analysing hourly pay rates using payroll data.

We begin by discussing the evidence for nominal rigidity in earnings per hour for hourly-paid and salaried workers, and then consider the influence of non-basic pay components. We again use histograms pooled over our sample period to describe the main findings, but also refer the reader to Appendix Tables E4-E7, where for both types of worker we display separately the annual frequencies of freezes and cuts in job-stayer earnings per hour, basic wages, and the marginal contributions of non-basic pay components. Figure 6A shows the distributions of changes in log earnings per hour of hourly-paid (dark bars) and salaried (light bars) job stayers. Although the distributions appear similar at a first glance, there are two noteworthy differences. First, the percentage of freezes (cuts) is higher (lower) for hourly-paid workers. This is true for all years in our sample, and the difference between the two types of job stayers is particularly large in 2009-10 and 2010-11 at 4.0 and 3.3 percentage points, respectively (Appendix Table E4). Second, the histogram shows a relative lack of very small positive changes in earnings per hour for hourly-paid workers. A larger share of this group sees its earnings per hour rise in the range of 2-7 log points. These facts are consistent with there being significant menu costs incurred in the adjustment of hourly-paid workers' earnings, but we see no such evidence for salaried workers.

\footnotetext{
${ }^{14}$ See Appendix Tables E2 \& E3 for descriptive statistics comparing hourly-paid and salaried workers.
} 
FIGURE 6: Distribution of year-to-year adjustments in log earnings per hour \& basic wage for job stayers, 2006-18: hourly-paid vs salaried

A. Earnings per hour

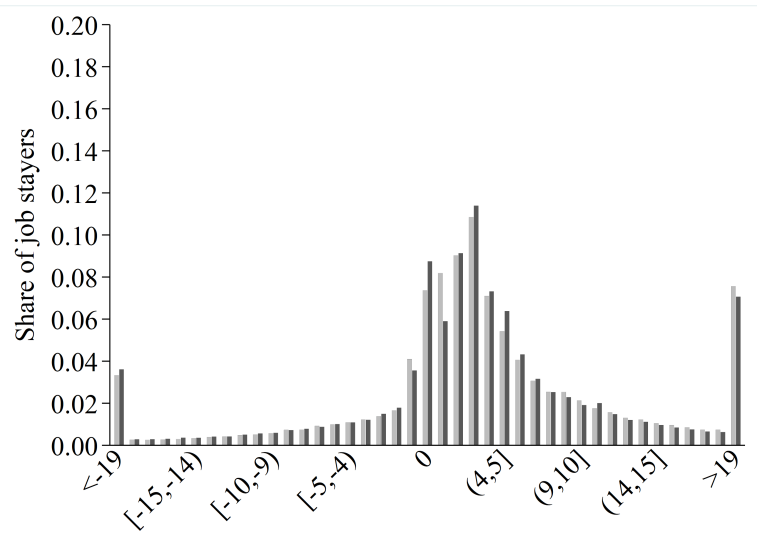

B. Basic wage

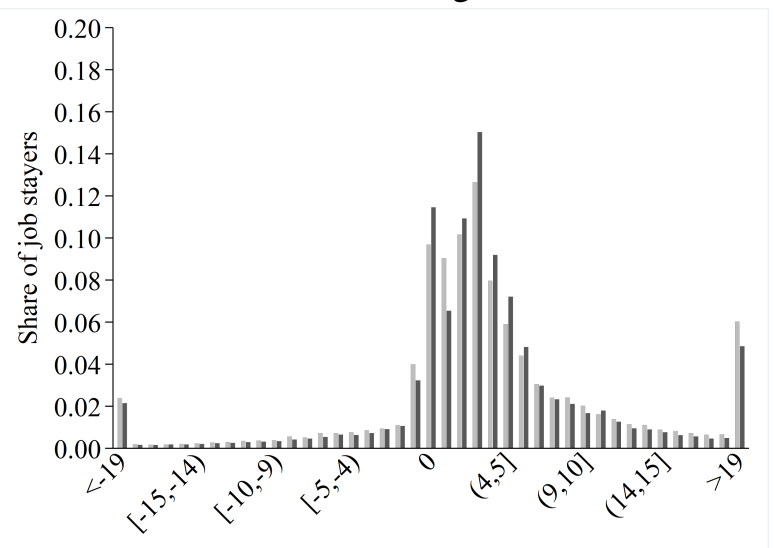

Notes.- See Figure 1. Pooled data for 2006-2018. Dark bars: hourly-paid workers. Light bars: salaried workers. The underlying data for the left and right panels are also represented in Appendix Tables E4 \& E5, respectively.

The combined effects on downward flexibility of abstracting from all non-basic pay components are shown in Figure 6B. Both hourly-paid and salaried job stayers have their basic wages frozen more commonly from year-to-year than their earnings per hour. Removing non-basic pay components has a large effect on the apparent extent of DNWR for hourly-paid workers: the percentage with freezes increases by 4.1 points in 2010-11, while the percentage with cuts plummets by 8.2 points in the same years (Appendix Tables E5). Additionally, hourly-paid job stayers during 2009-10 and 2010-11 were more likely to have their basic wages frozen rather than cut. The histogram shows a relative lack of very small positive changes in earnings per hour for hourly-paid workers. A larger share of this group sees its earnings per hour rise in the range of 2-7 log points. The dip in the distributions at very small pay changes is consistent with there being adjustment costs, or 'menu costs', incurred in the adjustment of hourly-paid workers' basic wages, but we see no such evidence for salaried workers.

We also provide a full account of each pay component's marginal contribution to the prevalence of freezes and cuts in earnings per hour, separately for hourly-paid and salaried workers (Appendix Tables E6 \& E7), respectively. Notably, the impact of considering overtime pay on the measured shares of freezes and cuts among job stayers is nearly twice as large for hourly-paid than salaried workers. This supports the conjecture of Devereux (2001) and the estimates of Shin and Solon (2007), that overtime pay provides substantial year-to-year flexibility in hourly-paid earnings. Shift premiums, incentive pay, and other pay each act to marginally decrease the apparent extent of DNWR for hourly-paid workers, doing so approximately in that order of magnitude. 


\subsection{Hourly Wage Rates}

The ASHE includes the reported hourly pay rate, measured in pence, of hourly-paid employees. This allows us to compare changes in the hourly rates and the basic wages of job stayers. The two pay measures should in theory be identical for most workers, because the ASHE questionnaire asks employers to report the hourly rate if it was used to compute the returned level of basic pay. The only difference should come from hours worked at a shift premium, which are excluded from basic pay but included and indistinguishable within the records of basic hours. ${ }^{15}$ Regardless, we find a substantially larger percentage of freezes in hourly pay rates than in basic wages among job stayers, with the former exceeding the latter by between 4.0 (2007-08) and 8.1 (2017-18) points (Table 7). Similarly, the frequency of year-to-year nominal cuts in the hourly pay rate is relatively low and never exceeds $7.1 \%$ in the sample period. These differences strike us as quite significant, and they lend support to the findings of Kahn (1997) and Elsby, Shin and Solon (2016) from US household surveys that there is DNWR in hourly pay rates.

TABLE 7: Nominal adjustments in hourly-paid job-stayer wages, 2006-18

\begin{tabular}{|c|c|c|c|c|}
\hline \multirow[b]{2}{*}{ Years } & \multicolumn{2}{|c|}{ Basic wage } & \multicolumn{2}{|c|}{ Hourly pay rate } \\
\hline & $\begin{array}{c}\text { Freezes }(\%) \\
\text { (I) }\end{array}$ & $\begin{array}{c}\text { Cuts }(\%) \\
\text { (II) }\end{array}$ & $\begin{array}{c}\text { Freezes }(\%) \\
\text { (III) }\end{array}$ & $\begin{array}{l}\text { Cuts (\%) } \\
\text { (IV) }\end{array}$ \\
\hline 2006-07 & 8.3 & 11.5 & 14.5 & 6.2 \\
\hline 2007-08 & 6.4 & 12.1 & 10.4 & 4.0 \\
\hline 2008-09 & 10.3 & 11.1 & 16.4 & 6.1 \\
\hline $2009-10$ & 16.3 & 15.3 & 24.0 & 5.7 \\
\hline $2010-11$ & 14.7 & 13.7 & 23.4 & 5.0 \\
\hline $2011-12$ & 14.0 & 14.0 & 24.7 & 4.5 \\
\hline $2012-13$ & 14.4 & 16.5 & 22.9 & 7.1 \\
\hline 2013-14 & 11.8 & 12.8 & 20.3 & 4.2 \\
\hline 2014-15 & 9.3 & 11.2 & 15.3 & 3.7 \\
\hline $2015-16$ & 9.9 & 13.5 & 17.9 & 6.2 \\
\hline 2016-17 & 9.6 & 12.5 & 16.3 & 3.5 \\
\hline $2017-18$ & 8.9 & 11.5 & 18.5 & 3.3 \\
\hline
\end{tabular}

Notes.- Freezes and Cuts show the percentage of job stayers with year-to-year no change and a negative change in the pay measure indicated. The samples of job stayers for both pay measures are identical. See Table E1 columns (VI) for annual sample sizes.

To better understand these findings, we display the distributions of year-to-year log changes in three pay measures for the hourly-paid employees in Figure 7 - earnings per hour, basic wages, and hourly pay rates - pooled throughout the sample period. Year-to-year hourly pay rate adjustments of less than one log point are less likely than in basic wages, while positive log changes of 2-5 points are more likely. Employees experience fewer changes in their reported hourly pay rates that lie outside the range of plus/minus $19 \log$ points than in the derived basic wage, and cuts in hourly pay rates

\footnotetext{
${ }^{15}$ The ONS also adjusts basic hours if the basic wage is within 0.5 pence of the hourly pay rate. Specifically, basic hours are imputed to equal basic weekly pay divided by the hourly pay rate in such cases.
} 
occur less often, regardless of the size of the cut. It seems reasonable to assume that hourly pay rates and basic weekly pay are both measured relatively accurately, because this information is directly available in payroll records. In this case, a plausible explanation for the excess mass of negative basic wage growth is that the frequency of changes in basic hours worked is overestimated.

FIGURE 7: Distributions of year-to-year adjustments in log earnings per hour, basic wages and hourly pay rates. Hourly-paid job stayers, 2006-2018

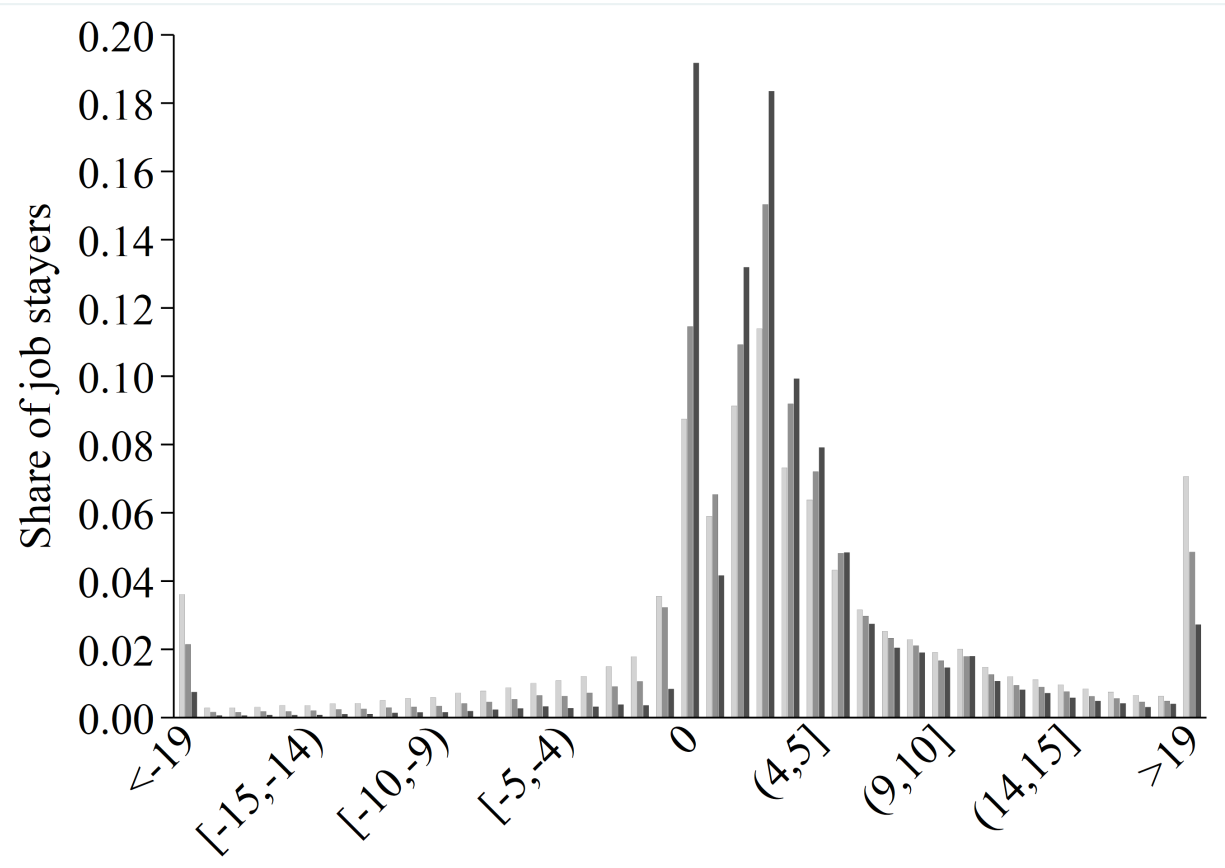

Notes.- See Figure 1. Pooled data for 2006-2018. Light grey bars: earnings per hour; Medium grey bars: basic wages; Dark grey bars: reported hourly pay rates.

The apparent lack of small changes and freezes in basic wages in these data could be due to either classical measurement error in basic hours, made more likely by the fact that the effect is symmetric around zero, changes in the number of hours worked at a shift premium, or because employers incorrectly report rounded values of hourly pay rates. Smith (2000) also argued that classical measurement error will increase the estimated flexibility of nominal wage adjustments, while rounding by employees will lead to overestimates of wage freezes. She found that the latter is more prevalent in the British Household Panel Survey. We assess the potential effects of any rounding on the estimated flexibility of hourly pay rates in the ASHE. Year-to-year freezes are more common among the hourly-paid job stayers who had hourly pay rates in the previous year that were multiples of ten pence (Figure 8). Kahn (1997) similarly found that US hourly pay rates ending in exact dollar or half-dollar amounts made up $50 \%$ of the job stayers with hourly rate freezes in household survey data. There are two possible explanations. First, employers are incorrectly reporting rounded hourly pay rates. Second, round hourly rates are accurately reported and just happen to be more rigid, i.e., employers only make an adjustment when the optimal change is sufficiently large to justify doing so. This could be the case, for example, if round hourly rates are somehow preferred. We also see that employees with round hourly rates are more likely to see 
their pay change by larger amounts than other employees. Figure 8 shows that changes of 5 and 12 log points, for example, are 5 and 2 percentage points more common, respectively, than changes of the same size for non-round hourly pay rates.

FIGURE 8: Distributions of year-to-year adjustments in log hourly pay rates, hourly-paid job stayers, 2006-18: the potential effects of rounding

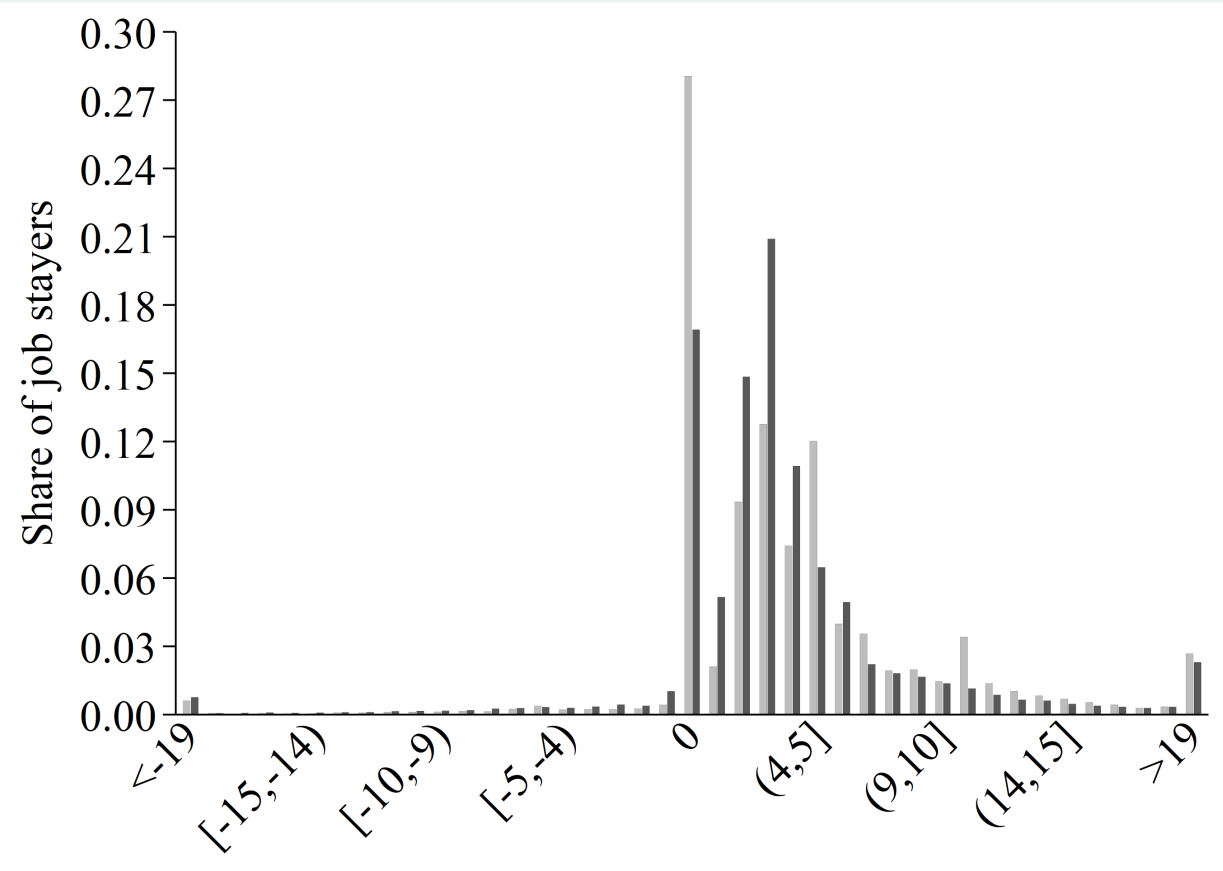

Notes.- See Figure 1. Pooled data for 2006-18. Dark bars: reported hourly pay rates not ending in zero pence in the first year $(N=271,810)$. Light bars: reported hourly pay rates ending in zero in the first year $(N=70,415)$.

In summary, the evidence in this section shows that directly reported hourly pay rates in the UK display strong signs of DNWR. The data show few year-to-year pay rate cuts, even during and in the aftermath of the 2008-09 recession. Pay rate freezes are also common among hourly-paid employees, affecting up to a quarter of yearly job stayers following the recession. These results persist even when we exclude round hourly pay rates, albeit to a somewhat lesser extent for the incidence of exactly zero changes. However, it is worth recalling that non-basic pay components, particularly overtime, still allow cuts in gross pay per hour to be common among hourly-paid workers, despite the apparent downward rigidity in hourly pay rates.

\section{Internal Wage Structures}

The analysis up to this point has focused on the nominal wages of job stayers. But according to a large literature based on labour markets with search frictions, the key determinant for a firm's hiring decision, and consequently aggregate unemployment fluctuations, is the flexibility of hiring wages (Shimer, 2004; Pissarides, 2009). Even in this context, the theoretical framework proposed by Snell and Thomas (2010) shows how our findings regarding existing employee wages can still be relevant. In their model, risk neutral firms insure their risk averse employees against income fluctuations. 
Further, Snell and Thomas impose an equal treatment constraint that requires firms to offer the same wage contracts to new hires and existing workers. The insurance motive that creates rigidity for existing employees prevents the wages of new hires from falling sufficiently far during recessions, which leads to relatively less hiring and cyclical unemployment fluctuations.

Empirically, if firms were constrained by internal pay structures in the described manner, then hiring wages should be as cyclical as the wages of existing employees. To assess the evidence for internal pay structures in Great Britain, we adapt the empirical strategy of Snell, Stüber and Thomas (2018). The estimation is carried out in two steps. In the first step, nominal wages are regressed on year-region dummy variables and a set of worker-firm-level controls, distinguishing between new hires and existing employees. New hires are all workers who joined the firm within the given year, and all other workers are incumbents. This first step controls for cyclical changes in the average worker quality (Solon, Barsky and Parker, 1994). In the second step, we regress the estimated year-region effects for incumbents and new hires on business cyclical indicators. This provides us with estimates of the cyclicality of new hire and incumbent worker wages, which are robust to region-year clustering of the model errors. The key test is then whether the cyclicality estimates differ significantly between new hires and incumbents. As explained by Snell, Stüber and Thomas (2018), it is important to control for as much worker-firm heterogeneity as possible when analysing internal pay structures. Failing to control for cyclical changes in match quality - the average quality of a match formed during an expansion is usually considered to be higher (Hagedorn and Manovskii, 2013) - may lead to an overestimation of the cyclicality of hiring wages. We therefore include match fixed effects (MFEs) and proxies for worker-firm tenure to account for cyclical match quality. One potential downside of this approach is that any difference in the cyclicality of the hiring and incumbent wages that is persistent over the duration of the match will be absorbed by the MFEs.

The first step regression is given by:

$$
\log \left(w_{i j r t}\right)=\theta_{i j}+\mathbb{I}\left\{\text { Incumbent }_{i t}\right\} \cdot \beta_{r t}^{I}+\mathbb{I}\left\{\text { New hire }{ }_{i t}\right\} \cdot \beta_{r t}^{N}+\mathbf{x}_{i t}^{\prime} \delta+\varepsilon_{i j r t}
$$

where $w_{i j r t}$ is the nominal wage of worker $i$, in firm $j$, which is in region $r$ and in year $t$. The firm-worker-match fixed effect is $\theta_{i j}$, and $\mathbf{x}_{i t}^{\prime}$ is a vector of time-varying worker characteristics. ${ }^{16}$ The indicator variable $\mathbb{I}\left\{\right.$ Incumbent $\left._{i t}\right\}$ equals one if worker $i$ is an incumbent in year $t$ and zero otherwise. Similarly, $\mathbb{I}\left\{\right.$ New hire $\left.{ }_{i t}\right\}$ equals one if the wage observation belongs to a new hire. The coefficient estimates of interest are $\hat{\beta}_{r t}^{I}$ and $\hat{\beta}_{r t}^{N}$, which give the composition-adjusted period means, within each region, of the incumbent and hiring wages, respectively.

In the second step, we regress changes in the estimated coefficients on cyclical indicators:

$$
\begin{aligned}
& \Delta \hat{\beta}_{r t}^{z}=c_{u}^{z}+\gamma_{u}^{z} u_{r t}+\eta_{r t}^{z}, \\
& \Delta \hat{\beta}_{r t}^{z}=c_{y}^{z}+\gamma_{y}^{z} \Delta y_{r t}+e_{r t}^{z},
\end{aligned}
$$

\footnotetext{
${ }^{16}$ This vector includes a worker's age and age squared in years, and worker-firm tenure squared.
} 
for $z=\{I, N\}$. The business cycle indicators in region $r$ and period $t$ are the unemployment rate $u_{r t}$, and the change in the logarithm of nominal gross value added (GVA), $\Delta y_{r t}$. The estimates of $\gamma_{u}^{z}$ measure the semi-elasticity of nominal wage growth with respect to the unemployment rate of incumbents $(z=I)$ and new hires $(z=N)$. Similarly, the estimates of $\gamma_{y}^{z}$ show the elasticity of incumbent wage growth with respect to nominal GVA growth. Wages may be correlated over time within region, and also across regions in a given period, therefore we cluster standard errors in the second step at both region and year levels. The time period of employee wages used is 2006-2017 and the regions are the eleven EU-NUTS1 administrative regions of Great Britain (e.g., London, Wales, Scotland, North West).

Table 8 displays the estimates of $\gamma_{u}^{z}$ and $\gamma_{y}^{z}$ from the second step, i.e., Equations (2) \& (3), for different measures of nominal wages used in the first step, i.e., Equation (1). The growth in earnings per hour, basic wages and the hourly pay rates of incumbent workers decreases by 0.33-0.36 percent when the unemployment rate increases by one percentage point. The wages of new hires generally show a stronger response: earnings per hour growth decreases by 0.49 percent, basic wage growth by 0.52 percent, and hourly pay rate growth by 0.46 percent when the unemployment rate increases by one percentage point. These differences appear to be economically not very significant. However, to assess whether the hiring wages are statistically more cyclical than for incumbents, we compute the

differences between the estimated year-region coefficients from the first step, $\left(\hat{\beta}_{r t}^{I}-\hat{\beta}_{r t}^{N}\right)$, and regress these on the cyclical indicators in the second step. The results are shown in the third column of Table 8 . The coefficients are precisely estimated and not significantly different from zero, suggesting that new hire wage growth and incumbent wage growth exhibit the same cyclicality with respect to the unemployment rate. Importantly, similar conclusions hold for all the considered nominal wage measures, and also when we use gross value added instead of the unemployment rate as the business cycle indicator (Table 8, rows 4-6). These findings support the notion that firms are constrained in their pay setting by internal pay structures.

\section{Heterogeneity}

One benefit of the ASHE being a payroll survey is that it it contains detailed job characteristics. In this section, we summarise the patterns of DNWR in Great Britain across different types of employees, jobs and firms (further results regarding heterogeneity are presented in greater detail in Appendix D).

\subsection{Firm Size}

Focusing on one of the starker sets of differences between jobs, Figure 9 displays the distribution of job-stayer log changes in earnings per hour separately in small firms with less than 50 employees, medium-sized firms who employ between 50 and 249 workers, and large firms with 250 employees 
TABLE 8: Estimated nominal wage responses of new hires and job stayers to regional unemployment and gross value added, Great Britain, 2006-2017

\begin{tabular}{lccc}
\hline $\begin{array}{l}\text { Dependent variable / } \\
\text { Cyclical indicator }\end{array}$ & $\begin{array}{c}\text { Incumbents } \\
\left(\begin{array}{c}1 \text { year in job) } \\
\text { (I) }\end{array}\right.\end{array}$ & $\begin{array}{c}\text { New hires } \\
(<1 \text { year in job) } \\
\text { (II) }\end{array}$ & $\begin{array}{c}\text { Difference } \\
\text { (Stayer-hire) } \\
\text { (III) }\end{array}$ \\
\hline $\begin{array}{l}\text { Unemployment rate: } \\
\text { 1. Earnings per hour }\end{array}$ & $-0.0036^{* *}$ & $-0.0049^{* * *}$ & 0.0013 \\
& $(0.0012)$ & $(0.0015)$ & $(0.0016)$ \\
2. Basic wages & $-0.0036^{* *}$ & $-0.0052^{* * *}$ & 0.0015 \\
& $(0.0012)$ & $(0.0015)$ & $(0.0016)$ \\
3. Hourly pay rate & $-0.0033^{* *}$ & $-0.0046^{* * *}$ & 0.0013 \\
& $(0.0010)$ & $(0.0012)$ & $(0.0009)$ \\
Nominal GVA: & & & \\
4. Earnings per hour & $0.275^{* * *}$ & 0.200 & 0.075 \\
& $(0.058)$ & $(0.121)$ & $(0.129)$ \\
5. Basic wages & $0.295^{* * *}$ & $0.241^{*}$ & 0.053 \\
& $(0.056)$ & $(0.103)$ & $(0.103)$ \\
6. Hourly pay rate & $0.200^{* * *}$ & $0.158^{*}$ & 0.041 \\
& $(0.043)$ & $(0.070)$ & $(0.058)$ \\
\hline
\end{tabular}

Notes.- see Table D3.

${ }^{* * *},{ }^{* *},{ }^{*}$ indicate significance at the $0.1 \%, 1 \%$, and $5 \%$ levels, respectively.

Two-sided tests and standard errors in parentheses robust to both year-level and NUTS1 region-level clustering.

Sample sizes: first-step estimates for earnings per hour and basic wages $1,816,289$, for hourly pay rate 738,451 . Second-step estimates based on 121 year-region observations.

Column 1 shows estimates of the cyclical response of wages from the second-step regressions for job stayer wages. Column 2 shows the equivalent estimates for new hire wages. Column 3 shows estimates from second-step regressions where the dependent variable is the difference between the incumbent and new hire coefficients from the first step, i.e., $\hat{\beta}_{r t}^{I}-\hat{\beta}_{r t}^{N}$.

Rows 1-3 show semi-elasticity estimates of nominal wages with respect to the unemployment rate.

Rows 4-6 show elasticity estimates of nominal wages with respect to gross value added.

Sources.- Wages are from the Annual survey of Hours and Earnings. NUTS1 unemployment rates are from the Office for National Statistics (ONS) for April of each year, corresponding to the reporting period of the ASHE. Regional GVA are also from the ONS and correspond to calendar years, i.e., April-to-April changes in wages are regressed on the annual change in GVA over the years prior to each April.

or more. ${ }^{17}$ The frequency of earnings per hour freezes for employees in small firms is over three times greater than in large firms, and double the frequency in medium-sized firms. This is mainly accounted for by moderate positive growth in earnings per hour being less common in small firms, rather than there being relatively fewer wage cuts in small firms. These results support the US based findings of Kurmann and McEntarfer (2019), who documented similar features for the distribution of changes in gross pay per hour according to firm size.

\subsection{Shrinking vs Expanding Firms}

Figure 10 shows the distribution of year-to-year log hourly earnings per hour changes, dependent on whether a firm's total number of employees was shrinking (light bars) or expanding (dark bars)

\footnotetext{
${ }^{17}$ These employee counts are provided in the ASHE dataset from the Inter-Departmental Business Register (IDBR), which is the official list of UK enterprises. We use the more common term 'firm' interchangeably with 'enterprise', which refers to a UK-specific administrative definition an employer which could contain several local units or plants.
} 
FIGURE 9: Distributions of year-to-year adjustments in log earnings per hour by firm size, 2006-18.

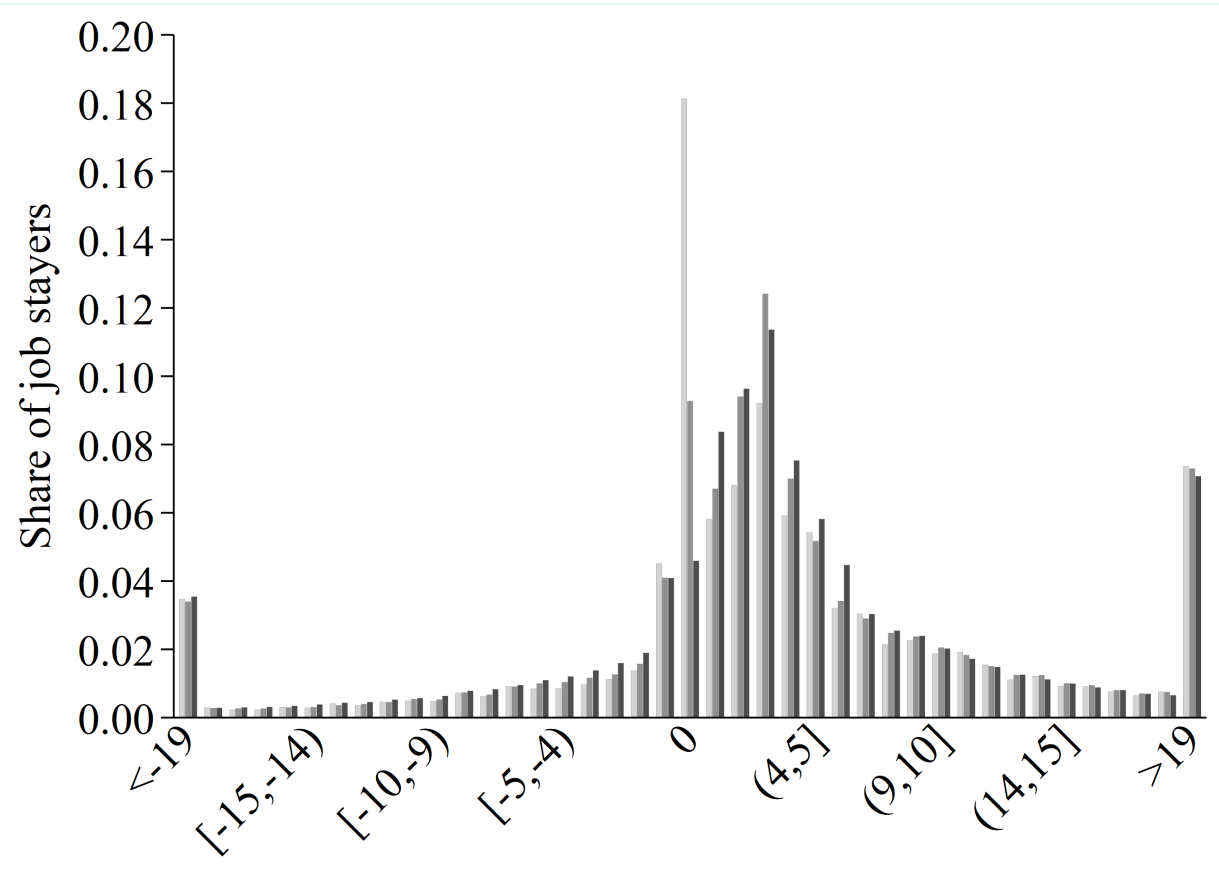

Notes.- See Figure 1. Pooled data for 2006-18. Dark grey bars: large firms ( $\geq 250$ employees). Medium grey bars: medium-sized firms (50 - 249 employees). Light grey bars: small firms ( $<50$ employees). The size of a job stayer's firm is defined in the first of two consecutive years.

between the same years. 18 Earnings per hour freezes are more common among job stayers in shrinking firms than in expanding firms. However, because the share of nominal cuts among job stayers is also larger in shrinking firms, the evidence is not clear regarding the strength of state-contingent downward rigidity in earnings per hour. Our data do not allow us to empirically assess how many workers in shrinking firms lost their jobs because of nominal rigidity in earnings per hour, since we cannot exclude that negative idiosyncratic shocks to firm-level productivity caused both more layoffs and more freezes when comparing shrinking and expanding firms. We also find that these results are not significantly different when we focus on firms with more substantial employment changes of at least $10 \%$ or 1000 employees (Appendix Figure F2).

The observation that shrinking firms seem to compress wage growth can be rationalised by a theoretical model of wage-setting with forward-looking firms that face DNWR, as Elsby (2009) has shown. In his model, firms correctly anticipate that the probability of wage rigidity being binding in the future is higher if they raise employee wages today, with the prediction that firms will find it optimal to compress wage growth. Another potential explanation of state-dependent nominal wage setting is that firms might face explicit costs from making adjustments. These costs may generate a region of inaction, such that wages are only adjusted once they are sufficiently far from their optimal level. This would suggest that wages are adjusted infrequently and by large amounts. This dovetails

\footnotetext{
${ }^{18}$ Job stayers in 2007-08 and 2017-18 are excluded from this analysis because it appears as though the ONS imputed the number of employees in firms using the previous years' values. We could find no information in the relevant documentation explaining why the ASHE dataset shows that almost all firms in these years registered no change in their number of employees.
} 
FIGURE 10: Distributions of year-to-year adjustments in log earnings per hour, 2006-18: shrinking vs expanding firms

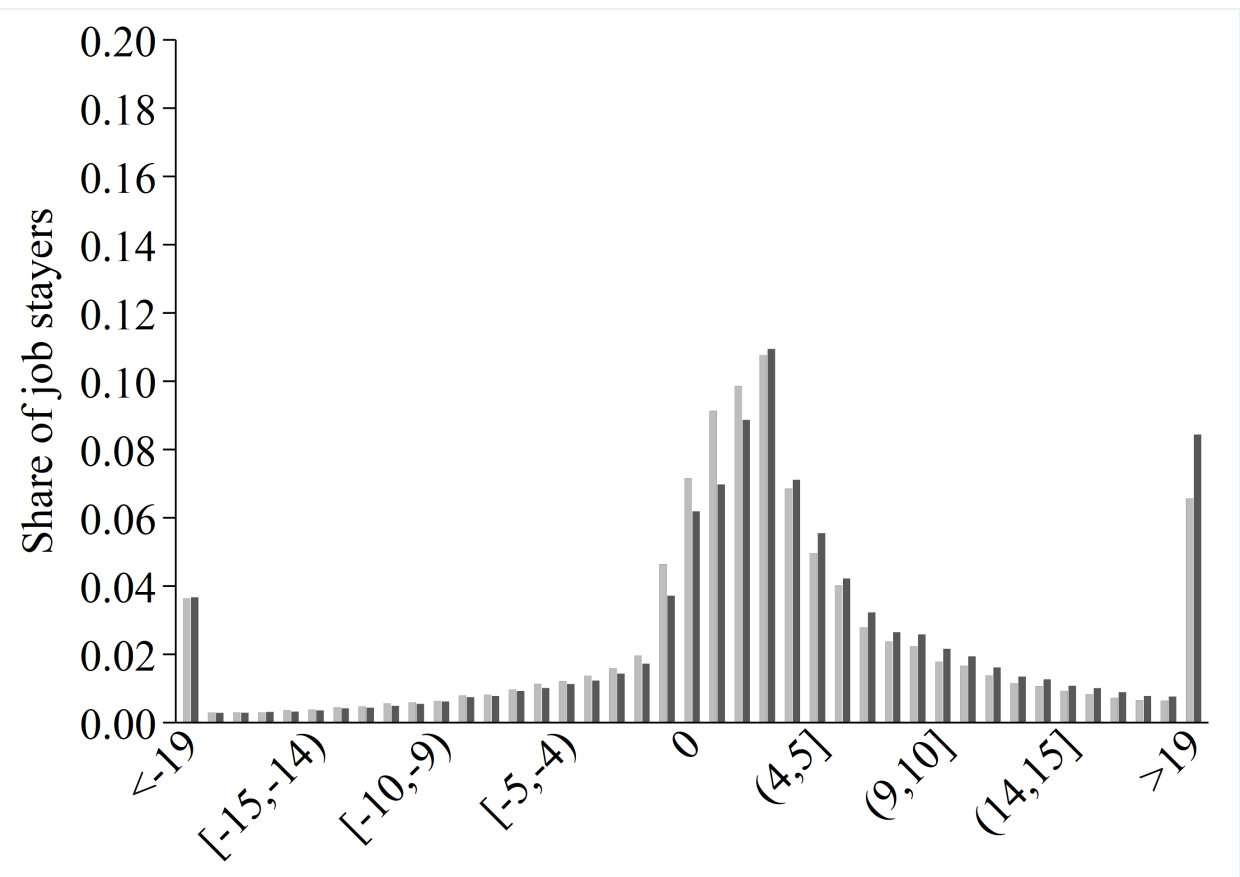

Notes.- See Figure 1. Pooled data for 2006-2018. Dark bars: 259,236 job stayers whose firms experienced positive year-to-year employment growth over the same period. Light bars: 277,001 job stayers whose firms experienced negative year-to-year employment growth over the same period.

with the evidence in Figure 7 that small annual increases in basic nominal wages are relatively rare among hourly-paid job stayers.

Figure 11 displays throughout the sample period how far the adjustments of gross pay per hour, earnings per hour, basic wages and hourly pay rates are associated with whether a firm's employment is shrinking or expanding from year-to-year. The results suggest that cuts in basic wages are more common among job stayers in shrinking than in expanding firms. Basic wage freezes were considerably more likely during and since the 2008-09 recession in shrinking firms, while the frequency of freezes for job stayers in growing firms appears not to have been notably affected by the recession. Our results therefore suggest that wage setting is to some extent state-dependent rather than exclusively time-dependent (i.e., Calvo (1983), adjustment or staggered contracts): firms with decreasing employment cut wages more frequently than firms with increasing employment, and the prevalence of freezes or cuts during the Great Recession was higher than in other years, especially among firms that were also shrinking their workforce. Unfortunately, with these data, we cannot say anything specific about the extent to which time-dependence plays a role in British wage setting. But Grigsby, Hurst and Yildirmaz (2019) use the monthly frequency of the US payroll data in their study to show that time-dependence does matter, and Calvo adjustment may be a reasonable approximation of the basic wage adjustment process in the economy during normal times. 
FIGURE 11: Shares of year-to-year freezes and cuts in the pay components of job stayers, 2006-18: shrinking vs expanding firms
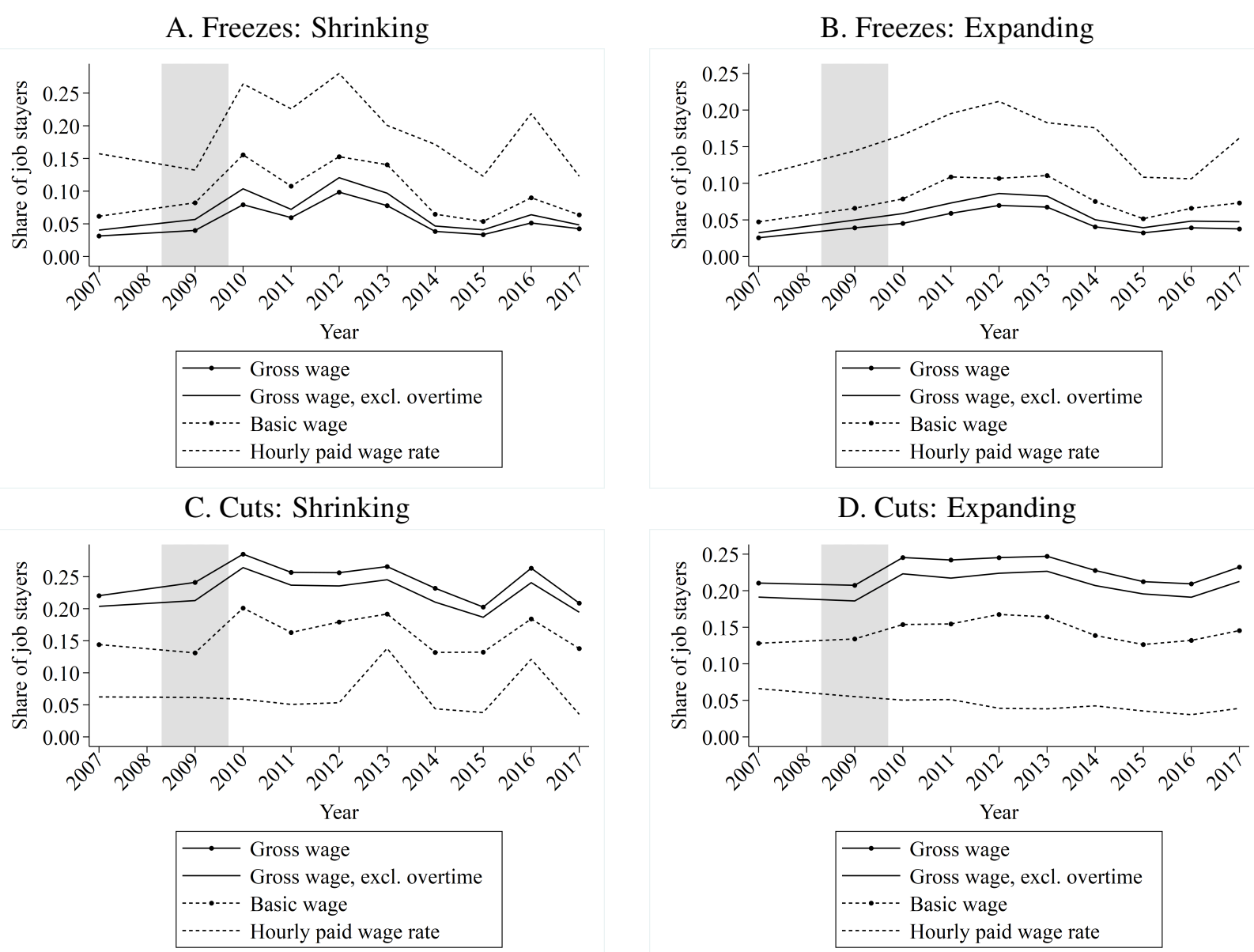

Notes.- 'Shrinking' indicates job stayers whose firm experienced a decreased number of employees over the same period. 'Expanding' indicates job stayers whose firm experienced an increased number of employees over the same period, from year-to-year. 'Hourly paid wage rate' concerns only hourly-paid job stayers, whereas the other series represent all sample job stayers. The grey shaded area represents official UK recession dates.

\subsection{Other Heterogeneity}

To isolate the effects of different job characteristics on the probabilities that an hourly pay cut or freeze is observed, we separately estimate probit models for the basic wages of salaried workers, the basic wages of hourly-paid workers, and hourly pay rates (see Appendix Tables D2 \& D3). In general, the different worker and job characteristics included in the regressions are associated with significantly different likelihoods of observing pay cuts and pay freezes, across both salaried and hourly-paid workers. Men experience more common wage cuts and freezes than women. Being in the private sector and a salaried worker is associated with more common wage cuts and freezes, but the opposite is the case for hourly-paid workers. Collective bargaining agreements tend to be observed alongside significantly fewer wage cuts and freezes. Older workers have more wage freezes and wage cuts than younger workers. Higher earnings are associated with a greater likelihood of a wage cut, but also less chance of a wage freeze for salaried workers. Wage cuts are less 
common for salaried workers in larger firms, but more common for hourly-paid workers in larger firms. Wage freezes are substantially less likely in larger firms, conditional on other worker and job characteristics. After controlling for other observable differences between job stayers, wage cuts and wage freezes are significantly more likely in shrinking than expanding firms. Finally, having an hourly pay rate ending in zero pence is associated with a significantly higher likelihood of having a year-to-year wage freeze.

\section{Conclusion}

The prevailing low inflation environment in many developed countries has pushed the topic of DNWR back to the centre stage of macroeconomics. We have used British payroll data to uncover new facts about wage adjustments, which can reconcile some seemingly contradictory findings in the previous literature. Based on results for job-stayer earnings per hour, i.e., the sum of basic wages and non-basic wage components, we conclude that labour costs are downward flexible. This confirms the findings in several other studies that analyse earnings based on administrative data or payroll-records, as recently summarised by Elsby and Solon (2019). At the same time, we conclude that the directly reported pay rates of hourly-paid employees show substantial evidence of downward rigidity. These rates are rarely cut and there is an abundance of wage freezes. This is consistent with what past studies have found when analysing household survey data, despite those results being doubted because of concerns about measurement error. We have also highlighted the additional wage flexibility that firms achieve through non-basic wage components, which can explain why earnings per hour show so little evidence of nominal rigidity among British job stayers. These non-basic wage components seem to be more essential for adjusting the earnings of hourly-paid workers.

The differences in flexibility between basic and non-basic wages, and especially hourly pay rates, require some reflection on what the appropriate wage measure in macroeconomic models actually is. Basic wages account for the entire income of more than half of all employees. This suggests that gaining a clear picture of this principal component of earnings is important to understand the connection between nominal wages and unemployment. This is reinforced by our finding that the hourly wages of new hires and existing employees are equally responsive to the business cycle, on average, regardless of whether we look at total earnings, basic wages or hourly pay rates. This result hints at the widescale presence of internal pay structures, such that job-stayer nominal wage rigidity can have allocative consequences for the macroeconomy. 


\section{References}

Akerlof, G. A., W. T. Dickens, and G. L. Perry. 1996. "The Macroeconomics of Low Inflation.” Brookings Papers on Economic Activity, 27(1): 1-59.

Altonji, J. G., and P. J. Devereux. 2000. "The extent and consequences of downward nominal wage rigidity." In Research in Labor Economics. Emerald Group Publishing Limited, 383-431.

Barattieri, A., S. Basu, and P. Gottschalk. 2014. "Some Evidence on the Importance of Sticky Wages." American Economic Journal: Macroeconomics, 6(1): 70-101.

Barro, R. J. 1977. "Long-term contracting, sticky prices, and monetary policy." Journal of Monetary Economics, 3(3): 305-316.

Basu, S., and C. House. 2016. "Chapter 6 - Allocative and Remitted Wages: New Facts and Challenges for Keynesian Models." Vol. 2 of Handbook of Macroeconomics Elsevier, 297-354.

Becker, G. S. 1962. "Investment in Human Capital: A Theoretical Analysis." Journal of Political Economy, 70(5): 9-49.

Bell, D. N. F., and R. A. Hart. 2003. "Wages, Hours, and Overtime Premia: Evidence from the British Labor Market." Industrial and Labor Relations Review, 56(3): 470-480.

Bewley, T. F. 1999. Why wages don't fall during a recession. Cambridge, MA: Harvard University Press.

Bils, M. J. 1985. "Real Wages over the Business Cycle: Evidence from Panel Data." Journal of Political Economy, 93(4): 666-689.

Calvo, G. 1983. "Staggered prices in a utility-maximizing framework." Journal of Monetary Economics, 12(3): 383-398.

Campbell III, C. M., and K. S. Kamlani. 1997. "The Reasons for Wage Rigidity: Evidence From a Survey of Firms.” The Quarterly Journal of Economics, 112(3): 759-789.

Card, D., and D. Hyslop. 1996. "Does Inflation “Grease the Wheels of the Labor Market”?" NBER Working Paper Series 5538, National Bureau of Economic Research, Inc.

Devereux, P. J. 2001. "The Cyclicality or Real Wages within Employer-Employee Matches." Industrial and Labor Relations Review, 54(4): 835-850.

Devereux, P. J., and R. A. Hart. 2006. "Real Wage Cyclicality of Job Stayers, Within-Company Job Movers, and Between-Company Job Movers." Industrial and Labor Relations Review, 60(1): 105-119.

Dickson, A., and M. Fongoni. 2019. "Asymmetric reference-dependent reciprocity, downward wage rigidity, and the employment contract." Journal of Economic Behavior \& Organization, 163(1): 409-429.

Elsby, M. W. L. 2009. "Evaluating the economic significance of downward nominal wage rigidity." Journal of Monetary Economics, 56(2): 154-169.

Elsby, M. W. L., D. Shin, and G. Solon. 2016. "Wage Adjustment in the Great Recession and Other Downturns: Evidence from the United States and Great Britain." Journal of Labor Economics, 34(S1): S249-S291.

Elsby, M. W. L., and G. Solon. 2019. "How Prevalent Is Downward Rigidity in Nominal Wages? International Evidence from Payroll Records and Pay Slips." Journal of Economic Perspectives, 33(3): 185-201.

Fehr, E., and L. Goette. 2005. "Robustness and real consequences of nominal wage rigidity." Journal of Monetary Economics, 52(4): 779-804. 
Fongoni, M. 2020. “Asymmetric Reciprocity and the Cyclical Behaviour of Wages, Effort and Job Creation.” mimeo.

Grigsby, J., E. Hurst, and A. Yildirmaz. 2019. "Aggregate Nominal Wage Adjustments: New Evidence from Administrative Payroll Data." NBER Working Paper Series 25628, National Bureau of Economic Research, Inc.

Hagedorn, M., and I. Manovskii. 2013. "Job Selection and Wages over the Business Cycle." American Economic Review, 103(2): 771-803.

Jardim, E. S., G. Solon, and J. L. Vigdor. 2019. "How prevalent is downward rigidity in nominal wages? Evidence from payroll records in Washington State.” NBER Working Paper Series 25470, National Bureau of Economic Research, Inc.

Kahn, S. 1997. "Evidence of Nominal Wage Stickiness from Microdata." American Economic Review, 87(5): 993-1008.

Kaplan, G., and G. L. Violante. 2014. "A Model of the Consumption Response to Fiscal Stimulus Payments." Econometrica, 82(4): 1199-1239.

Kaufman, R. T. 1984. “On Wage Stickiness in Britain's Competitive Sector.” British Journal of Industrial Relations, 22(1): 101-112.

Kaur, S. 2019. "Nominal Wage Rigidity in Village Labor Markets." American Economic Review, 109(10): 3585-3616.

Keynes, J. M. 1936. The General Theory of Employment, Interest and Money. London: Macmillan.

Krusell, P., and A. A. Smith Jr.. 2006. "Quantitative Macroeconomic Models with Heterogeneous Agents." In Advances in Economics and Econometrics: Theory and Applications, Ninth World Congress. Eds. by R. Blundell, W. K. Newey, and T. Persson, No. 1 of Econometric Society Monographs, Cambridge University Press, 298-340.

Kurmann, A., and E. McEntarfer. 2019. "Downward Nominal Wage Rigidity in the United States: New Evidence from Worker-Firm Linked Data.” Working Papers 19-07, Center for Economic Studies, U.S. Census Bureau.

Lebow, D. E., R. E. Saks, and B. A. Wilson. 2003. "Downward Nominal Wage Rigidity: Evidence from the Employment Cost Index." Advances in Macroeconomics, 3(1): 1-28.

Mayshar, J., and G. Solon. 1993. "Shift Work and the Business Cycle." American Economic Review: Papers \& Proceedings, 83(2): 224-228.

McLaughlin, K. 1994. "Rigid wages?" Journal of Monetary Economics, 34(3): 383-414.

Nickell, S., and G. Quintini. 2003. "Nominal Wage Rigidity and the Rate of Inflation.” The Economic Journal, 113(490): 762-781.

Office for National Statistics. 2005. "The new Annual Survey of Hours and Earnings questionnaire."

Office for National Statistics. 2019. "Annual Survey of Hours and Earnings, 1997-2018: Secure Access. [data collection]." 14th Edition. UK Data Service. SN: 6689, http://doi.org/10.5255/UKDA-SN-6689-13.

Park, S., and D. Shin. 2017. "The extent and nature of downward nominal wage flexibility: An analysis of longitudinal worker/establishment data from Korea." Labour Economics, 48(3): 67-86.

Pissarides, C. A. 2009. "The Unemployment Volatility Puzzle: Is Wage Stickiness the Answer?." Econometrica, 77(5): 1339-1369. 
Schaefer, D., and C. Singleton. 2019. "Cyclical Labor Costs Within Jobs.” European Economic Review, 120: 103317.

Schaefer, D., and C. Singleton. 2020. "Recent changes in British wage inequality: Evidence from large firms and occupations." Scottish Journal of Political Economy, 67(1): 100-125.

Schmitt-Grohé, S., and M. Uribe. 2016. "Downward Nominal Wage Rigidity, Currency Pegs, and Involuntary Unemployment." Journal of Political Economy, 124(5): 1466-1514.

Schoefer, B. 2016. "The Financial Channel of Wage Rigidity." 2016 Meeting Papers 1605, Society for Economic Dynamics.

Shimer, R. 2004. "The Consequences of Rigid Wages in Search Models." Journal of the European Economic Association, 2(2-3): 469-479.

Shin, D., and G. Solon. 2007. "New Evidence on Real Wage Cyclicality within Employer-Employee Matches." Scottish Journal of Political Economy, 54(5): 648-660.

Smith, J. C. 2000. "Nominal Wage Rigidity in the United Kingdom." The Economic Journal, 110(462): $176-195$.

Snell, A., H. Stüber, and J. P. Thomas. 2018. "Downward real wage rigidity and equal treatment wage contracts: Theory and evidence." Review of Economic Dynamics, 30(3): 265-284.

Snell, A., and J. P. Thomas. 2010. "Labor Contracts, Equal Treatment, and Wage-Unemployment Dynamics." American Economic Journal: Macroeconomics, 2(3): 98-127.

Solon, G., R. Barsky, and J. A. Parker. 1994. "Measuring the Cyclicality of Real Wages: How Important is Composition Bias?" The Quarterly Journal of Economics, 109(1): 1-25.

Solon, G., W. Whatley, and A. H. Stevens. 1997. "Wage Changes and Intrafirm Job Mobility over the Business Cycle: Two Case Studies." Industrial and Labor Relations Review, 50(3): 402-415.

Tobin, J. 1972. "Inflation and Unemployment." American Economic Review, 61(1): 1-18. 


\section{Appendix A. Further Description of the Data}

In what follows, we provide further details on the datasets used. All the relevant documentation and variable descriptions are publicly available from the UK Data Service. The ONS has also published various documents concerning the quality and consistency of the ASHE.

For each year in the period 2004-2018, the ASHE should in principle be a random sample of all UK employees, irrespective of occupation, size of employer, etc. Given the legal obligation of employers to respond using their payrolls, it has a high response rate, over employees, and is generally considered to be very accurate. Conditional on a hundred percent response and success in locating employees and employers, the ASHE is a true one percent random sample of UK employees in each year: all those with an administrative life-long National Insurance number which has a numerical part ending in two specific digits are included in the sampling frame every year, making it a worker-level panel dataset. However, there are two major sources of systematic under-sampling, both occurring if individuals do not have a current tax record when they are looked up each year. This could happen for some individuals who have recently moved jobs, or for those who earn little (mostly part-time) and are not paying income tax or National Insurance in the period when their employers are looked up. From 2004, the ASHE, after it replaced its predecessor the New Earnings Survey, aimed to sample some of those employees which were likely under-represented before. It added supplementary responses for those without a PAYE reference, and also attempted to represent employees whose jobs changed between the determination of the sampling frame in January and the reference period in April. There is no cumulative attrition from the panel, as any individual not included in the ASHE in any year, for whatever reason, remains in the sampling frame the following year. One exception to this occurs where individuals have been assigned temporary National Insurance numbers, typically in the case of non-UK nationals. Following ONS recommendations, to address this we drop all person observations where there are inconsistencies in age or sex within the National Insurance number-based ASHE longitudinal person identifier variable, piden.

The ASHE data contain information on the legal status of a firm, obtained from the administrative Inter-Departmental Business Register (IDBR). We classify private companies, sole proprietors, and partnerships as belonging to the private sector, while public corporations, nationalised industries, central government, local authorities, and non-profit organisations form the non-private sector in our analysis. The measure of firm size is also taken from the IDBR and refers to the total number of employees in the enterprise. An employee is working full-time hours when she works at least thirty hours. Some businesses have an arrangement with the ONS to provide their data electronically, which seems to be the case in particular for very large enterprises. Employees of such enterprises tend to have lower average earnings. Whenever it is reported that an employee's pay is set with reference to an agreement affecting more than one worker, e.g., pay agreed by a trade union or a workers' committee, we classify this employee's pay as affected by a collective agreement.

From 2005, a new questionnaire was introduced to the ASHE, which was intended to reduce the latitude for respondents' own interpretations of what was being asked of them. Prior to 2005, job stayers were identified by asking whether the job title and the description were the same as in the last reference period. From 2005 onward, the question became more specific, asking whether the employee had worked in the same job for more than a year. This relates to the ASHE identifier variable for job stayers, $s j d$, which we use to define job stayers for the analysis. Importantly, apparent inconsistencies can arise in the dataset when identifying who is and who isn't a job stayer: a worker can be marked as being in the same job, but the enterprise reference number can change. This is probably because of a change in a firm's ownership structure (e.g., a merger or a succession), which would result in a new administrative enterprise reference number being assigned, while the ASHE questionnaire explicitly tells the respondent to ignore such changes when answering whether an employee is working in the same job. We are also careful that each job stayer in our analysis actually features consecutive year-to-year job and wage records. This was accidentally not done in Elsby et al. (2016). According to that paper's published replication file, the researchers used sjd to select job stayers and then studied the difference between current wages and the last record of an individual, without conditioning that there was just one year between these records. This error in Elsby et al. (2016) marginally 
raises the measured frequency of nominal wage cuts and biases down the frequency of exactly zero changes throughout the Great Britain part of the study, typically within the range of one percentage point.

The key earnings variables that we analyse are the answers to the following questions in the ASHE questionnaire, whereby monetary values are measured in Pound sterling (GBP), including pence, and time variables in hours and minutes:

BPAY: "How much basic pay, before deductions, did the employee receive in the pay period?

Include: all basic pay, relating to the pay period, before deductions for PAYE, National Insurance, pension schemes, student loan repayments and voluntary deductions.

Include paid leave (holiday pay), maternity/paternity pay, sick pay and area allowances (e.g., London). Exclude: pay for a different pay period, shift premium pay, bonus or incentive pay, overtime pay, expenses and the value of salary sacrifice schemes and benefits in kind."

BHR: "How many basic hours does the [BPAY] relate to?

If your pay period is calendar month and hours are weekly, multiply the weekly hours by 4.348 to get calendar month hours. If the employee uses a decimal clock, please convert to hours and minutes. For example, 4.3 hours should be 4 hours and ( 0.3 multiplied by 60 ) minutes $=4$ hours 18 minutes.

Include: any hours paid at shift premium and paid hours even if not worked.

Exclude: any hours paid as overtime."

OVPAY: "How much overtime pay did the employee receive for work carried out in the pay period?

Exclude: any basic, shift premium and bonus or incentive pay in this period, as well as overtime pay from the previous pay period."

BHR: "How many overtime hours does [OVPAY] relate to?

If the employee uses a decimal clock, please convert to hours and minutes. For example, 4.3 hours should be 4 hours and ( 0.3 multiplied by 60$)$ minutes $=4$ hours 18 minutes Include: any hours paid at shift premium and paid.

Include: the actual number of hours. For example, for 4 hours paid at time and a half, enter 4 not 6 . Include any paid meal breaks taken during a period of overtime.

Exclude: any hours paid at the basic or shift premium rate."

SPPAY: "How much shift premium pay did the employee receive in the pay period?

Include: the element of shift premium pay. For example, for a 35 hour pay period, if the basic rate is $£ 10$ per hour and the premium rate is $£ 12$ per hour, multiply the difference of $£ 2$ by the hours worked (i.e. 35 multiplied by 2 ). The shift premium pay reported would therefore be $£ 70$.

Exclude: any basic, overtime and bonus or incentive pay."

IPAYALL: "How much bonus or incentive payments did the employee receive in the pay period?

Include: profit sharing, productivity, performance and other bonus or incentive pay, piecework and commission.

Exclude: basic, overtime and shift premium pay."

IPAYIN: "How much of [IPAYALL] related to work carried out in the pay period?

For example, if the bonus reported in [IPAYALL] was for a full year, the value should be divided by 12 if the employee was paid on a calendar month basis"

OTHPAY: "How much pay did the employee receive for other reasons in the pay period?

Include: for example, car allowances paid through the payroll, on call and standby allowances, clothing, first aider or fire fighter allowances.

Exclude: paid leave (holiday pay), basic, overtime, shift premium, maternity/paternity, sick, bonus or incentive pay, redundancy, arrears of pay, tax credits, profit share and expenses."

HPAY: "[W]as the employee's basic pay in the pay period calculated by multiplying the number of hours they worked by an hourly rate of pay? [If yes,] what was the employee's hourly rate of pay in the pay period?" 
AGP: "How much annual gross pay did the employee receive in their current job?

Include: pay before deductions for PAYE, National Insurance, pension schemes and voluntary deductions. Include basic, overtime, shift premium, profit sharing, productivity performance and bonus or incentive pay.

Exclude: any payments for expenses or previous employment."

ANIPAY: "How much of [AGP] is related to bonus or incentive payments for their current job?

Include: profit sharing, productivity performance and other bonus or incentive pay, piecework and commission.

Exclude: basic, overtime and shift premium pay."

One take-away from these questions is that BPAY excludes shift premium pay, while BHR includes shift premium hours. Therefore, if the shift pattern of a worker changes year-to-year, BHR might change while BPAY remains unchanged, all else equal. Moreover, firms are required to convert weekly hours into calendar month total hours if the employee is paid by calendar month, which is the case for $75 \%$ of our job-stayer sample. This is a potential source of errors. For example, if an employee works 40 basic hours per week, then the hours worked in the calendar month are 173 hours, 55 minutes, 12 seconds $(40 \times 4.348=173.92)$. It is in the discretion of the person who is answering the questionnaire whether she rounds up this number to 173 hours and 56 minutes, or rounds it down to 173 hours and 55 minutes. Another potential source of error is the conversion from decimal to minutes: the employer might incorrectly supply decimal numbers instead of hours and minutes. For example, a 38 hours week results in a monthly value of $165.224(38 \times 4.348=165.224)$, so 165 hours and 13 minutes (omitting seconds). It is conceivable that some employers might incorrectly report 165 hours and 22 minutes.

To avoid any ambiguity, we also drop any worker observations for years with multiple job holdings, because in these cases it is not clear to which job the same job marker refers to in the following year, and so we may introduce errors in how we designate job stayers. Although the ASHE dataset is available from 2004 onward, we use only data starting from 2006 because some questionnaire changes in 2005 and 2006 introduced inconsistencies between these earlier years. Specifically, the wording of the question about incentive payments was changed and new instructions were included on how firms should report employees hours worked. Before applying any further sample selection, the 2006-2018 ASHE panel dataset we have by this point created contains 2,096,927 worker-year observations. From this, we keep only observations where an employee is aged 16-64, and which have not been marked as having incurred a loss of pay in a reference period through absence, employment starting in the period, or short-time working, and which are marked as being on an adult rate of pay (i.e. dropping trainees and apprenticeships). This is practically the same filter applied by the ONS in their published results on UK "Patterns of Pay" using the ASHE. We drop observations with missing basic hours or earnings variables. We drop observations with over a hundred or less than one basic hour worked, as these could reflect measurement error and the inclusion of overtime. Applying these steps leaves 1,924,873 worker-year observations. To further address some potential for measurement error, we drop a further 3,571 observations whose derived hourly rates of pay, excluding overtime, are less than 80 percent of the applicable National Minimum Wage (NMW) each April, with allowance for the different age-dependent rates of the NMW over time. We set the threshold lower to avoid dropping observations where employers have rounded figures about the NMW, where the degree of rounding could vary with the actual value of the NMW, a behavior which has been hypothesized by the ONS. Note, any such rounding for pay measures, conditional on accurate hours records, would tend to bias upwards the incidence of nominal wage rigidity. The ASHE has introduced some earnings imputations, using similar matched 'donor' observations where responses were, for example, missing an entry of basic hours but had recorded pay. Hourly pay rates were never imputed. We exclude from our main results the approximate one percent of the remaining observations where imputations were made to any component of earnings, in the period they can be identified of 2013-2018. By focusing on this period, we were able to confirm that not dropping these observations did not meaningfully alter any of our results. Finally, before focusing on the job stayers, we trim the dataset by sequentially dropping the top and bottom $1 \%$ of hourly-paid wage rate and salaried worker-year observations. We trim twice as there are a tiny number of observations where there are clear coding errors for the reported hourly wage rate, such as $£ 9.34$ per hour in one year but $£ 934$ in the next year for a job stayer. 


\section{Appendix B. Measurement error}

If an employee's pay period is a calendar month, but working hours are weekly, then the ASHE asks employers to multiply weekly hours by 4.348 and to report the result as hours per calendar month. In our sample, almost $75 \%$ of job stayers are paid per calendar month. Because the questionnaire only allows employers to report hours and minutes worked, respondents have to round decimal values that result from the conversion of weekly hours. Unfortunately, no guidelines are provided on how employers are supposed to round in such cases. The ONS then computes weekly average hours worked by dividing the reported, and possibly rounded, calendar month hours by 4.348. This arbitrary rounding of calendar month hours means that the derived basic weekly hours worked provided in the ASHE dataset are potentially incorrect, and only reliable within a range of one minute. For example, if an employee works 40 basic hours per week, then the calendar month decimal value is 173.92 , which equals 173 hours, 55 minutes, 12 seconds. Therefore, 40 hours per week might be reported by the employer as either 173 hours and 55 minutes, or 173 hours and 56 minutes. The ONS converts these reported values back to average weekly hours, dividing monthly hours by 4.348 . This can potentially explain the relatively high frequency of weekly hours worked in the ASHE dataset with values of 39.999 and 40.003 .

To gain a better understanding of the significance of this novel source of measurement error, we compute the share of job stayers with non-zero changes in working hours of less than one minute from year-to-year. This is the case for around $18 \%$ of job stayers who are paid per calendar month in consecutive years, i.e., $13.5 \%$ $(18 \% \times 75 \%)$ of all job stayers in our sample. To check whether these small hours changes are more likely to be erroneous or actual changes, we turn to the affected job stayers' gross weekly pay, excluding overtime. These data are reported directly without requiring a conversion for the pay period, and so we expect them to be relatively more accurate. Among the job stayers that have marginal hours changes, only 57 employees show adjustments in weekly gross pay, excluding overtime, that match the change in basic hours worked, while the fraction with pay freezes is nearly $5 \%$ or 10,000 observations. This suggests that observed changes in weekly hours of less than one minute are indeed more likely to be measurement error than actual changes.

We perform another check by looking at changes in average gross weekly pay, excluding overtime, which is unaffected by any measurement error in basic hours worked. The results are displayed in Table B1 columns (I) \& (II), showing greater evidence for the presence of DNWR. While the frequency of cuts in weekly earnings is similar to that found in earnings per hour, the percentage of year-to-year freezes is substantially higher: between 1.9 (2007-08) and 5.2 (2011-12) percentage points more job stayers experience weekly earnings freezes from year-to-year than hourly earnings freezes. This is a larger impact of using weekly as compared to hourly earnings than Elsby et al. (2016) documented (see their footnote 17). We also find that the mass of nominal changes within one log point of zero for weekly and hourly earnings is approximately the same. In other words, either working hours are measured with small errors in the ASHE, or hours are quite flexible in Great Britain, allowing firms to make tiny adjustments which exactly offset simultaneous changes in hourly earnings, thus keeping weekly earnings exactly constant. 
TABLE B1: Nominal changes in job stayer weekly earnings and basic weekly pay, 2006-18

\begin{tabular}{|c|c|c|c|c|}
\hline \multirow[b]{2}{*}{ Years } & \multicolumn{2}{|c|}{ Weekly earnings, excl. overtime } & \multicolumn{2}{|c|}{ Basic weekly pay } \\
\hline & $\begin{array}{c}\text { Freezes }(\%) \\
\text { (I) }\end{array}$ & $\begin{array}{c}\text { Cuts (\%) } \\
\text { (II) }\end{array}$ & $\begin{array}{c}\text { Freezes }(\%) \\
\text { (III) }\end{array}$ & $\begin{array}{c}\text { Cuts }(\%) \\
\text { (IV) }\end{array}$ \\
\hline 2006-07 & 6.7 & 18.6 & 9.3 & 13.2 \\
\hline 2007-08 & 5.0 & 17.4 & 6.9 & 12.5 \\
\hline 2008-09 & 9.6 & 20.4 & 12.9 & 14.5 \\
\hline $2009-10$ & 13.7 & 22.3 & 18.4 & 16.2 \\
\hline $2010-11$ & 12.7 & 22.3 & 17.4 & 16.0 \\
\hline $2011-12$ & 16.4 & 21.3 & 21.2 & 15.5 \\
\hline $2012-13$ & 15.7 & 21.1 & 20.0 & 15.8 \\
\hline 2013-14 & 9.6 & 20.1 & 13.0 & 13.7 \\
\hline $2014-15$ & 8.3 & 19.2 & 10.4 & 14.0 \\
\hline $2015-16$ & 10.7 & 20.7 & 13.9 & 15.4 \\
\hline 2016-17 & 9.3 & 20.2 & 12.5 & 15.0 \\
\hline $2017-18$ & 9.7 & 19.1 & 12.2 & 14.7 \\
\hline
\end{tabular}

Notes.- Freezes and Cuts show the percentage of job stayers with no change and negative change in the pay measure indicated. 


\section{Appendix C. More on the Influence of Pay Composition}

Table $\mathrm{C} 1$ displays selected percentiles of the share in gross pay of its 5 components. Column (I) shows that basic pay is the most important source of earnings: the median share of basic pay in job-stayer gross pay is $100 \%$, and even at the 10 th percentile it still accounts for $77 \%$ of gross pay. We computed the same pay component percentiles for all workers in the ASHE, including job changers, but the results do not notably differ. Column (II) shows the shares of overtime pay in gross pay, within the subsample job stayers who actually worked overtime. This subsample includes nearly $20 \%$ of all job stayers. While overtime pay makes up a mere $2.2 \%$ of employee gross pay at the 10th percentile, for some job stayers it is a large part of their total earnings: for the top $10 \%$ of overtime recipients, it accounts for almost a third of their gross pay. Employees working overtime have lower mean and median earnings per hour than other job stayers, which suggests that overtime pay substitutes somewhat for basic pay (Appendix Table E2). Column (III) shows that the share of incentive pay in gross pay ranges from $1.1 \%$ at the lowest decile to $28.1 \%$ at the 90 th percentile, conditional on receiving incentive pay. Although incentive pay is only received by $7 \%$ of job stayers in our sample, these shares show that incentive pay contributes significantly to some workers' gross pay. The relative importance of shift premiums for those who receive them, column (IV), is similar to incentive pay. One noticeable difference between incentive and shift workers is that the latter are more likely to work in the non-private sector of the economy (Table E2). A relatively large fraction of job stayers, 19\%, receive other pay, such as car and clothing allowances. However, the values shown in column (V) suggest that other pay is relatively less important for the earnings of the median job stayer in this subsample than for the other components. This group of workers also has higher earnings per hour and a larger share of full-time contracts than among other job stayers (Table E2).

TABLE C1: Contribution of pay components to job-stayer gross weekly pay (\%), 2006-18

\begin{tabular}{lccccc}
\hline & $\begin{array}{c}\text { Basic } \\
\text { (I) }\end{array}$ & $\begin{array}{c}\text { Overtime } \\
\text { (II) }\end{array}$ & $\begin{array}{c}\text { Incentive } \\
(\text { III })\end{array}$ & $\begin{array}{c}\text { Shift } \\
(\text { IV })\end{array}$ & $\begin{array}{c}\text { Other } \\
(\mathrm{V})\end{array}$ \\
\hline 10th percentile & 77.0 & 2.2 & 1.1 & 1.7 & 0.7 \\
25th percentile & 91.1 & 5.3 & 2.9 & 4.5 & 2.0 \\
50th percentile & 100.0 & 11.6 & 7.0 & 10.2 & 5.6 \\
75th percentile & 100.0 & 21.4 & 14.7 & 16.7 & 10.9 \\
90th percentile & 100.0 & 32.6 & 28.1 & 23.1 & 18.2 \\
$N$ & $1,097,235$ & 216,243 & 71,962 & 115,132 & 208,591 \\
\hline
\end{tabular}

Notes.- Percentages of pay components in gross pay. Percentiles are computed within subsamples of job stayers who receive a positive amount of each respective pay component. 


\section{Appendix D. Heterogeneity Tables \& Figures}

Table D1 and Figures D1-D6 summarise the patterns of adjustments for different pay measures and different sub-samples of British job stayers in 2006-18. See Appendix A for descriptions of the ASHE variables used to determine these sub-samples of workers. We show these results for three different measures of hourly wages: basic wages for salaried workers, basic wages for hourly-paid workers, and directly reported hourly pay rates for employees paid by the hour. Table D1 rows 1-2 and Figure D1 compare male and female job stayers. Rows 3-4 and Figure D2 compare results for job stayers in firms which are administratively recorded as being in either the private or the non-private sector. Rows 5-6 and Figure D3 look at job stayers who are either affected by some form of collective pay agreement or not. Rows 7-9 and Figure D4 look at job stayers in three different age groups. Rows 10-12 and Figure D5 consider job stayers with low earnings (basic weekly pay less than $2 / 3$ of the median among all ASHE employees in the respective year), medium earnings (greater than or equal to $2 / 3$ and less than or equal to to $4 / 3$ of median basic weekly pay) and high earnings (greater than 4/3 of basic weekly pay). Rows 13-15 and Figure D6 looks at small (1-49 employees), medium (50-249) and large firms (250+). Rows 16-17 compare workers in the 'Wholesale \& Retail Trade, Hotels \& Restaurants sectors', where hourly-paid jobs are more likely to be (see Table E3), with those who aren't. Figure D7 shows the distribution of nominal hourly pay adjustments for job stayers not in those particular mentioned sectors. Finally, rows 18-19 show results for job stayers depending on whether their reported hourly pay rates ended in zero pence in the previous year.

In general, the overall patterns of nominal hourly wage adjustments described in the main text are common among the different groups of job stayers. There is less evidence for DNWR in basic hourly pay than in hourly pay rates across all groups. Exactly zero changes (cuts) in reported hourly wages are generally more (less) common for men than women, for jobs in the private sector than in the non-private sector, for employees without a collective pay agreement than with one, for older than younger workers, in smaller firms, and outside of the Wholesale \& Retail Trade, Hotels \& Restaurants sectors. Wage freezes appear to be more common for job stayers with medium earnings than low or high earnings.

To isolate the effects of various worker, job, and firm characteristics on the probability that an hourly pay cut or freeze is observed, we estimate separate probit models for, basic wages for salaried workers, basic wages for hourly-paid workers, and hourly pay rates. The following process describes whether a pay cut or freeze between periods $t-1$ and $t$ is observed:

$$
y_{i t}=\left\{\begin{array}{lll}
1 & \text { if } & y_{i t}^{*}>0 \\
0 & \text { if } & y_{i t}^{*} \leq 0
\end{array}\right.
$$

whereby the latent variable $y_{i t}^{*}$ for job stayer $i$ is

$$
y_{i t}^{*}=\mathbf{X}_{i t} \beta+\varepsilon_{i t}, \quad \varepsilon_{i t} \sim N(0,1)
$$

The vector of covariates, $\mathbf{X}_{i t}$, includes dummy variables indicating the employee's gender, whether the firm is in the private or public sector, whether the wage is set according to any form of collective agreement, and whether the job is in the 'Wholesale \& Retail Trade, Hotels \& Restaurants sectors' industry. We also include dummies for firm size and age bands, as well as the for the employee's position in the basic weekly pay distribution, all referring to period $t-1$. We also include indicator variables of firm size growth in terms of employees over the same period (shrinking/expanding/constant), which proxy for the state of the firm. For the hourly pay rate workers we additionally include a dummy variable that takes the value one if the reported hourly pay rate is a multiple of ten pence.

As well as being described briefly in the main text, the results of estimating the probit models are displayed in Tables D2 and D3, with both slope coefficients and margins (probabilities) displayed, and with the latter evaluated at the sample averages using the delta method. 
TABLE D1: Nominal adjustments in hourly wages, 2006-18: heterogeneity

\begin{tabular}{|c|c|c|c|c|c|c|}
\hline \multirow[b]{2}{*}{ Years } & \multicolumn{2}{|c|}{ Basic wage, salaried } & \multicolumn{2}{|c|}{ Basic wage, hourly-paid } & \multicolumn{2}{|c|}{ Hourly pay rate } \\
\hline & $\begin{array}{c}\text { Freezes (\%) } \\
\text { (I) }\end{array}$ & $\begin{array}{c}\text { Cuts (\%) } \\
\text { (II) }\end{array}$ & $\begin{array}{c}\text { Freezes }(\%) \\
\text { (III) }\end{array}$ & $\begin{array}{c}\text { Cuts (\%) } \\
\text { (IV) }\end{array}$ & $\begin{array}{c}\text { Freezes }(\%) \\
(\mathrm{V})\end{array}$ & $\begin{array}{c}\text { Cuts (\%) } \\
\text { (VI) }\end{array}$ \\
\hline 1. Male & 10.1 & 15.6 & 14.4 & 12.9 & 21.7 & 5.5 \\
\hline 2. Female & 7.7 & 16.4 & 8.8 & 13.3 & 16.9 & 4.5 \\
\hline 3. Private sector & 10.4 & 16.4 & 12.8 & 12.6 & 20.1 & 4.5 \\
\hline 4. Non-private sector & 7.1 & 15.6 & 7.2 & 14.7 & 26.1 & 6.5 \\
\hline 5. No coll. agreement & 10.7 & 26.8 & 15.0 & 12.6 & 23.2 & 4.5 \\
\hline 6. Coll. agreement & 7.3 & 15.3 & 7.7 & 13.6 & 15.0 & 5.4 \\
\hline 7. Age $15-29$ & 5.7 & 13.1 & 8.3 & 12.0 & 14.0 & 4.1 \\
\hline 8. Age $30-44$ & 8.3 & 16.0 & 11.4 & 13.4 & 19.0 & 5.2 \\
\hline 9. Age 45-64 & 10.5 & 16.9 & 12.7 & 13.4 & 21.4 & 5.1 \\
\hline 10. Low earnings & 8.8 & 21.8 & 9.3 & 13.7 & 16.7 & 4.5 \\
\hline 11. Medium earnings & 9.4 & 16.1 & 13.5 & 13.0 & 21.4 & 5.4 \\
\hline 12. High earnings & 8.5 & 13.9 & 10.8 & 11.4 & 19.0 & 5.1 \\
\hline 13. Small firms & 18.1 & 19.7 & 24.5 & 11.6 & 34.4 & 4.1 \\
\hline 14. Medium firms & 10.2 & 16.5 & 15.8 & 13.1 & 24.3 & 4.9 \\
\hline 15. Large firms & 7.1 & 15.3 & 6.5 & 13.6 & 13.7 & 5.3 \\
\hline 16. SIC G-H & 11.0 & 16.8 & 8.2 & 11.2 & 14.3 & 2.9 \\
\hline 17. Not SIC G-H & 8.6 & 15.9 & 13.0 & 14.0 & 21.5 & 5.9 \\
\hline 18. 'Round' rate & & & & & 28.1 & 3.7 \\
\hline 19. 'Non-rounded' rate & & & & & 16.9 & 5.3 \\
\hline
\end{tabular}

Notes.- Freezes and Cuts show the percentage of job stayers, pooled over all sample years, in each sub-sample of job stayers with year-to-year no change and a negative change in the pay measure indicated. 
TABLE D2: Incidence of negative nominal pay growth, wage cuts, among job stayers, 2006-18: probit model estimates

\begin{tabular}{|c|c|c|c|c|c|c|}
\hline & \multicolumn{2}{|c|}{ Basic wage, salaried } & \multicolumn{2}{|c|}{ Basic wage, hourly-paid } & \multicolumn{2}{|c|}{ Hourly pay rate } \\
\hline & $\begin{array}{l}\text { Coeff. } \\
\text { (I) }\end{array}$ & $\begin{array}{c}\text { Margin (Prob.) } \\
\text { (II) }\end{array}$ & $\begin{array}{l}\text { Coeff. } \\
\text { (III) }\end{array}$ & $\begin{array}{l}\text { Margin (Prob.) } \\
\text { (IV) }\end{array}$ & $\begin{array}{l}\text { Coeff. } \\
(\mathrm{V})\end{array}$ & $\begin{array}{c}\text { Margin (Prob.) } \\
\text { (VI) }\end{array}$ \\
\hline 1. Female & & 0.166 & & 0.127 & & 0.043 \\
\hline 2. Male & $0.025^{* * *}$ & 0.172 & $0.030^{* * *}$ & 0.133 & $0.138^{* * *}$ & 0.057 \\
\hline 3. Public sector & & 0.167 & & 0.138 & & 0.056 \\
\hline 4. Private sector & $0.014^{* *}$ & 0.170 & $-0.049^{* * *}$ & 0.127 & $-0.087^{* * *}$ & 0.047 \\
\hline 5. No coll. agree. & & 0.174 & & 0.129 & & 0.049 \\
\hline 6. Coll. agreement & $-0.042^{* * *}$ & 0.164 & 0.013 & 0.131 & -0.007 & 0.048 \\
\hline 7. Age $15-29$ & & 0.133 & & 0.123 & & 0.043 \\
\hline 8. Age $30-44$ & $0.156^{* * *}$ & 0.170 & $0.048^{* * *}$ & 0.133 & $0.075^{* * *}$ & 0.051 \\
\hline 9. Age 45-64 & $0.187^{* * *}$ & 0.177 & $0.033^{* * *}$ & 0.130 & $0.061^{* * *}$ & 0.049 \\
\hline 10. Low earnings & & 0.228 & & 0.144 & & 0.053 \\
\hline 11. Medium earnings & $-0.186^{* * *}$ & 0.176 & $-0.082^{* * *}$ & 0.127 & $-0.039^{* * *}$ & 0.049 \\
\hline 12. High earnings & $-0.311^{* * *}$ & 0.145 & $-0.203^{* * *}$ & 0.103 & $-0.139^{* * *}$ & 0.039 \\
\hline 13. Small firms & & 0.202 & & 0.117 & & 0.044 \\
\hline 14. Medium firms & $-0.092^{* * *}$ & 0.177 & $0.059^{* * *}$ & 0.129 & 0.022 & 0.047 \\
\hline 15. Large firms & $-0.154^{* * *}$ & 0.162 & $0.082^{* * *}$ & 0.134 & $0.065^{* * *}$ & 0.051 \\
\hline 16. SIC G-H & & 0.162 & & 0.107 & & 0.030 \\
\hline 17. Not SIC G-H & $0.030^{* * *}$ & 0.170 & $0.164^{* * *}$ & 0.141 & $0.316^{* * *}$ & 0.059 \\
\hline 18. Firm expanding & & 0.162 & & 0.120 & & 0.043 \\
\hline 19. Firm constant size & $0.014^{*}$ & 0.166 & $0.028^{* *}$ & 0.125 & 0.017 & 0.044 \\
\hline 20. Firm shrinking & $0.057^{* * *}$ & 0.176 & $0.116^{* * *}$ & 0.144 & $0.164^{* * *}$ & 0.060 \\
\hline 21. 'Non-rounded' & & & & & & 0.051 \\
\hline 22. 'Round' rate & & & & & $-0.107^{* * *}$ & 0.041 \\
\hline$N$ of job stayers & & 62,481 & & 48,199 & & 48,199 \\
\hline Log-likelihood & & 254,999 & & 95,948 & & 49,786 \\
\hline
\end{tabular}

Notes.- The dependent variable is an indicator that takes the value one if a job stayer experienced a pay cut occurred from year-to-year and zero otherwise. The omitted categories of the explanatory variables are female worker, non-private sector, not covered by collective agreement, age 15-29, low earnings, small firms, SIC G-H, 'non-rounded' rate, and growing firms. Marginal effects are evaluated at the sample average using the delta method. Excludes all job stayers in 2007-08 and 2017-18 because firm size was incorrectly recorded in the second years of those periods.

${ }^{* * *},{ }^{* *},{ }^{*}$ indicate significance from zero of the model coefficients at the $0.1 \%, 1 \%$ and $5 \%$ levels, respectively, two-sided tests and robust standard errors. 
TABLE D3: Incidence of zero nominal pay growth, wage freezes, among job stayers, 2006-18: probit model estimates

\begin{tabular}{|c|c|c|c|c|c|c|}
\hline & \multicolumn{2}{|c|}{ Basic wage, salaried } & \multicolumn{2}{|c|}{ Basic wage, hourly-paid } & \multicolumn{2}{|c|}{ Hourly pay rate } \\
\hline & $\begin{array}{l}\text { Coeff. } \\
\text { (I) }\end{array}$ & $\begin{array}{c}\text { Margin (Prob.) } \\
\text { (II) }\end{array}$ & $\begin{array}{l}\text { Coeff. } \\
\text { (III) }\end{array}$ & $\begin{array}{c}\text { Margin (Prob.) } \\
\text { (IV) }\end{array}$ & $\begin{array}{l}\text { Coeff. } \\
\text { (V) }\end{array}$ & $\begin{array}{c}\text { Margin (Prob.) } \\
\text { (VI) }\end{array}$ \\
\hline 1. Male & \multirow[t]{2}{*}{$0.133^{* * *}$} & 0.087 & \multirow[t]{2}{*}{$0.225^{* * *}$} & 0.132 & \multirow[t]{2}{*}{$0.135^{* * *}$} & 0.207 \\
\hline 2. Female & & 0.068 & & 0.090 & & 0.171 \\
\hline 3. Private sector & \multirow[t]{2}{*}{$0.029^{* * *}$} & 0.079 & \multirow[t]{2}{*}{-0.014} & 0.127 & \multirow[t]{2}{*}{$-0.105^{* * *}$} & 0.180 \\
\hline 4. Public sector & & 0.075 & & 0.111 & & 0.209 \\
\hline 5. Coll. agreement & \multirow[t]{3}{*}{$-0.025^{* * *}$} & 0.075 & \multirow[t]{3}{*}{$-0.165^{* * *}$} & 0.094 & \multirow[t]{3}{*}{$-0.156^{* * *}$} & 0.167 \\
\hline 6. No coll. agree. & & 0.079 & & 0.125 & & 0.209 \\
\hline 7. Age $15-29$ & & 0.045 & & 0.079 & & 0.141 \\
\hline 8. Age $30-44$ & \multirow{3}{*}{$\begin{array}{l}0.235^{* * *} \\
0.362^{* * *}\end{array}$} & 0.072 & $0.173^{* * *}$ & 0.107 & \multirow{3}{*}{$\begin{array}{l}0.179^{* * *} \\
0.257^{* * *}\end{array}$} & 0.184 \\
\hline 9. Age 45-64 & & 0.091 & $0.243^{* * *}$ & 0.121 & & 0.206 \\
\hline 10. Low earnings & & 0.078 & & 0.097 & & 0.171 \\
\hline 11. Medium earnings & \multirow{3}{*}{$\begin{array}{r}0.028^{* * *} \\
-0.034^{* * *}\end{array}$} & 0.082 & $-0.120^{* * *}$ & 0.119 & \multirow{3}{*}{$\begin{array}{l}0.112^{* * *} \\
0.079^{* * *}\end{array}$} & 0.201 \\
\hline 12. High earnings & & 0.073 & $0.054^{* * *}$ & 0.107 & & 0.191 \\
\hline 13. Small firms & & 0.153 & & 0.233 & & 0.328 \\
\hline 14. Medium firms & \multirow{2}{*}{$\begin{array}{l}-0.321^{* * *} \\
-0.492^{* * *}\end{array}$} & 0.089 & $-0.334^{* * *}$ & 0.144 & \multirow{2}{*}{$\begin{array}{l}-0.295^{* * *} \\
-0.618^{* * *}\end{array}$} & 0.230 \\
\hline 15. Large firms & & 0.065 & $-0.706^{* * *}$ & 0.076 & & 0.144 \\
\hline 16. Not SIC G-H & \multirow{2}{*}{$-0.025^{* *}$} & 0.077 & $0.178^{* * *}$ & 0.119 & \multirow[t]{2}{*}{$0.194^{* * *}$} & 0.204 \\
\hline 17. SIC G-H & & 0.080 & & 0.087 & & 0.153 \\
\hline 18. Firm expanding & \multirow{5}{*}{$\begin{array}{l}0.148^{* * *} \\
0.165^{* * *}\end{array}$} & 0.064 & \multirow{5}{*}{$\begin{array}{l}0.088^{* * *} \\
0.133^{* * *}\end{array}$} & 0.097 & \multirow{3}{*}{$\begin{array}{l}0.073^{* * *} \\
0.153^{* * *}\end{array}$} & 0.169 \\
\hline 19. Firm constant size & & 0.085 & & 0.112 & & 0.188 \\
\hline 20. Firm shrinking & & 0.088 & & 0.121 & & 0.210 \\
\hline 21. 'Round' rate & & & & & \multirow[t]{2}{*}{$0.211^{* * *}$} & 0.234 \\
\hline 22. 'Non-rounded' & & & & & & 0.175 \\
\hline$N$ of job stayers & \multicolumn{2}{|c|}{562,481} & \multicolumn{2}{|c|}{248,199} & \multicolumn{2}{|c|}{248,199} \\
\hline Log-likelihood & \multicolumn{2}{|c|}{$-155,978$} & \multicolumn{2}{|c|}{$-86,551$} & \multicolumn{2}{|c|}{$-116,758$} \\
\hline
\end{tabular}

Notes.- see Table D3.

$* * *,{ }^{* *},{ }^{*}$ indicate significance from zero of the model coefficients at the $0.1 \%, 1 \%$ and $5 \%$ levels, respectively, two-sided tests and robust standard errors. 
FIGURE D1: Distributions of job-stayer year-to-year log changes for different wage measures by gender, 2006-18

A. Male

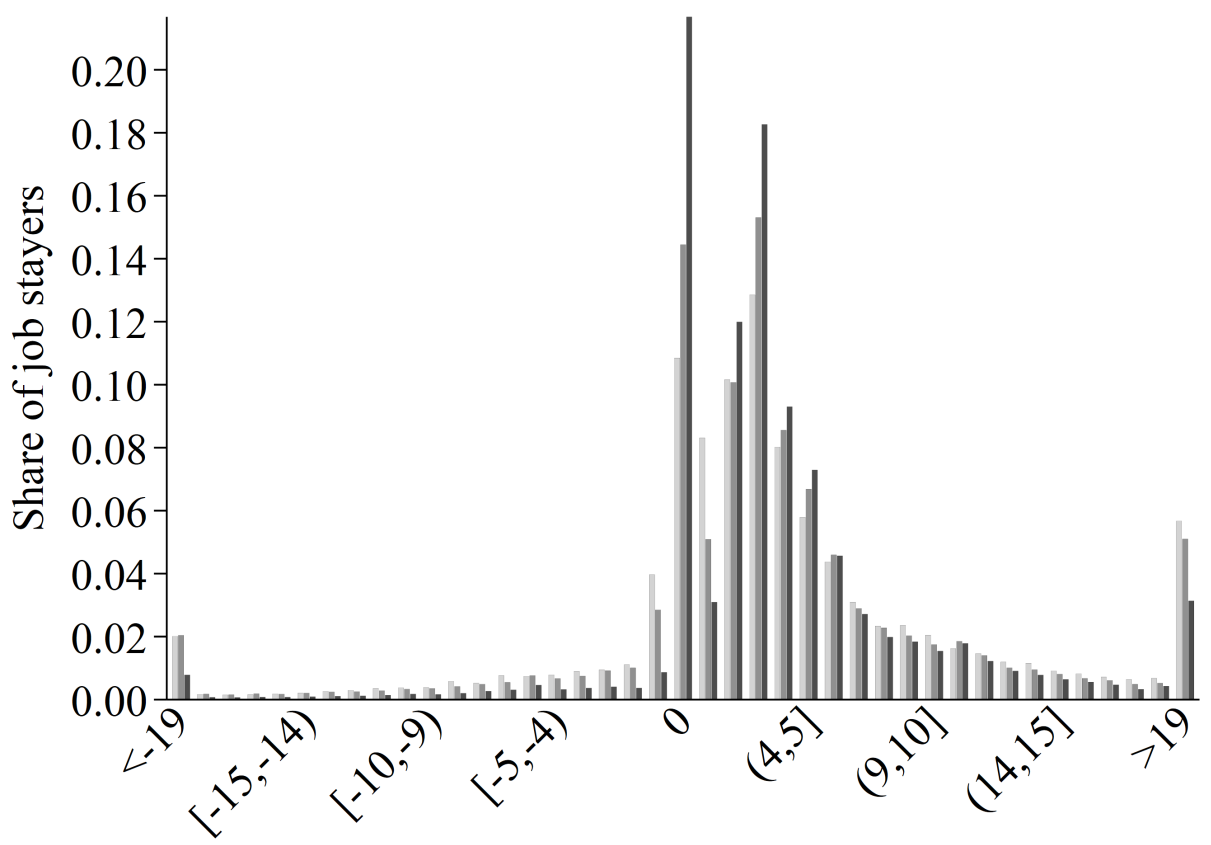

B. Female

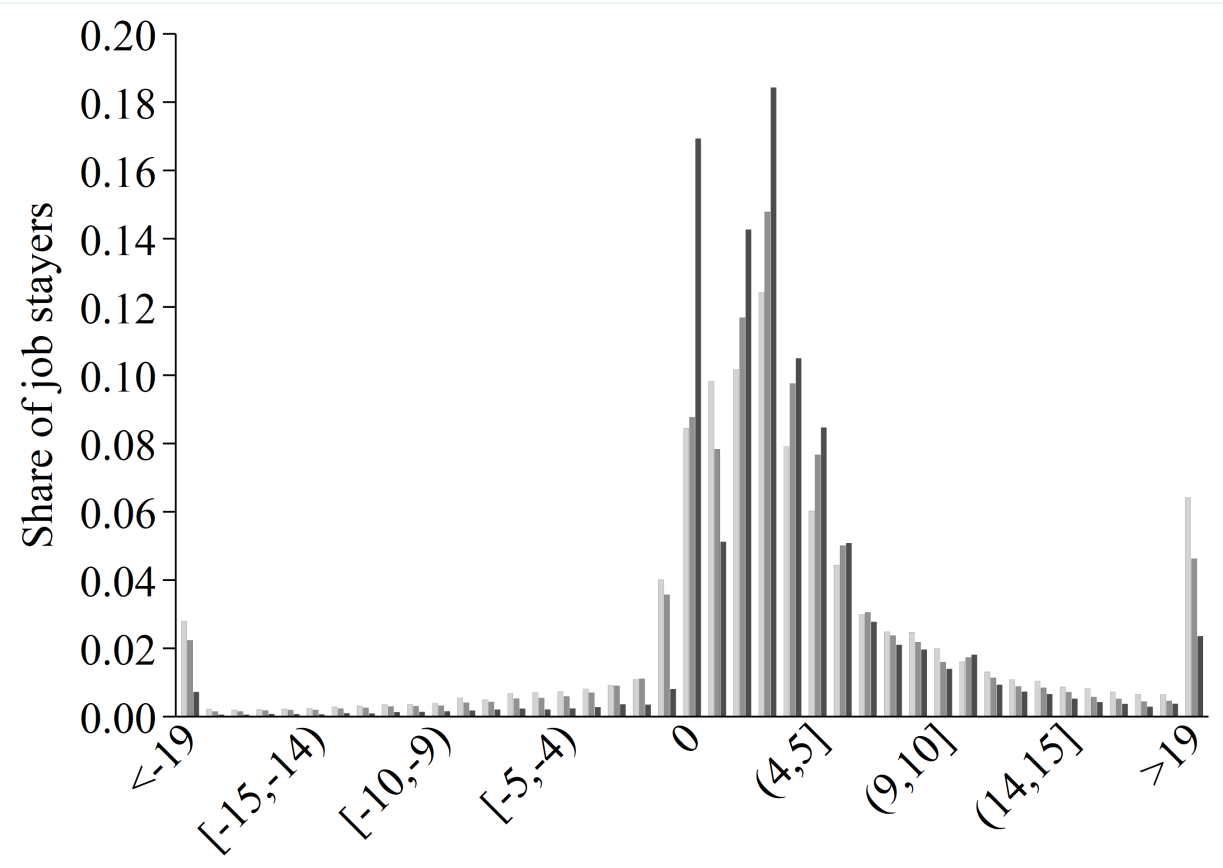

Notes.- see Figure 1 in the main text. Dark grey bars: reported hourly pay rates. Medium grey bars: basic wage for hourly-paid workers. Light grey bars: basic wage for salaried workers. 
FIGURE D2: Distributions of job-stayer year-to-year log changes for different wage measures by private sector status, 2006-18

\section{A. Private sector}

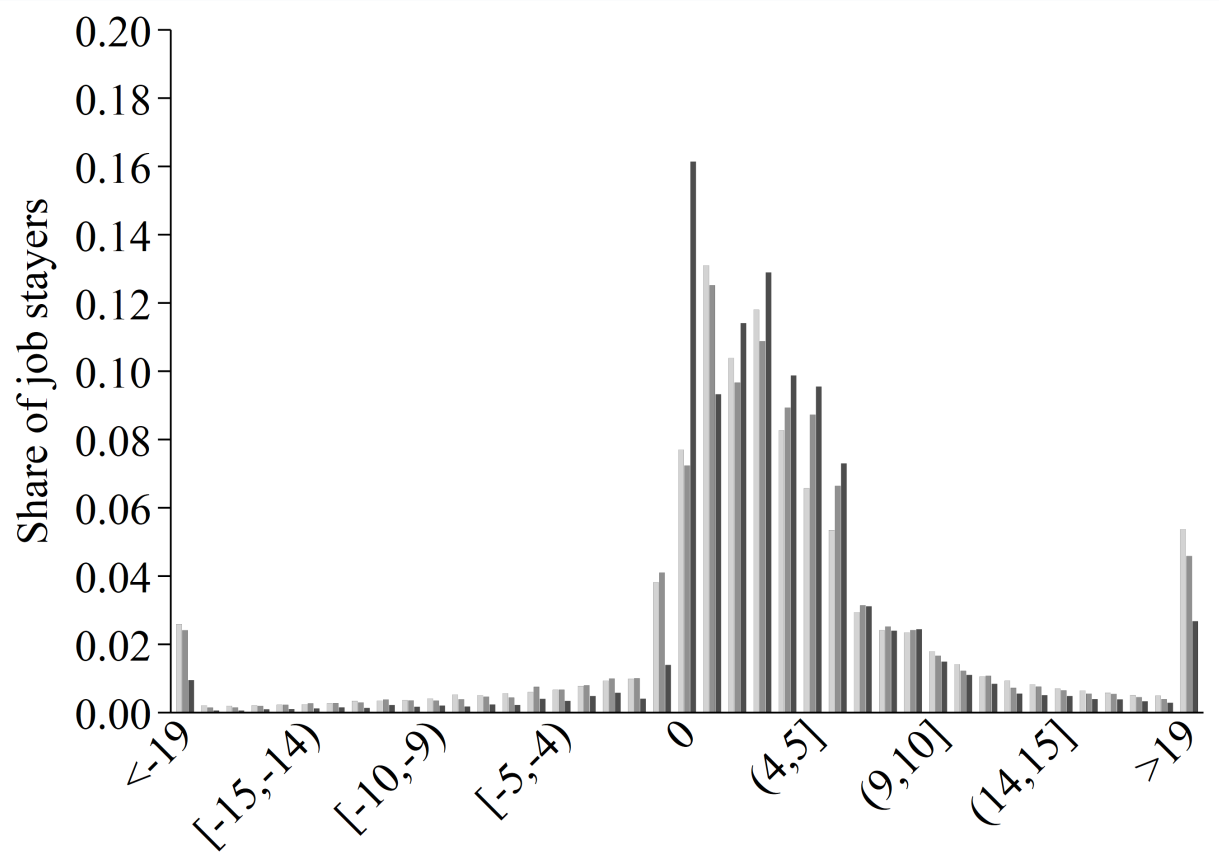

B. Non-private sector

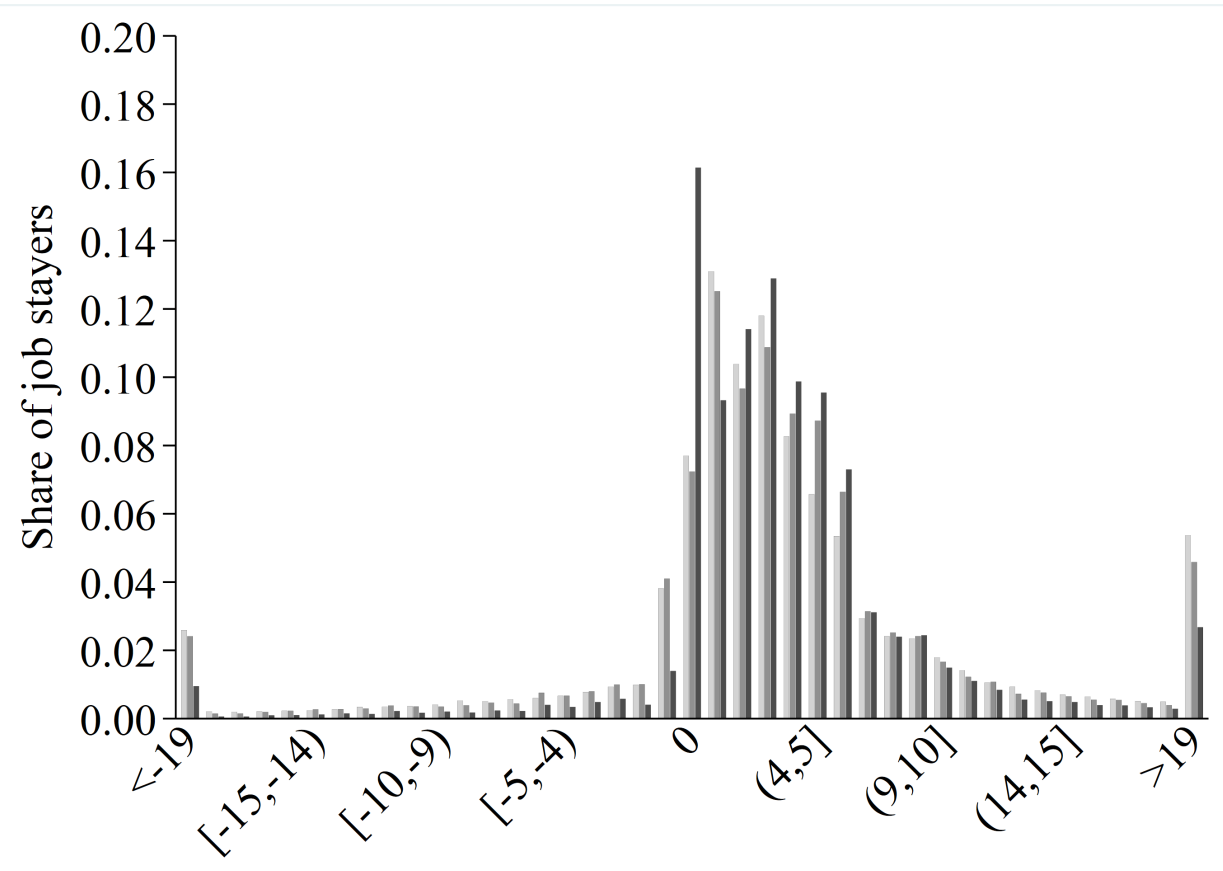

Notes.- see Figure 1 in the main text. Dark grey bars: reported hourly pay rates. Medium grey bars: basic wage for hourly-paid workers. Light grey bars: basic wage for salaried workers. 
FIGURE D3: Distributions of job-stayer year-to-year log adjustments for different wage measures by collective agreement status, 2006-18
A. With agreement
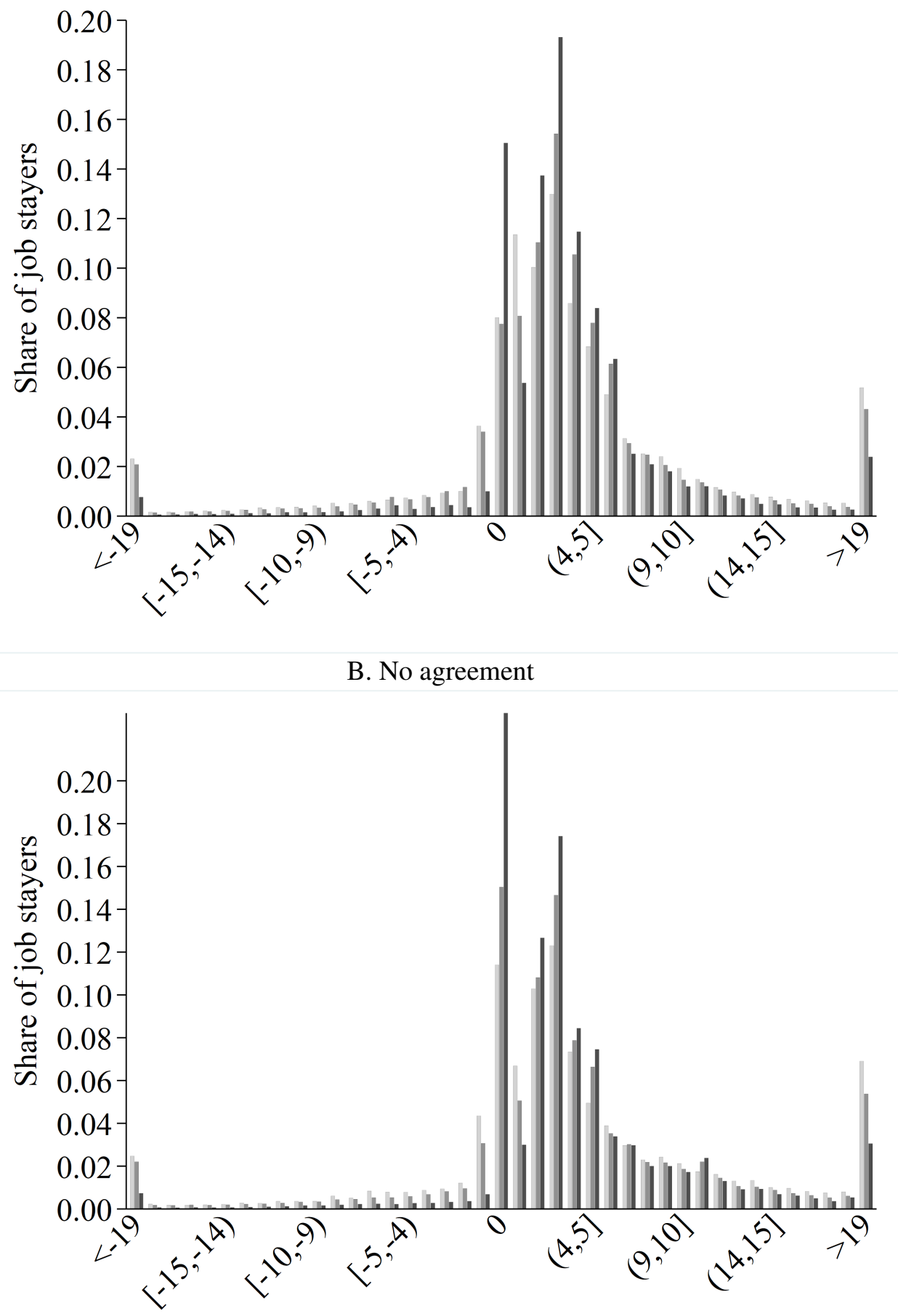

Notes.- see Figure 1 in the main text. Dark grey bars: reported hourly pay rates. Medium grey bars: basic wage for hourly-paid workers. Light grey bars: basic wage for salaried workers. 
FIGURE D4: Distributions of job-stayer year-to-year log changes for different wage measures by age group, 2006-18

A. $16-29$

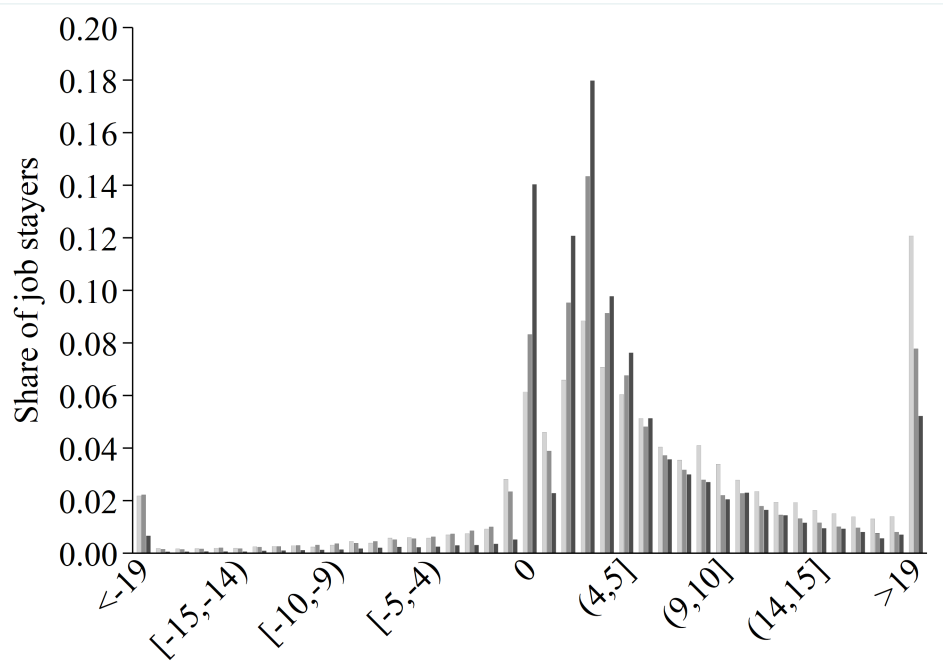

B. $30-44$

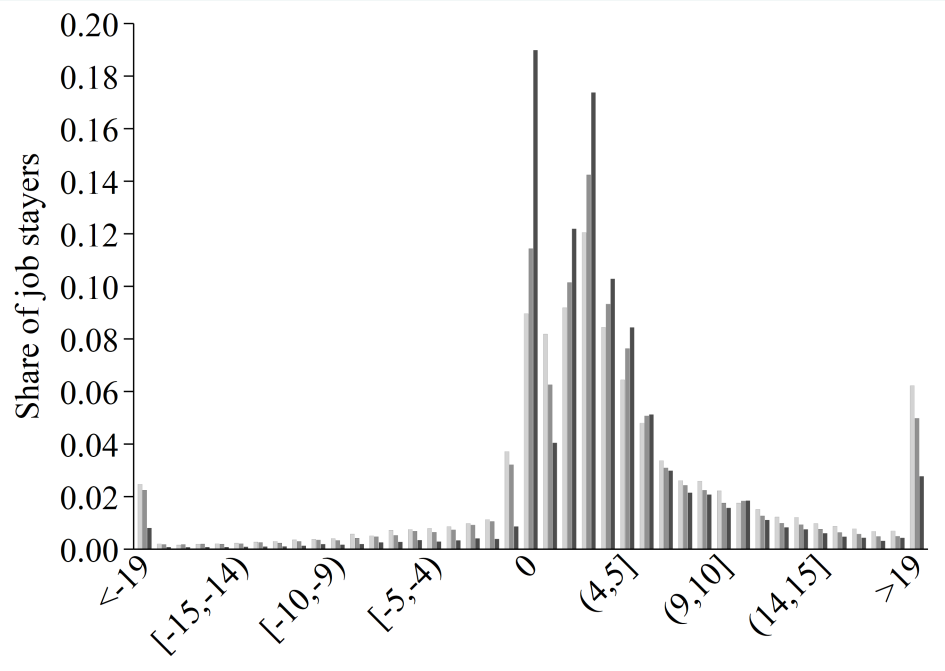

C. $45-64$

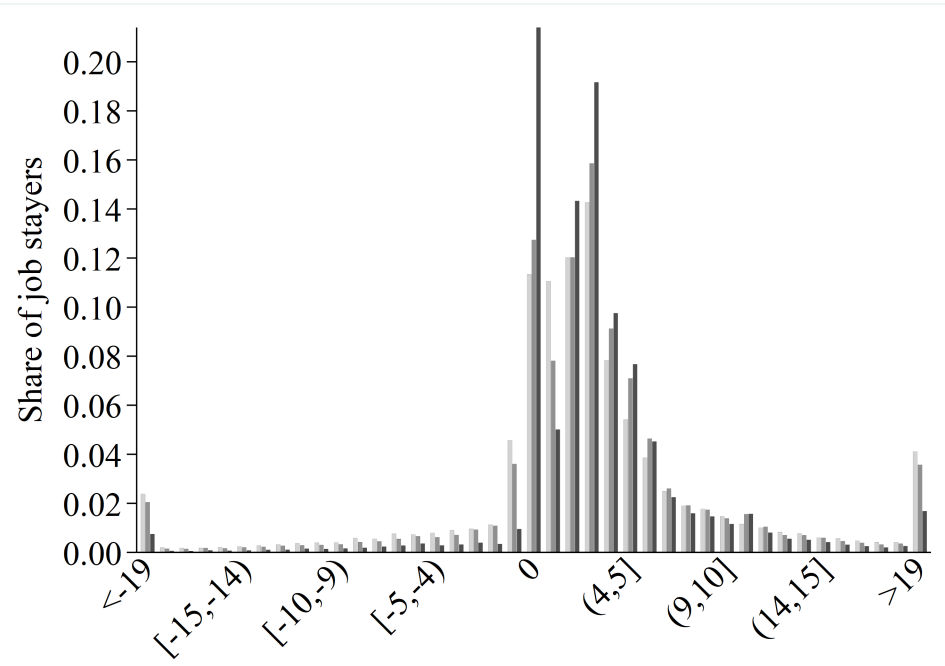

Notes.- see Figure 1 in the main text. Dark grey bars: reported hourly pay rates. Medium grey bars: basic wage for hourly-paid workers. Light grey bars: basic wage for salaried workers. 
FIGURE D5: Distributions of job-stayer year-to-year log changes for different wage measures by earnings relative to the median, 2006-18

A. Less than $2 / 3$ of median earnings

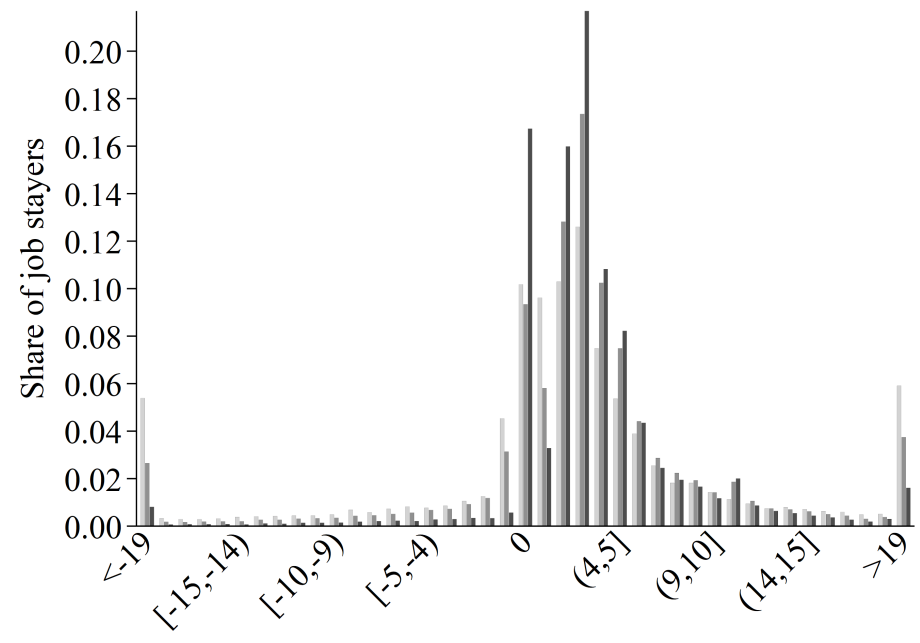

B. Between $2 / 3$ and $4 / 3$ of median earnings

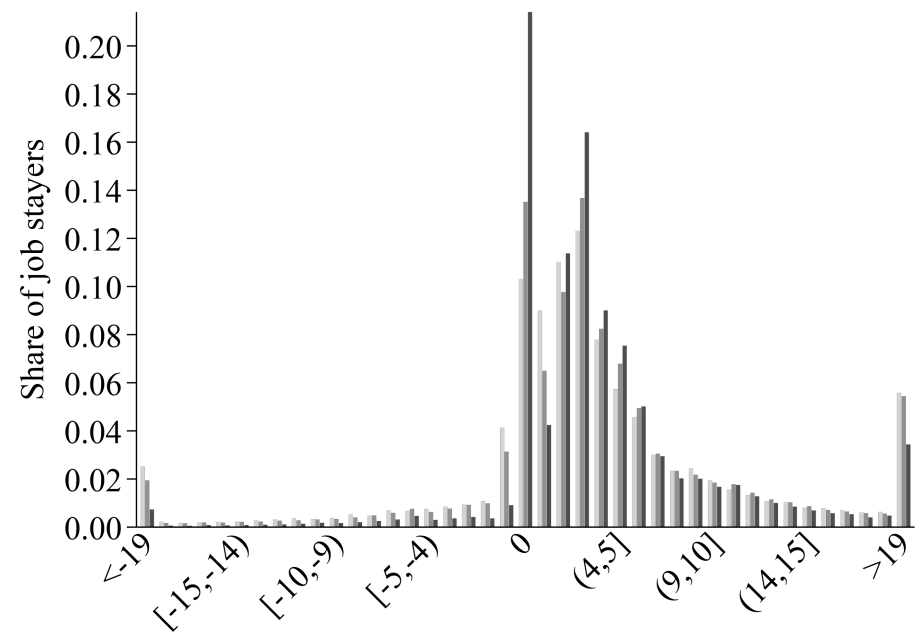

C. Greater than $4 / 3$ of median earnings

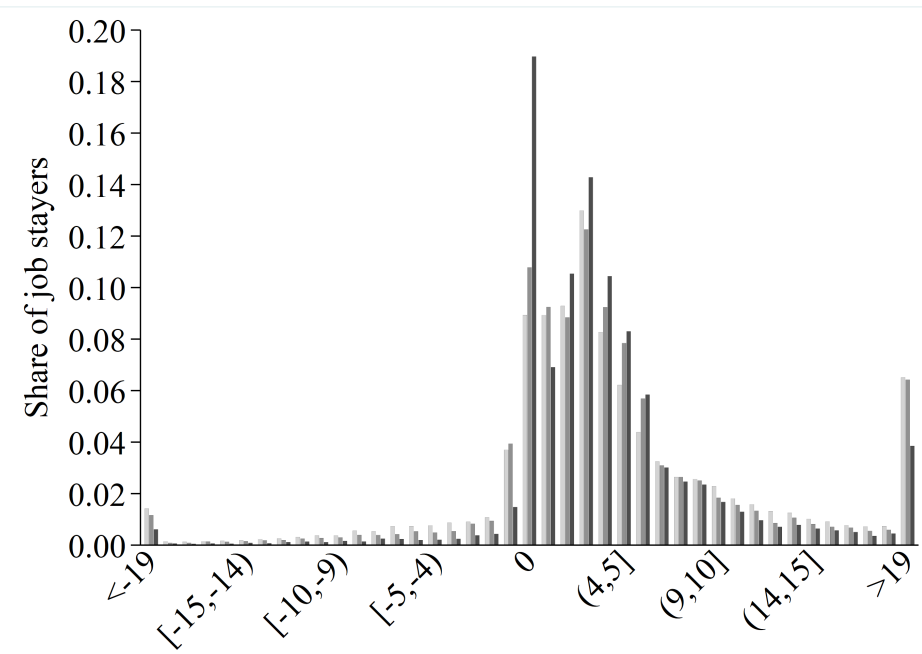

Notes.- see Figure 1 in the main text. Median earnings are calculated within year, using all ASHE employee observations of basic weekly pay. Dark grey bars: reported hourly pay rates. Medium grey bars: basic wage for hourly-paid workers. Light grey bars: basic wage for salaried workers. 
FIGURE D6: Distributions of job-stayer year-to-year log changes for different wage measures by firm size, 2006-18

A. Small firms

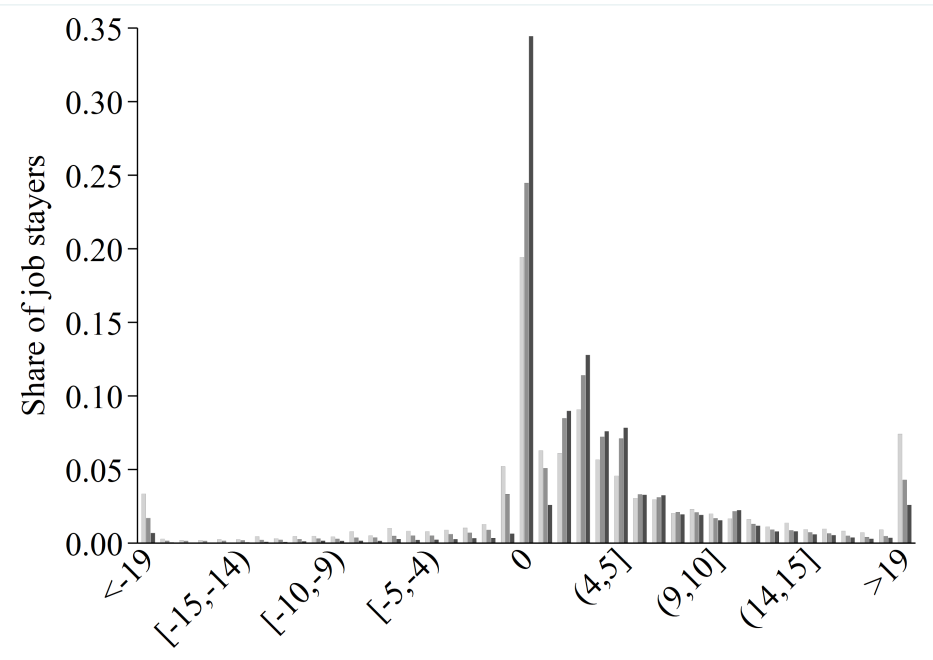

B. Medium firms

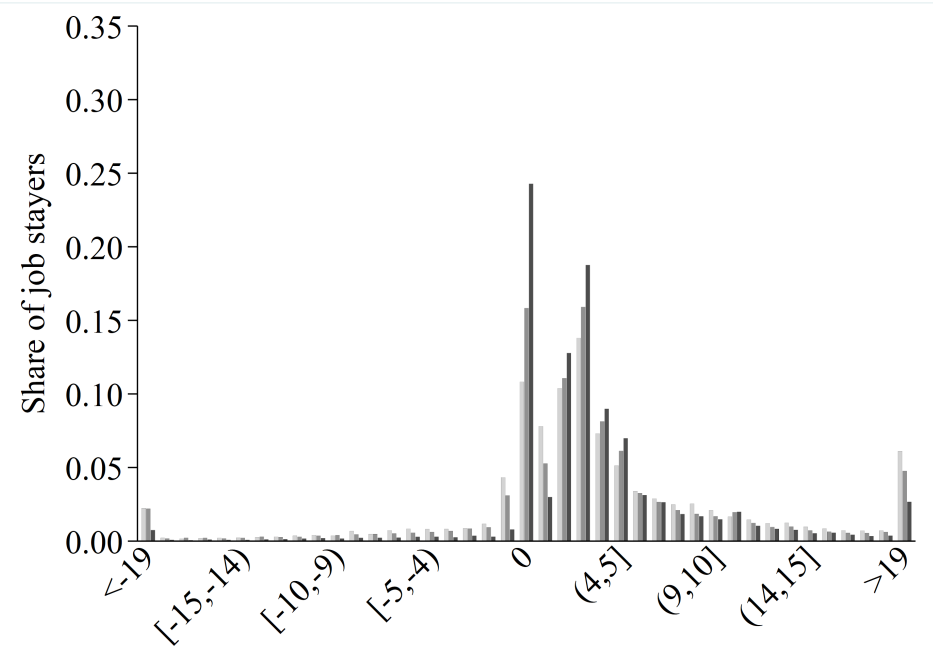

C. Large firms

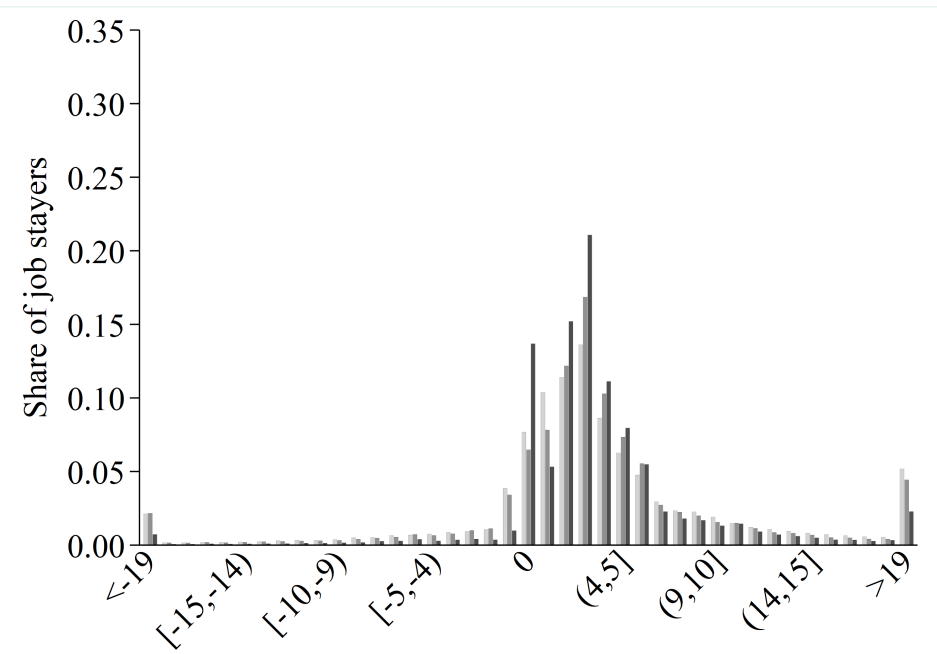

Notes.- see Figure 1 in the main text. Dark grey bars: reported hourly pay rates. Medium grey bars: basic wage for hourly workers. Light grey bars: basic wage for salaried workers. Small firms have $1-49$ employees, medium firms have $50-249$, and large firms have $250+$ employees. 
FIGURE D7: Distributions of job-stayer year-to-year log changes for different wage measures, excluding Wholesale \& Retail Trade, Hotels \& Restaurants, 2006-18

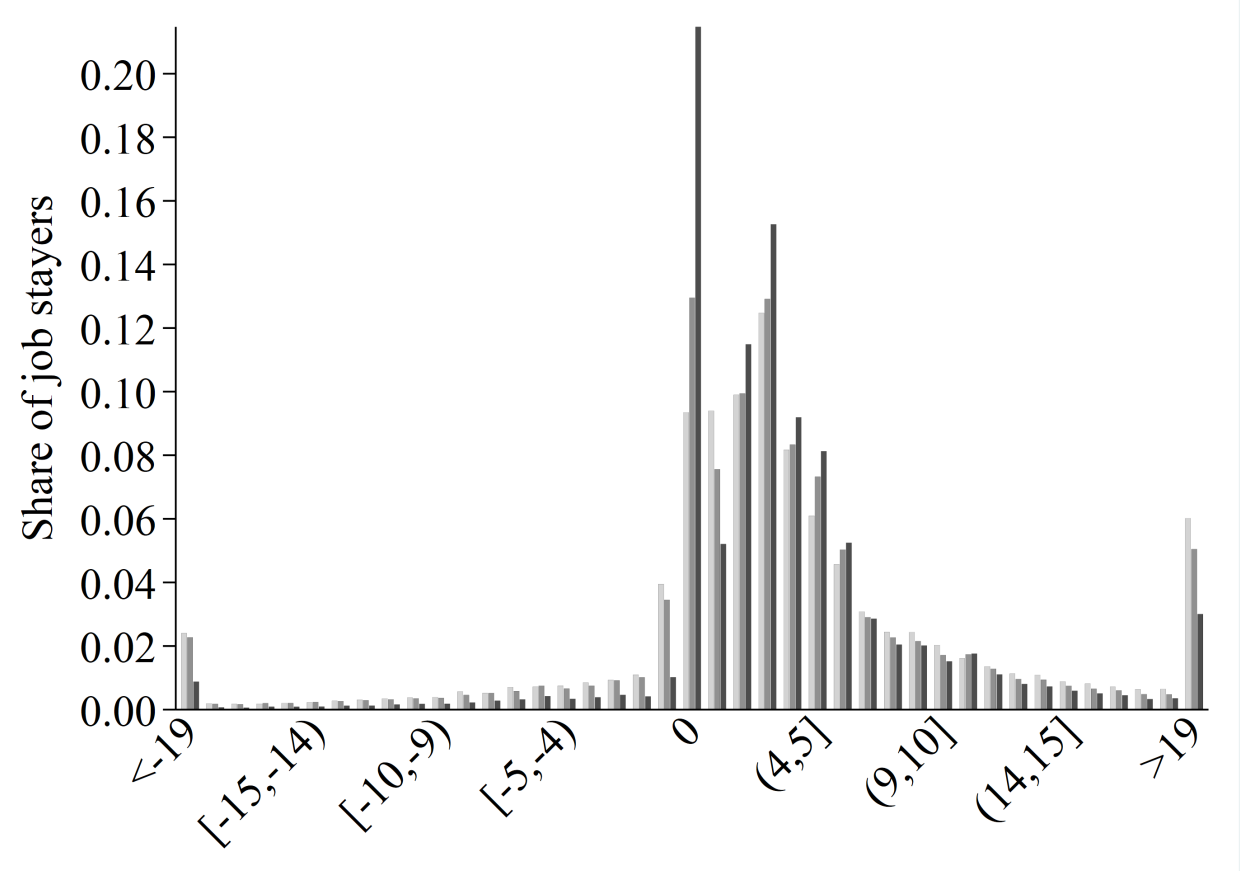

Notes.- see Figure 1 in the main text. Dark grey bars: reported hourly pay rates. Medium grey bars: basic wage for hourly-paid workers. Light grey bars: basic wage for salaried workers. Compared with the main results, this distributions exclude SIC2003 sectors G-H. 


\section{Appendix E. Additional Tables of Results}

TABLE E1: Sample sizes of job-stayer wage change observations

\begin{tabular}{lccccccc}
\hline Years & $\begin{array}{c}\text { GPOX } \\
(\mathrm{I})\end{array}$ & $\begin{array}{c}\text { OVPAY } \\
(\mathrm{II})\end{array}$ & $\begin{array}{c}\text { SPPAY } \\
(\mathrm{III})\end{array}$ & $\begin{array}{c}\text { IPAYIN } \\
(\mathrm{IV})\end{array}$ & $\begin{array}{c}\text { OTHPAY } \\
(\mathrm{V})\end{array}$ & $\begin{array}{c}\text { Hourly } \\
(\text { VI })\end{array}$ & $\begin{array}{c}\text { Salaried } \\
(\text { VII })\end{array}$ \\
\hline $2006-07$ & 77,206 & 21,342 & 10,357 & 8,634 & 20,362 & 20,121 & 57,085 \\
$2007-08$ & 78,984 & 21,589 & 9,721 & 7,625 & 19,864 & 23,031 & 55,953 \\
$2008-09$ & 79,591 & 19,757 & 9,060 & 7,154 & 19,442 & 23,391 & 56,200 \\
$2009-10$ & 100,766 & 22,458 & 10,492 & 7,673 & 22,501 & 31,248 & 69,518 \\
$2010-11$ & 101,878 & 25,247 & 12,462 & 8,921 & 24,184 & 32,459 & 69,419 \\
$2011-12$ & 99,922 & 23,536 & 11,674 & 9,094 & 22,110 & 32,816 & 67,106 \\
$2012-13$ & 96,994 & 22,802 & 11,963 & 8,422 & 21,073 & 31,114 & 65,880 \\
$2013-14$ & 97,752 & 23,096 & 12,241 & 7,710 & 21,453 & 31,027 & 66,725 \\
$2014-15$ & 96,401 & 22,601 & 11,753 & 7,325 & 21,267 & 31,245 & 65,166 \\
$2015-16$ & 92,622 & 20,945 & 10,948 & 7,360 & 20,150 & 29,755 & 62,867 \\
$2016-17$ & 88,790 & 19,655 & 10,334 & 6,547 & 18,609 & 28,082 & 60,708 \\
$2017-18$ & 86,329 & 18,600 & 9,521 & 5,965 & 17,007 & 27,946 & 58,383 \\
\hline
\end{tabular}

Notes.- displays annual sample sizes of job stayers for the different sub-samples used throughout the main text.

TABLE E2: Descriptive statistics for job-stayer sub-samples, 2006-18

\begin{tabular}{lccccccc}
\hline & $\begin{array}{c}\text { ALL } \\
\text { (I) }\end{array}$ & $\begin{array}{c}\text { OVPAY } \\
\text { (II) }\end{array}$ & $\begin{array}{c}\text { IPAYIN } \\
\text { (III) }\end{array}$ & $\begin{array}{c}\text { SPPAY } \\
\text { (IV) }\end{array}$ & $\begin{array}{c}\text { OTHPAY } \\
\text { (V) }\end{array}$ & $\begin{array}{c}\text { Hourly } \\
\text { (VI) }\end{array}$ & $\begin{array}{c}\text { Salaried } \\
\text { (VII) }\end{array}$ \\
\hline Private sector (\%) & 62.6 & 71.8 & 87.4 & 57.3 & 58.2 & 76.3 & 56.4 \\
Female (\%) & 50.7 & 37.9 & 34.2 & 44.7 & 41.5 & 52.7 & 49.8 \\
Age (years) & 42.8 & 42.3 & 41.4 & 42.9 & 43.4 & 42.5 & 42.9 \\
Full-time ( $\geq$ 30 hours, \%) & 76.3 & 78.1 & 87.6 & 78.2 & 83.9 & 64.6 & 81.5 \\
Collective agreement (\%) & 50.6 & 53.1 & 37.4 & 71.3 & 61.0 & 49.2 & 51.3 \\
Firm size (n. of employees, median) & 2,938 & 3,394 & 1,271 & 6,786 & 6,686 & 2,717 & 3.010 \\
Weekly basic hours (median) & 37.0 & 37.4 & 37.5 & 37.5 & 37.9 & 36.3 & 37.0 \\
Earnings per hour (mean, $\mathfrak{f})$ & 14.39 & 11.71 & 13.01 & 11.87 & 16.77 & 10.48 & 16.16 \\
Earnings per hour (median, $\mathfrak{f})$ & 11.93 & 10.34 & 10.91 & 10.54 & 14.42 & 8.92 & 13.92 \\
$N$ & $1,097,235$ & 216,243 & 71,962 & 115,132 & 208,591 & 342,225 & 755,010 \\
\hline
\end{tabular}

Notes.- Wages are in 2015 GBP, deflated using the UK Consumer Price Index. Columns (II)-(V) show statistics for the sub-samples of job stayers in receipt positive pay components, as per Table C1. Columns (VI)-(VII) show descriptive for the subsamples of hourly-paid and salaried workers, as represented by Figure 6 and discussed in the main text.

TABLE E3: Distribution of job stayers over industry sectors, 2006-18

\begin{tabular}{lrr}
\hline Industry (SIC2003) & Hourly-paid & $\begin{array}{r}\text { Salaried } \\
\text { (II) }\end{array}$ \\
\hline A-F: Agric., Mining, Manuf., Energy, Constr. etc. & 0.19 & 0.15 \\
G-H: Wholesale \& Retail Trade, Hotels \& Restaurants & 0.32 & 0.12 \\
M-N: Education \& Health & 0.27 & 0.31 \\
I-L, O: Other Services & 0.22 & 0.41 \\
\hline
\end{tabular}

Notes.- statistics use the later period for each job stayer observation. Classification according to the ONS Standard Industrial Classification 2003. We convert ONS Standard Industrial Classification (SIC) 2007 to 2003, using files made available by the UK Data Service. This conversion uses the 2008 Annual Respondents Dataset, where both classifications were applied, and where any 2007 code mapping to multiple 2003 codes is decided using whichever of the two bore a greater share of economic output. 
TABLE E4: Nominal adjustments in job-stayer earnings per hour, 2006-18: hourly-paid vs salaried

\begin{tabular}{|c|c|c|c|c|}
\hline \multirow[b]{2}{*}{ Years } & \multicolumn{2}{|c|}{ Hourly } & \multicolumn{2}{|c|}{ Salaried } \\
\hline & Freezes $(\%)$ & Cuts (\%) & Freezes $(\%)$ & Cuts (\%) \\
\hline 2006-07 & 5.9 & 21.5 & 3.9 & 18.9 \\
\hline $2007-08$ & 4.7 & 18.5 & 2.5 & 17.7 \\
\hline 2008-09 & 7.8 & 19.2 & 6.1 & 20.1 \\
\hline $2009-10$ & 12.3 & 23.0 & 8.3 & 24.3 \\
\hline $2010-11$ & 10.6 & 21.9 & 7.3 & 22.7 \\
\hline $2011-12$ & 11.5 & 21.4 & 11.0 & 23.1 \\
\hline $2012-13$ & 11.2 & 21.2 & 10.1 & 23.5 \\
\hline $2013-14$ & 8.8 & 21.3 & 5.9 & 19.7 \\
\hline 2014-15 & 7.3 & 18.5 & 5.2 & 18.8 \\
\hline $2015-16$ & 7.4 & 19.2 & 6.9 & 21.0 \\
\hline $2016-17$ & 7.5 & 19.0 & 5.8 & 19.7 \\
\hline $2017-18$ & 7.1 & 17.0 & 6.6 & 19.4 \\
\hline
\end{tabular}

Notes.- Freezes and Cuts show the percentage of job stayers with year-to-year no change and a negative change in the pay measure indicated. See Table E1 columns (VI) and (VII) for annual sample sizes.

TABLE E5: Nominal adjustments in job-stayer basic wages, 2006-18: hourly-paid vs salaried

\begin{tabular}{|c|c|c|c|c|}
\hline \multirow[b]{2}{*}{ Years } & \multicolumn{2}{|c|}{ Hourly } & \multicolumn{2}{|c|}{ Salaried } \\
\hline & Freezes $(\%)$ & Cuts $(\%)$ & Freezes $(\%)$ & Cuts (\%) \\
\hline 2006-07 & 8.3 & 11.5 & 5.5 & 14.6 \\
\hline $2007-08$ & 6.4 & 12.1 & 3.3 & 13.2 \\
\hline 2008-09 & 10.3 & 11.1 & 8.2 & 15.0 \\
\hline $2009-10$ & 16.3 & 15.3 & 11.6 & 19.2 \\
\hline $2010-11$ & 14.7 & 13.7 & 10.6 & 17.2 \\
\hline $2011-12$ & 14.0 & 14.0 & 13.5 & 19.0 \\
\hline $2012-13$ & 14.4 & 16.5 & 13.6 & 17.9 \\
\hline $2013-14$ & 11.8 & 12.8 & 7.7 & 14.3 \\
\hline 2014-15 & 9.3 & 11.2 & 6.4 & 14.2 \\
\hline $2015-16$ & 9.9 & 13.5 & 8.9 & 16.1 \\
\hline 2016-17 & 9.6 & 12.5 & 7.6 & 15.0 \\
\hline $2017-18$ & 8.9 & 11.5 & 8.3 & 15.3 \\
\hline
\end{tabular}

Notes.- Freezes and Cuts show the percentage of job stayers with year-to-year no change and a negative change in the pay measure indicated. See Table E1 columns (VI) and (VII) for annual sample sizes. 
TABLE E6: Marginal contribution of individual pay components to nominal adjustments, HOURLY-PAID, 2006-18

\begin{tabular}{|c|c|c|c|c|c|}
\hline \multirow[b]{2}{*}{ Years } & \multirow{2}{*}{$\begin{array}{l}\text { Earnings } \\
\text { per hour }\end{array}$} & \multirow{2}{*}{$\frac{\text { Adding }}{\text { Overtime pay }}$} & \multicolumn{3}{|c|}{ Excluding } \\
\hline & & & Shift premium pay & Incentive pay & Other pay \\
\hline \multicolumn{6}{|c|}{ Freezes $(\%)$ : } \\
\hline 2006-07 & 5.9 & 4.1 & 6.2 & 6.6 & 6.9 \\
\hline $2007-08$ & 4.7 & 3.3 & 5.0 & 5.0 & 5.2 \\
\hline $2008-09$ & 7.8 & 5.3 & 8.1 & 8.6 & 8.5 \\
\hline $2009-10$ & 12.3 & 8.6 & 13.0 & 13.3 & 13.4 \\
\hline $2010-11$ & 10.6 & 8.0 & 10.9 & 11.4 & 11.8 \\
\hline $2011-12$ & 11.5 & 8.5 & 11.9 & 12.3 & 12.7 \\
\hline $2012-13$ & 11.2 & 8.4 & 11.9 & 12.0 & 12.3 \\
\hline $2013-14$ & 8.8 & 6.5 & 9.6 & 9.6 & 9.7 \\
\hline 2014-15 & 7.3 & 5.6 & 7.7 & 7.9 & 8.0 \\
\hline $2015-16$ & 7.4 & 5.3 & 7.9 & 8.0 & 8.3 \\
\hline $2016-17$ & 7.5 & 5.9 & 8.0 & 7.9 & 8.2 \\
\hline $2017-18$ & 7.1 & 5.7 & 7.6 & 7.6 & 7.7 \\
\hline \multicolumn{6}{|l|}{ Cuts $(\%)$ : } \\
\hline $2006-07$ & 21.5 & 24.1 & 19.7 & 18.4 & 18.8 \\
\hline $2007-08$ & 18.5 & 21.6 & 17.2 & 17.7 & 16.3 \\
\hline 2008-09 & 19.2 & 22.9 & 17.3 & 17.8 & 16.6 \\
\hline $2009-10$ & 23.0 & 26.1 & 20.4 & 21.9 & 20.9 \\
\hline $2010-11$ & 21.9 & 25.1 & 20.3 & 20.9 & 18.7 \\
\hline $2011-12$ & 21.4 & 24.5 & 18.8 & 20.3 & 19.1 \\
\hline $2012-13$ & 21.2 & 24.1 & 19.3 & 20.2 & 21.1 \\
\hline 2013-14 & 21.3 & 24.0 & 18.3 & 20.3 & 18.5 \\
\hline 2014-15 & 18.5 & 20.9 & 15.7 & 17.5 & 16.8 \\
\hline $2015-16$ & 19.2 & 22.1 & 17.7 & 18.5 & 17.4 \\
\hline 2016-17 & 19.0 & 21.6 & 16.6 & 18.1 & 16.9 \\
\hline $2017-18$ & 17.0 & 19.2 & 14.8 & 16.4 & 15.4 \\
\hline
\end{tabular}

Notes.- Percentages of job stayers with exactly zero year-to-year changes in nominal hourly pay, or cuts. Each column uses hourly gross pay, excluding overtime, as the baseline pay variable and then either adds or excludes the shown pay component. 
TABLE E7: Marginal contribution of individual pay components to nominal adjustments, SALARIED, 2006-18

\begin{tabular}{|c|c|c|c|c|c|}
\hline \multirow[b]{2}{*}{ Years } & \multirow{2}{*}{$\begin{array}{l}\text { Earnings } \\
\text { per hour }\end{array}$} & \multirow{2}{*}{$\frac{\text { Adding }}{\text { Overtime pay }}$} & \multicolumn{3}{|c|}{ Excluding } \\
\hline & & & Shift premium pay & Incentive pay & Other pay \\
\hline \multicolumn{6}{|l|}{ Freezes: } \\
\hline 2006-07 & 3.9 & 3.3 & 4.0 & 4.3 & 4.6 \\
\hline 2007-08 & 2.5 & 2.1 & 2.5 & 2.8 & 2.7 \\
\hline 2008-09 & 6.1 & 5.1 & 6.3 & 6.8 & 6.8 \\
\hline $2009-10$ & 8.3 & 7.0 & 8.5 & 9.2 & 9.7 \\
\hline $2010-11$ & 7.3 & 6.4 & 7.3 & 7.9 & 8.6 \\
\hline 2011-12 & 11.0 & 9.5 & 11.9 & 12.0 & 13.0 \\
\hline $2012-13$ & 10.1 & 8.6 & 10.5 & 11.1 & 11.7 \\
\hline $2013-14$ & 5.9 & 5.2 & 6.2 & 6.5 & 6.5 \\
\hline $2014-15$ & 5.2 & 4.6 & 5.3 & 5.7 & 5.7 \\
\hline $2015-16$ & 6.9 & 6.1 & 7.1 & 7.4 & 7.9 \\
\hline 2016-17 & 5.8 & 5.1 & 6.0 & 6.3 & 6.6 \\
\hline $2017-18$ & 6.6 & 5.8 & 6.9 & 7.1 & 7.2 \\
\hline \multicolumn{6}{|l|}{ Cuts: } \\
\hline 2006-07 & 18.9 & 20.4 & 18.5 & 17.4 & 17.3 \\
\hline 2007-08 & 17.7 & 19.1 & 17.2 & 16.5 & 15.6 \\
\hline 2008-09 & 20.1 & 22.0 & 19.3 & 18.8 & 18.0 \\
\hline $2009-10$ & 24.3 & 26.1 & 23.7 & 23.2 & 21.9 \\
\hline $2010-11$ & 22.7 & 24.5 & 22.1 & 21.6 & 20.8 \\
\hline $2011-12$ & 23.1 & 24.6 & 22.8 & 21.7 & 21.0 \\
\hline $2012-13$ & 23.5 & 25.2 & 23.1 & 21.5 & 21.5 \\
\hline 2013-14 & 19.7 & 21.5 & 18.7 & 18.5 & 17.4 \\
\hline 2014-15 & 18.8 & 20.2 & 17.9 & 17.7 & 17.1 \\
\hline $2015-16$ & 21.0 & 22.6 & 20.3 & 19.8 & 18.8 \\
\hline 2016-17 & 19.7 & 21.1 & 18.8 & 18.8 & 17.7 \\
\hline $2017-18$ & 19.4 & 20.6 & 18.6 & 18.2 & 18.0 \\
\hline
\end{tabular}

Notes.- Percentages of job stayers with exactly zero year-to-year changes in nominal hourly pay, or cuts. Each column uses hourly gross pay, excluding overtime, as the baseline pay variable and then either adds or excludes the shown pay component. 


\section{Appendix F. Additional Figures}

FIGURE F1: Shares of year-to-year freezes and cuts in the pay components of job stayers, 2007-18

A. Freezes

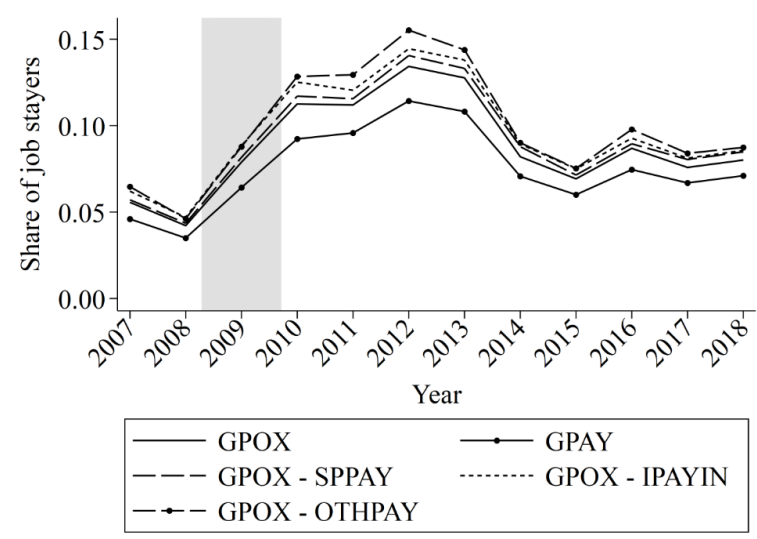

B. Cuts

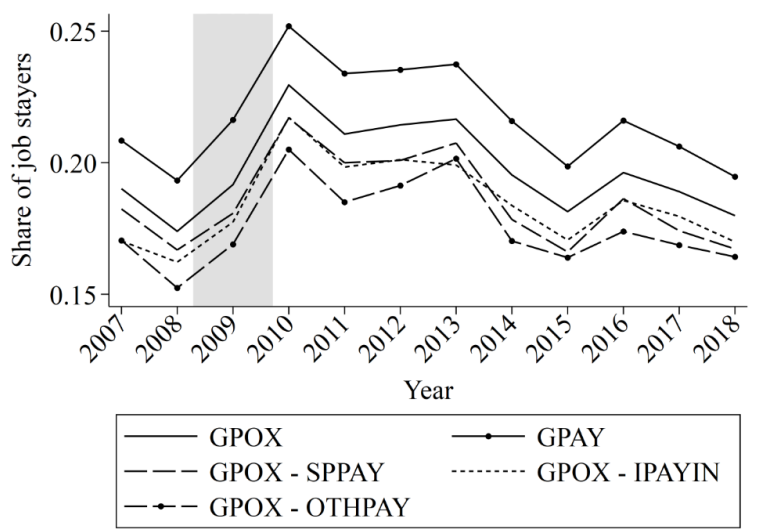

Notes.- Demonstrates the marginal contributions of pay components to freezes and cuts in nominal hourly pay. The underlying data is displayed in Table 4 . The grey shaded area represents official UK recession dates.

FIGURE F2: Distributions of year-to-year adjustments in log earnings per hour by firm size, 2006-18: substantially shrinking vs substantially expanding firms

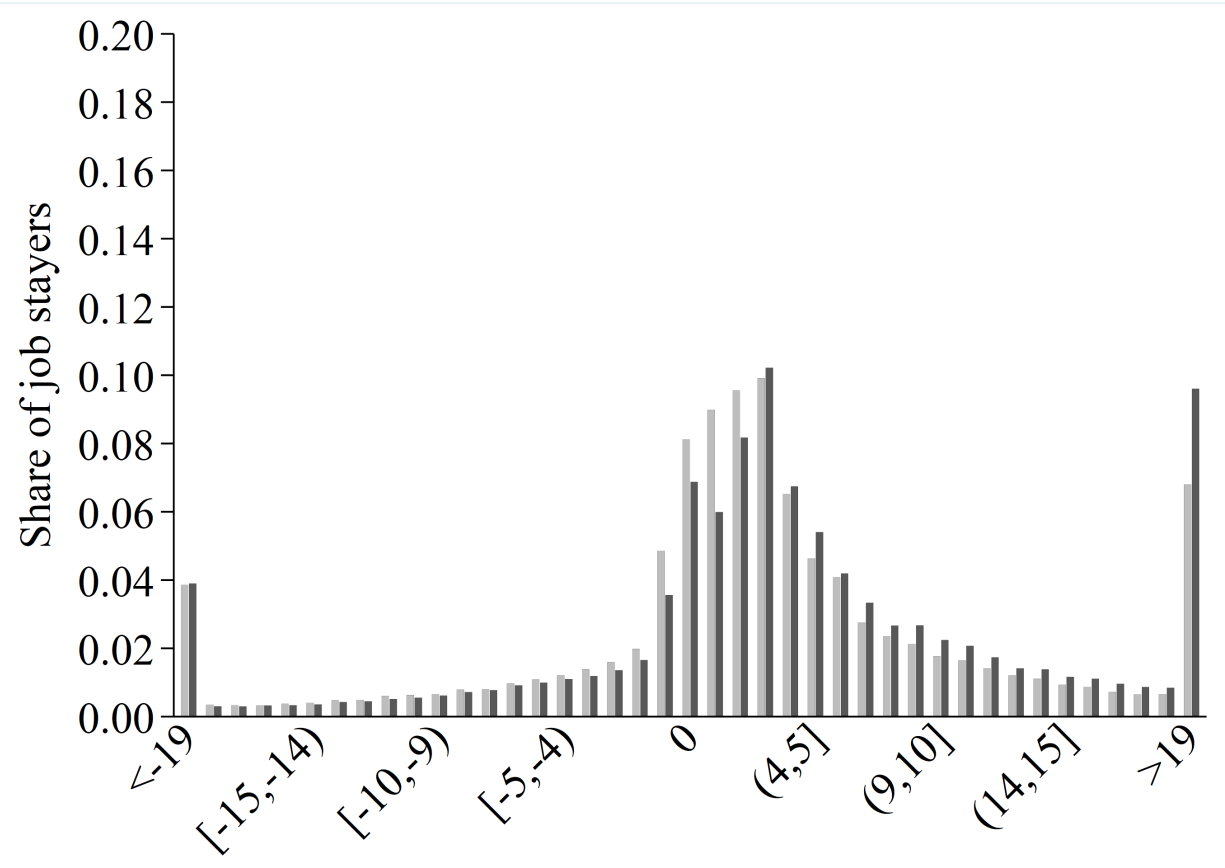

Notes.- See Figure 1. Pooled data for 2006-2018. Dark bars: 108,245 job stayers whose firms experienced positive year-to-year employment growth of at least $10 \%$ or 1,000 employees over the same period. Light bars: 124,202 job stayers whose firms experienced negative year-to-year employment growth of at least $10 \%$ or 1,000 employees over the same period. 